Análise baseada em contexto do movimento de pedestres em terminais de transporte

\author{
Joelma Cristina Costa e Silva
}

TESE APRESENTADA

AO

Instituto DE MATEMÁTICA E EstatísticA

DA

UNIVERSIDADE DE S Ão PAUlO

PARA

OBTENÇÃO DO TÍTULO

$\mathrm{DE}$

DOUTOR EM CIÊNCIAS

Programa: Ciência da Computação

Orientador: Prof. Dr. Flávio Soares Corrêa da Silva

São Paulo, fevereiro de 2020 


\title{
Análise baseada em contexto do movimento de pedestres em terminais de transporte
}

\author{
Esta versão da tese contém as correções e alterações sugeridas \\ pela Comissão Julgadora durante a defesa da versão original do trabalho, \\ realizada em 12/02/2020. Uma cópia da versão original está disponível no \\ Instituto de Matemática e Estatística da Universidade de São Paulo.
}

Comissão Julgadora:

- Prof. Dr. Flávio Soares Corrêa da Silva (orientador) - IME-USP

- Prof. Dr. Paulo Andre Vechiatto de Miranda - IME-USP

- Prof. Dr. Orlando Fontes Lima Junior - FEC-UNICAMP

- Prof $^{a}$. Dr ${ }^{\mathrm{a}}$. Helena Beatriz Bettella Cybis - EP-UFRGS

- Prof. Dr. Daniel Furtado Leite - DAT-UFLA 


\section{Agradecimentos}

Agradeço ao Prof. Flávio pelos ensinamentos durante todo o período do doutorado. Pelo tempo dispensado para orientar e ouvir os problemas que ocorrem ao longo do projeto, onde nem sempre foi possível separar o pessoal, o profissional e o acadêmico. Obrigada pela compreensão e pela paciência.

Agradeço aos meus filhos, Guilherme e Larissa, que apareceram ao longo desta jornada e trouxeram muitos momentos de alegria e diversão.

Agradeço ao Rafael e a minha família, pela torcida e apoio incondicional.

Agradeço ao Edson, meu professor de inglês e amigo, pelo apoio e auxílio nos mais diversos momentos ao longo de todo este período. 


\section{Resumo}

SILVA, J. C. C. Análise baseada em contexto do movimento de pedestres em terminais de transporte. 2020. 91 f. Tese (Doutorado) - Instituto de Matemática e Estatística, Universidade de São Paulo, São Paulo, 2020.

A aquisição de dados de deslocamentos de pessoas através de vídeos traz consigo uma imprecisão inerente que advém tanto da qualidade das imagens capturadas quanto da dinâmica do movimento de pedestres no ambiente. A obtenção de informações precisas de rastreamento e contagem de pedestres a partir de vídeos ainda é um desafio. Este trabalho explora características específicas do comportamento de pedestres no domínio dos terminais de transporte e apresenta uma ferramenta que agrega informações do contexto para aumentar a precisão dos dados obtidos de vídeos para a contagem de pedestres e determinação dos fluxos em cenarios reais. A ferramenta proposta (1) rearranja os rótulos dos pedestres de acordo com o comportamento associado ao contexto considerado, (2) melhora a precisão na contagem dos pedestres a partir das rotas rastreadas, e (3) usa informações dinâmicas de movimentação para melhorar a identificação do percurso completo realizado pelos pedestres individualmente. Com isso, a ferramenta proposta incrementa a acurácia das rotas rastreadas, agregando informações com base no comportamento característico dos pedestres em terminais de transporte.

Palavras-chave: Análise contextual, aquisição de dados de vídeo, comportamento de pedestres, monitoramento de terminais de transporte. 


\section{Abstract}

SILVA, J. C. C. Context-based understanding of pedestrian motion in transportation terminals. 2020. 91 f. Tese (Doutorado) - Instituto de Matemática e Estatística, Universidade de São Paulo, São Paulo, 2020.

Acquisition of pedestrian data through video brings with it an inherent inaccuracy that comes from both the quality of the images captured and the dynamics of pedestrian movement in the environment. Getting accurate pedestrian tracking and counting information from videos is still a challenge. This paper explores specific pedestrian behavior characteristics in the transport terminals domain and presents a tool that aggregates context information, thus increasing the accuracy of data obtained from videos that count and determine pedestrian flows in real scenarios. The proposed tool (1) reorganizes pedestrian labels according to the context-associated behavior considered, (2) improves pedestrian counting accuracy from tracked routes, and (3) uses dynamic movement information to improve complete path identification taken by pedestrians individually. Consequently, the proposed tool increases the accuracy of the tracked routes by aggregating information based on the characteristic behavior of pedestrians in transport terminals.

Keywords: Contextual analysis, video data-acquisition, pedestrian behavior, transport terminal monitoring. 


\section{Sumário}

$\begin{array}{ll}\text { Lista de Abreviaturas } & \text { ix }\end{array}$

Lista de Símbolos $\quad$ xi

$\begin{array}{ll}\text { Lista de Figuras } & \text { xiii }\end{array}$

Lista de Tabelas $\quad$ xv

1 Introdução $\quad 1$

1.1 Contexto de Pesquisa e Motivação $\ldots \ldots \ldots \ldots \ldots \ldots \ldots \ldots$

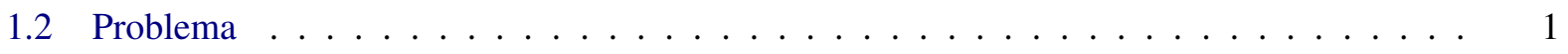

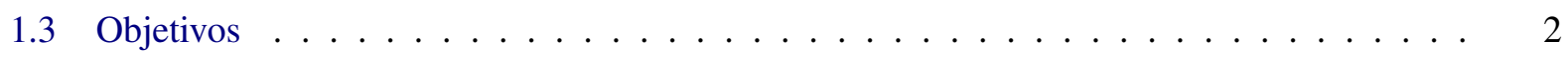

1.4 Questões de Pesquisa . . . . . . . . . . . . . . . . . . . . . 3

1.5 Justificativa de Pesquisa . . . . . . . . . . . . . . . . . . . 3

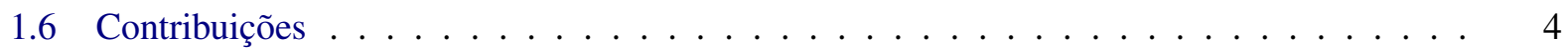

1.7 Visão Global da Metodologia . . . . . . . . . . . . . . . . . . . . . . . . 4

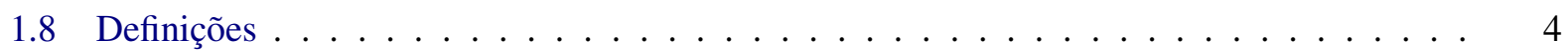

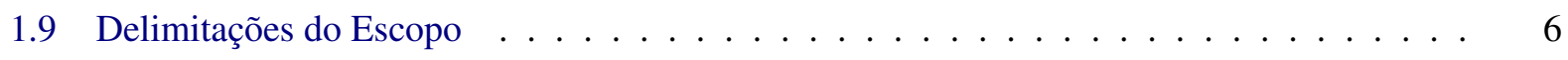

1.10 Organização do Trabalho . . . . . . . . . . . . . . . . . . . . . 7

2 Trabalhos Relacionados 9

2.1 Comportamento de Indivíduos em Multidões . . . . . . . . . . . . . . . . . . . . . . . . . . . . . . . . . . . .

2.2 Escalas de Análise . . . . . . . . . . . . . . . . . . . . . . . . 10

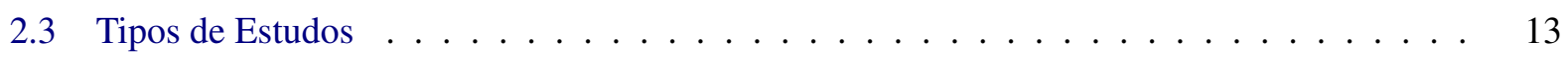

2.4 Análise do Movimento de Pedestres . . . . . . . . . . . . . . . . . . . . . . . 14

2.4 .1 Processamento de Imagens . . . . . . . . . . . . . . . . . . . . . . . . . . . . . . . . . . . . . . . . . . .

2.4 .2 Métodos de Análise Empírica . . . . . . . . . . . . . . . . . . . 15

2.4 .3 Análises Experimentais . . . . . . . . . . . . . . . . . . . . . . . . . . . . . . . 16

2.4.4 Estudos Teóricos de Simulação e Síntese . . . . . . . . . . . . . . . . . . . . 16

2.5 Parâmetros de Referência . . . . . . . . . . . . . . . . . . . . . . . . . . . . . . . . . . . . . . .

2.5 .1 Medidas Antropométricas . . . . . . . . . . . . . . . . . 16

2.5.2 Velocidade de Caminhada . . . . . . . . . . . . . . . . . 17

2.5.3 Indicadores de Engenharia de Tráfego . . . . . . . . . . . . . . . . . . . . . . 19

2.5 .4 Níveis de Serviços . . . . . . . . . . . . . . . . . . . . . . . . . . . 19

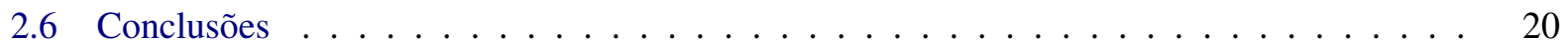


3 Análise Baseada em Contexto do Movimento de Pedestres 23

3.1 Coleta de Dados e Pré-processamento . . . . . . . . . . . . . . . . . . . . 23

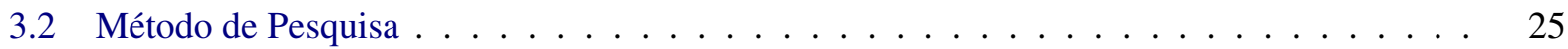

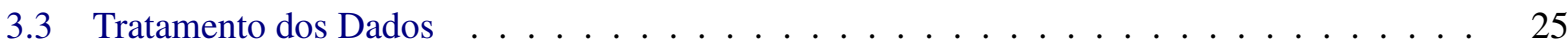

3.3.1 Sumário dos Parâmetros Contextuais _ . . . . . . . . . . . . . . . 26

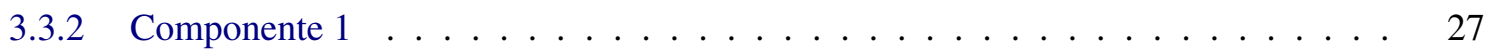

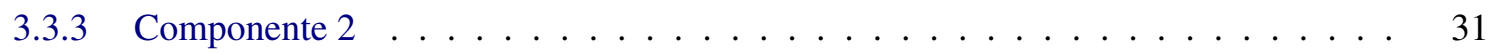

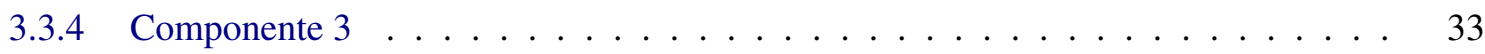

3.3.5 Sequência de Aplicação dos Componentes . . . . . . . . . . . . . . . . . . . . . . 37

3.4 Síntese dos Dados . . . . . . . . . . . . . . . . . . . . . . . . 37

4 Resultados e Discussões $\quad 43$

4.1 Coleção de Dados . . . . . . . . . . . . . . . . . . . . . . . . . . . . . . . 43

4.2 Inicialização dos Parâmetros . . . . . . . . . . . . . . . . . . 45

4.3 Testes Qualitativos . . . . . . . . . . . . . . . . . . . . . . . . 47

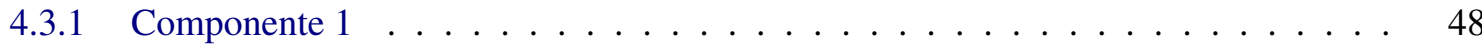

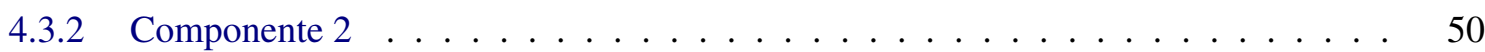

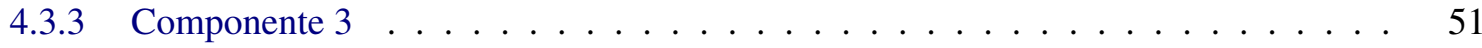

4.4 Testes de Estabilidade . . . . . . . . . . . . . . . . . . . . . . . . . . . 52

4.4.1 Execução Individualizada dos Componentes . . . . . . . . . . . . . . . . . 52

4.4.2 Execução Sequencial dos Componentes . . . . . . . . . . . . . . . . . . . 55

4.5 Testes de Quantitativos . . . . . . . . . . . . . . . . . . . . . . 57

4.5.1 Definição do Indicador de Efetividade . . . . . . . . . . . . . . . . . . . . 57

4.5 .2 Efetividade do Componente $1 \ldots \ldots \ldots \ldots$

4.5 .3 Efetividade do Componente $2 \ldots \ldots \ldots \ldots$. . . . . . . . . . 61



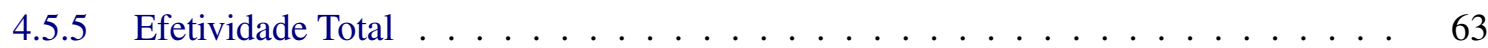

4.6 Aplicações e Limitações da Ferramenta . . . . . . . . . . . . . . . . . . . . . 63

5 Conclusões e trabalhos futuros $\quad \mathbf{6 5}$

5.1 Considerações Finais . . . . . . . . . . . . . . . . . . . . . . . 65



$\begin{array}{lr}\text { A Tabelas } & 67\end{array}$

Referências Bibliográficas $\quad 69$ 


\title{
Lista de Abreviaturas
}

\author{
GCTNY Grand Central Terminal de Nova York \\ ConVelocity Constant Velocity Model \\ FMT Fator de Melhora Total
}




\title{
Lista de Símbolos
}

\author{
$m / s \quad$ Metros/segundo \\ $\theta \quad$ Ângulo de mudança de direção no percurso do pedestre \\ $\eta \quad$ Tamanho da amostra para análise \\ $\tau \quad$ Total de trajetórias na coleção de dados original
}




\section{Lista de Figuras}

1.1 Representação conceitual da solução . . . . . . . . . . . . . . . . . . 5

$2.1 \quad$ Elipse corporal . . . . . . . . . . . . . . . . . . . . . . . . . . . 17



3.1 Entrada e saída da etapa de pré-processamento dos dados . . . . . . . . . . . . . 25

3.2 Esquema representativo da etapa de tratamento de dados . . . . . . . . . . . . . . 26

3.3 Parâmetros ângulo limiar de deslocamento/mudança de direção . . . . . . . . . . . . . . 27

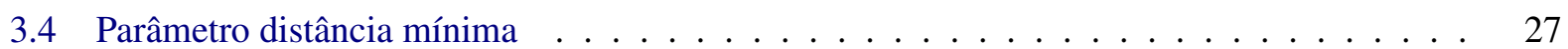

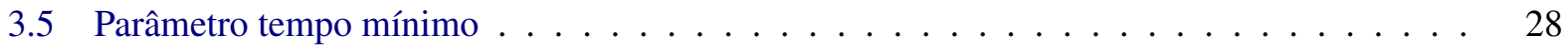

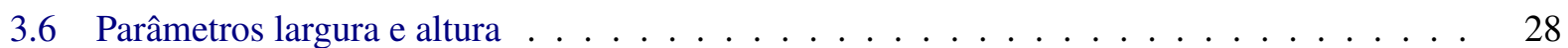



3.8 Entrada e saída do algoritmo que desagrega trajetórias adivindas de oclusão . . . . . . . . 31

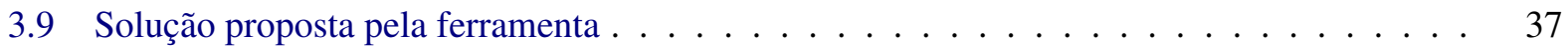

3.10 Relatório de visualização das trajetórias obtidas pela aplicação dos componentes . . . . . . 38

3.11 Frame produzido para um conjunto de trajetórias . . . . . . . . . . . . . . . . 39

3.12 Contagem de pedestres e velocidade $\mathrm{x}$ tempo de vídeo f . . . . . . . . . . . . . 40

3.13 Mapa de densidade para verificação das regiões de gargalo $\ldots \ldots \ldots$. . . . . . . . . . 41

4.1 Entrada e saída de pedestres do Grand Central Terminal de Nova York . . . . . . . . . . . 44

4.2 Dados obtidos do cenário real . . . . . . . . . . . . . . . . . . . . . . 45

4.3 Velocidade média $\mathrm{m} / \mathrm{s}$ por tempo de vídeo em segundos . . . . . . . . . . . . . . 47

4.4 Visualização das trajetórias obtidas pelo Componente 1 com uma divisão . . . . . . . . . . 49

4.5 Visualização das trajetórias obtidas pelo Componente 1 com duas divisões . . . . . . . . . 50

4.6 Visualização das trajetórias obtidas pelo Componente 1 com três divisões . . . . . . . . . 50

4.7 Visualização das trajetórias obtidas pela aplicação do Componente $2 \ldots \ldots$. . . . . . 51

4.8 Visualização das trajetórias obtidas pela aplicação do Componente $3 \ldots \ldots$. . . . . . . . . 52

4.9 Variação das trajetórias pela execução individualizada . . . . . . . . . . . . . . . 53

4.10 Quantidade de trajetórias corrigidas pela execução individualizada . . . . . . . . . . . . 54

4.11 Variação do total de trajetórias pela execução sequencial _ . . . . . . . . . . . . . 55

4.12 Quantidade de trajetórias corrigidas pela execução sequencial dos componentes . . . . . 56

4.13 Variação do indicador proposto em relação as variáveis que o compõe $\ldots$. . . . . . . . . 58 


\section{Lista de Tabelas}

1.1 Delimitações do escopo . . . . . . . . . . . . . . . . . . . . . . 7

2.1 Largura dos pedestres dependendo da bagagem . . . . . . . . . . . . . . . . 17

2.2 Definições de níveis de serviços para velocidade de pedestre . . . . . . . . . . . . 18

2.3 Classificação em níveis de serviços . . . . . . . . . . . . . . . . . . . . . . . . 20

3.1 Parâmetros contextuais por tipo e escopo de utilização nos componentes . . . . . . . . . . 27

3.2 Amostra do arquivo com os indicadores de trajetórias produzidos pela ferramenta . . . . . 40

4.1 Valoração dos parâmetros para a coleção Grand Central Terminal de Nova York . . . . . . 46

4.2 Quantidades de trajetórias resultantes da execução individualizada . . . . . . . . . . . . 54

4.3 Quantidades de trajetórias resultantes da execução sequencial dos componentes . . . . . . 56

4.4 Apuração da equação 4.6 para o Componente 1 e amostra de tamanho $\eta=30 \ldots$. . . . . . 60

4.5 Valores obtidos para as equações do fator de melhora para o Componente $1 \ldots \ldots$

4.6 Valores obtidos para as equações do fator de melhora para o Componente $2 \ldots$. . . . . . . 62

4.7 Valores obtidos para as equações do fator de melhora para o Componente $3 \ldots 62$

A.1 Apuração da equação 4.6 para o Componente 2 e amostra de tamanho $\eta=30 \ldots 67$

A.2 Apuração da equação 4.6 para o Componente 3 e amostra de tamanho $\eta=30 \ldots$. . . . . . 68 


\section{Capítulo 1}

\section{Introdução}

\subsection{Contexto de Pesquisa e Motivação}

A movimentação de pedestres em ambientes e contextos específicos tem sido objeto de estudo de especialistas de variados campos, como engenheiros de tráfego, psicólogos e arquitetos.

De acordo com Zhan et al. (2008), a análise comportamental de multidões é essencial para uma ampla variedade de aplicações, como gerenciamento de multidões em grandes eventos, design de espaços públicos, desenvolvimento de ambientes virtuais, vigilância e desenvolvimento de ambientes interativos inteligentes.

A complexidade da análise de multidões abrange diferentes problemas, dependendo de qual aspecto é primordialmente considerado. Segundo Junior et al. (2010), temos quatro principais frentes de pesquisa na área de gestão de multidões:

1. Domínio do espaço da imagem;

2. Domínio sociológico;

3. Nível de serviços; e

4. Domínio de computação gráfica.

Atualmente, não existe um método adequado para conectar o conhecimento entre estas áreas, o que leva à ruptura da cadeia de conhecimento. Por exemplo, as informações obtidas pelos estudos do espaço da imagem muitas vezes não têm sido aproveitadas para alimentar as pesquisas nas demais frentes de pesquisa.

\subsection{Problema}

A multidisciplinaridade de áreas envolvidas na análise de multidões impõe barreiras para o desenvolvimento de métodos mais precisos para o gerenciamento de espaços com grande circulação de pessoas.

Do ponto de vista de visão computacional, existem dificuldades para conseguir capturar informações das trajetórias dos passageiros de forma individual em cenários com um fluxo elevado de pessoas. Em ambientes muito cheios, existe a oclusão de passageiros, que pode levar à geração equivocada de trajetórias dos passageiros ou à descontinuidade das mesmas. As abordagens existentes denotam relutância em tratar este problema (Maheshwari e Heda, 2016, pág.1).

Alguns estudos objetivam a compreensão do comportamento de passageiros através da simulação de cenários hipotéticos, fazendo uso de premissas e parâmetros aleatórios que podem ser apenas parcialmente 
representativos dos cenários que se pretende estudar. Sendo assim, tais estudos muitas vezes não conseguem prever ou descrever de maneira precisa o comportamento dos indivíduos em situações reais. Apesar de existirem modelos altamente sofisticados considerando, por exemplo, o comportamento individualizado de acordo com objetivos e traços psicológicos, eles muitas vezes dependem do uso de muitos parâmetros de inicialização arbitrários que podem ser distintos do que ocorre em situações reais Kim et al. (2012) Guy et al. (2011) Durupinar et al. (2016). Tais estudos podem levar, portanto, a conclusões enviesadas pela escolha arbitrária de parâmetros.

Os métodos existentes de análise utilizando dados empíricos têm majoritariamente realizado medições baseadas no comportamento agregado de multidões, ao invés de tentar coletar os dados no nível individual Haghani e Sarvi (2017) Teknomo et al. (2016).

Atualmente, não existe um método considerado consensualmente adequado que prepare, organize e sintetize informações obtidas dos algoritmos de visão computacional que forneçam dados precisos sobre cenários reais a especialistas em segurança de transportes. Diversas abordagens têm sido exploradas, gerando resultados parciais relevantes.

Dentre estas alternativas, temos o uso de abordagens de simulação, que apresentam desafios para a obtenção de modelos estatísticos que possam ser utilizados na prática e sejam suficientemente detalhados para representar cenários reais.

Outra alternativa se fundamenta em estudos experimentais, que em geral apresentam elevado custo e dificuldade de realização, pois conseguir uma amostra relevante de pessoas com dispositivos de rastreamento para aferir a realidade observável pode demandar tempo e recursos materiais significativos.

Ainda outra possibilidade de pesquisa consiste em utilizar várias coleções de dados para produzir uma análise mais generalizada do comportamento dos pedestres. No entanto, existem poucos dados disponíveis para tais pesquisas. $\mathrm{O}$ uso de algoritmos de aprendizado de máquina nestes cenários demandaria dados pré-rótulados, que por sua vez demandariam recursos significativos para sua obtenção.

A abordagem que escolhemos para a realização deste trabalho é utilizar dados existentes de um cenário real, visando explorar as características de uma amostra de dados e extrapolar estas características para a criação de uma ferramenta que tem como objetivo efetuar correções importantes relacionadas ao contexto analisado. A ferramenta apresentada neste trabalho faz uso de parâmetros que podem ser ajustados a contextos específicos por especialistas da área de transportes.

O resultado central deste trabalho é uma ferramenta que provê mecanismos para uma captura de dados mais precisos em cenários reais, tomando como base trajetórias inconsistentes e incompletas obtidas de algoritmos de rastreamento reconhecidos na literatura. A solução foi aplicada e testada no Grand Central Terminal de Nova York. Foram feitas comparações das trajetórias obtidas pela ferramenta com as trajetórias brutas obtidas de um dos algoritmos de rastreamento mais utilizados na na literatura. Os resultados indicam que a ferramenta apresentada é eficaz no tratamento de dados de pedestres no contexto de terminais de transporte.

\subsection{Objetivos}

O objetivo deste trabalho é prover recursos para que engenheiros de transportes, segurança e projetos públicos possam fazer uma análise mais precisa de cenários reais por meio de correções realizadas nos dados obtidos através de ferramentas de rastreamento aplicadas em vídeo. Estes recursos são apresentados em uma ferramenta que possibilita a calibração dos parâmetros associados ao contexto estudado. A ferramenta 
faz correções nas informações obtidas de modelos de visão computacional, para prover recursos para uma análise mais acurada de informações do deslocamento de pedestres em espaços públicos internos.

Este trabalho foca na criação de uma solução apropriada para a análise de pessoas usando vídeos de vigilância, provendo mecanismos para a análise de características de movimentos dos passageiros como velocidade, direção do movimento e principais fluxos, levando em consideração toda a multidão e explorando informações relevantes, como períodos de maior e menor fluxo, caminhos preferidos e outros fenômenos emergentes.

Este estudo visa, também, contribuir para a literatura no campo do comportamento de multidões, com a criação e implantação de um método eficaz para reorganizar dados imprecisos e ausentes, incorporando mecanismos semi-automáticos para analisar dados de passageiros. As análises obtidas oferecem uma série de métricas, levando em consideração o comportamento de um indivíduo quanto aos demais integrantes da multidão e o contexto de tempo analisado.

\subsection{Questões de Pesquisa}

Esta tese dedica-se a apresentar uma solução para análise contextualizada da movimentação de passageiros. A questão de pesquisa central investiga se é possível utilizar informações do contexto para mitigar distorções de dados obtidos do processamento de vídeos. Sendo assim, a hipótese principal é que as estratégias de deslocamento adotadas pelos indivíduos são impactadas pelo contexto em que se encontram.

Para validarmos a hipótese, foram necessários os seguintes passos investigativos:

- A aquisição de informações do movimento de pedestres em terminais de transportes, que podem ser obtidas pelo processamento de imagens e, especificamente, algoritmos de rastreamento aplicados a vídeos de segurança;

- A redução de distorções das informações tratadas utilizando dados do contexto em que os pedestres se encontram sobre as informações brutas obtidas dos algoritmos de rastreamento;

- A aferição de convergência do tratamento das informações após algumas iterações, levando a uma análise de dados estabilizada e consistentemente melhor do que as informações brutas iniciais.

\subsection{Justificativa de Pesquisa}

A análise do comportamento dos passageiros em situações reais fornece parâmetros essenciais para a simulação e desenvolvimento de projetos envolvendo multidões, como pode ser encontrado em estações de trem Zhong et al. (2015) Zhou et al. (2014), travessias de pedestres Zhou et al. (2014) Gorrini et al. (2016), exposições privadas e públicas Crociani et al. (2016), planos de evacuação Moussaïd et al. (2016b) e prevenção de desastres Moussaid et al. (2011). Este trabalho foca em terminais públicos de transporte monitorados por câmeras de vídeo. Foi realizado um estudo de caso do Grand Central Terminal de Nova York para aferir a precisão e a aplicabilidade de nossa solução para coletar, organizar e analisar informações de movimento.

As informações captadas de câmeras de segurança têm demonstrado potencial para uma compreensão mais profunda do comportamento, principalmente nos últimos anos, devido ao aumento da quantidade de câmeras de segurança instaladas em ambientes urbanos. Entretanto, o processamento das informações geradas é um desafio. 
Neste contexto, uma solução criteriosa para o processamento, organização e também a análise de informações da movimentação de passageiros em cenários reais, como apresentado por Haghani e Sarvi (2017), é um aspecto relevante a ser explorado para a melhor compreensão da relação do comportamento dos indivíduos em contextos reais.

\subsection{Contribuições}

O objetivo desta pesquisa é formular uma ferramenta para analisar os padrões de caminhada dos pedestres em terminais de transporte fechados.

As principais contribuições são:

1. Avanços na captura, tratamento e processamento dos dados obtidos de algoritmos de rastreamento, possibilitando a análise contextualizada da movimentação de pedestres.

2. Uma ferramenta que permite que parâmetros possam ser ajustados para representar diferentes cenários.

3. A análise semi-automática das informações tratadas pela ferramenta e visualização de dados.

4. Estabilidade de convergência computacional, para garantir que simulações e experimentos convirjam e possam ser realizados na prática.

\subsection{Visão Global da Metodologia}

A contribuição principal desta pesquisa está em munir engenheiros e pesquisadores com uma ferramenta capaz de tratar informações sobre pedestres e fornecer informações mais precisas sobre terminais de transporte. A ferramenta recebe como dados de entrada as trajetórias obtidas do rastreamento de pedestres, fazendo uso de algoritmos de visão computacional. A Figura 1.1 mostra o esboço da arquitetura do método proposto e sua relação com as demais áreas de pesquisas em movimentação de multidões.

A ferramenta, primeiramente, provê o tratamento dos dados de trajetórias obtidos de algoritmos de processamento de imagens: nesta fase, composta por três componentes, são realizadas correções de diferentes falhas nos dados brutos das trajetórias obtidas pelos algoritmos de processamento de imagens. Estas correções são, posteriormente, reportadas/analisadas na etapa de síntese dos dados, onde são fornecidos indicadores quantitativos e qualitativos das trajetórias modificadas com funcionalidades para a visualização espaço-temporal das trajetórias dos indivíduos e de sua identificação no video do cenário real.

A pesquisa descritiva, como definida por Selltiz et al. (1965), busca descrever um fenômeno ou situação em detalhes, principalmente, o que está ocorrendo, possibilitando abranger as características do objeto em estudo, bem como desvendar a relação entre os eventos. Neste trabalho, este método de pesquisa foi adotado para a compreensão dos problemas associados a aquisição de dados de pedestres de dispositivos de vídeos com o intuito de desenvolver novos instrumentos que estendam a capacidade de aquisição de dados de terminais de transporte reais.

\subsection{Definições}

$\mathrm{Na}$ área de pesquisa de multidões existe uma ampla variedade de conceitos, por vezes mal interpretados e conflitantes. Com o intuito de evitar discordâncias e ambiguidades com outros trabalhos apresentados na 


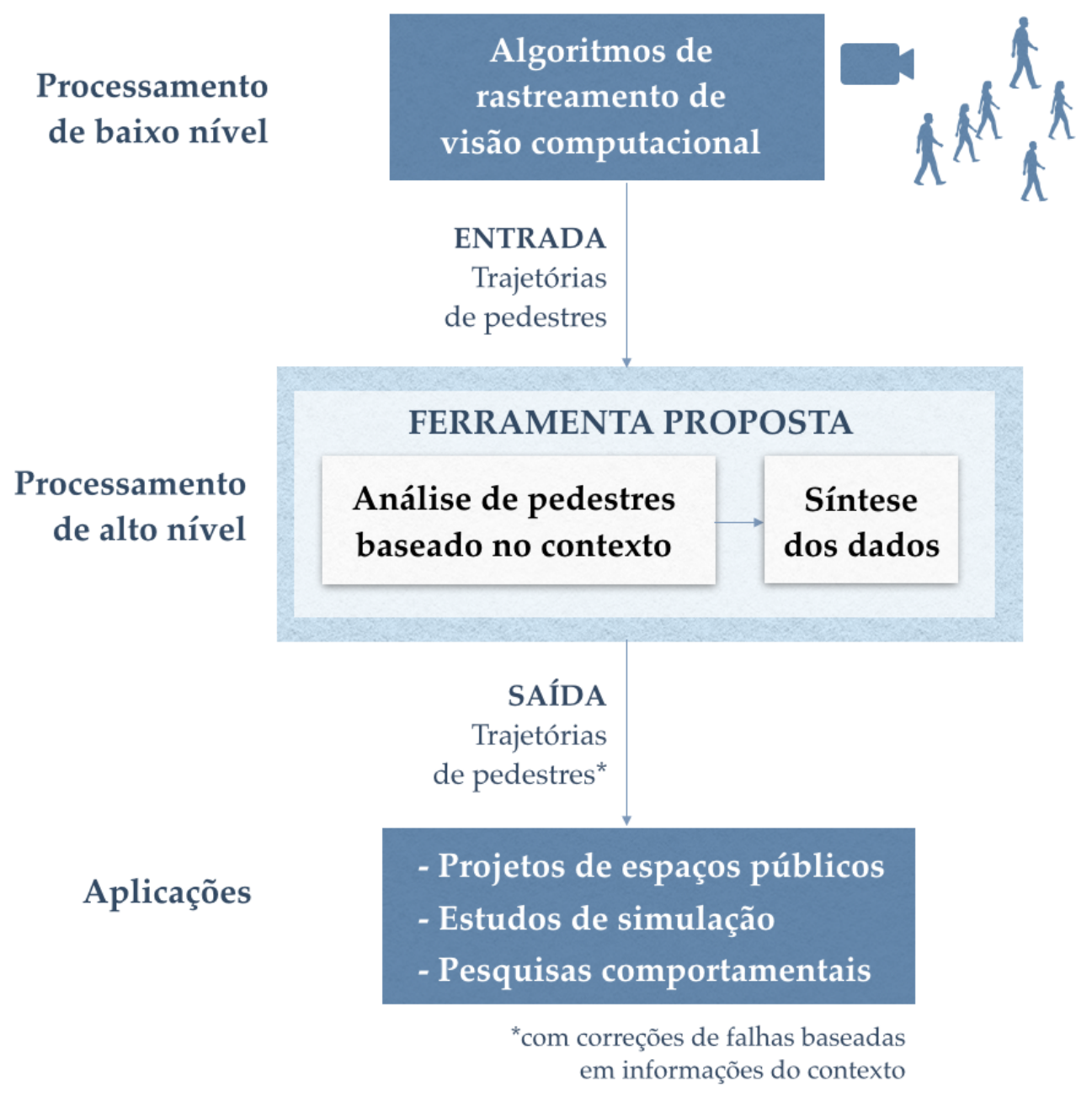

Figura 1.1: Representação conceitual da solução

literatura, nesta seção são explicados os principais conceitos adotados no presente trabalho.

\section{Estações e/ou Terminais de Transporte}

Neste trabalho foi adotado o conceito apresentado por Kone (2005) em que estações de transporte são caracterizadas pela ausência de uma população estática ou permanente e pela presença de fluxos intensos e pulsantes de pessoas movendo-se através de um espaço. Em tal ambiente, é essencial que as pessoas possam avançar suavemente sem formar filas cumulativas durante sua jornada pela estação. Circulação em estações requer um planejamento cuidadoso de todos os dispositivos de transporte para que suas capacidades de manuseio atendam à demanda de pico de tráfego. A circulação em uma estação deve ser sempre fluente e a evacuação da estação também deve ser considerada durante a fase de projeto.

\section{Multidão}

Multidão é uma aglomeração de pessoas que estão próximas fisicamente e têm um mesmo objetivo. Considerando-se o escopo deste trabalho o objetivo da multidão é utilizar o terminal de transporte como uma área de passagem. 


\section{Pedestre, Passageiro e Indivíduo}

No contexto de terminal de transporte, são adotadas por convenção neste texto, como equivalentes, os termos pedestre, passageiro e indivíduo, sendo que o conceito adotado aqui é basicamente a composição destes três conceitos com a seguinte caracterização:

- Pedestre: é uma pessoa que viaja a pé, seja andando ou correndo;

- Indivíduo: são anônimos e não há diferenciação de classe social, cor etc.

- Passageiro: é um adjetivo que se usa de diversas maneiras: pode se referir a uma pessoa que realiza uma viagem em algum tipo de meio de transporte, sem ser quem o conduz e sem fazer parte da tripulação.

\section{Contexto e Dinâmica}

Contexto pode ser caracterizado como sendo uma relação entre circunstâncias que acompanham um fato ou uma situação. No nosso caso, circunstâncias seriam, por exemplo, a quantidade de pessoas e o intervalo de tempo analisado. Por se tratar de um terminal de transporte, a questão do tempo influencia diretamente o contexto, por termos horários bem definidos de partida e chegada do meio de transporte, que influencia diretamente a lotação do terminal e, consequentemente, o comportamento das pessoas. Dinâmica da multidão é considerada como sendo equivalente à palavra contexto.

\section{Semântica}

Semântica é o estudo do significado. O estudo da semântica inclui o estudo de como o significado é construído, interpretado, esclarecido, obscurecido, ilustrado, simplificado, negociado, contradito e parafraseado.

Expandindo-se este conceito para a área de análise de multidões, a semântica trata de interpretar o significado dos dados gerados por algoritmos de rastreamento no contexto. Uma compreensão da semântica relacionada ao contexto de terminais de transporte é essencial para ajustar e corrigir os dados advindos de algoritmos de rastreamento.

\subsection{Delimitações do Escopo}

A Tabela 1.1, resume o que está dentro e fora do escopo deste trabalho. Neste trabalho, assumimos que os indivíduos transitam em terminais fechados de transporte e tem-se como premissa que os mesmos se deslocam de uma determinada porta de entrada a outra de saída. Ao mesmo tempo, os indivíduos são analisados de forma individual, ou seja, não é levado em consideração que possam fazer parte de algum grupo.

Embora se tenha como objetivo uma eficiência computacional que garanta a viabilidade da simulação em vários cenários, vale ressaltar que não está no escopo deste trabalho a realização de análises e simulações em tempo real. Consequentemente, não está no escopo deste trabalho a análise e simulação de cenários macroscópicos em que as decisões dos indivíduos são limitadas devido à sua densidade muito grande como ocorrem em aplicações para ambientes de grandes eventos, festivais e estádios. 
Tabela 1.1: Delimitações do escopo

\begin{tabular}{|c|c|c|}
\hline \multirow{2}{*}{ Aspecto } & \multicolumn{2}{|c|}{ Escopo } \\
\cline { 2 - 3 } & Dentro & Fora \\
\hline Ambiente & Fechado e monitorado por camera & Aberto ou sem monitoramento por camêra \\
\hline Escala & Meso & Micro ou macro \\
\hline Tratamento de dados & Correções de inconsistências e incompletudes & Extração dos dados de vídeo \\
\hline Análise & Contagem de pedestres e trajetória & Grupos ou aspectos psicológicos \\
\hline Processamento & Offline & Tempo real \\
\hline Aplicações & Estações de trem, metrô, rodoviárias e aeroportos & Ruas, avenidas, eventos, etc \\
\hline
\end{tabular}

\subsection{Organização do Trabalho}

Este capítulo 1 estabelece as bases para a tese, com a introdução do problema e das questões de pesquisa, as justificativas e uma descrição breve da metodologia. O capítulo 2 apresenta alguns conceitos e pesquisas encontradas na bibliografia, bem como a forma como se dividem os trabalhos que se dedicam à análise da movimentação de pedestres. O Capítulo 3 descreve a ferramenta desenvolvida com detalhes da etapa de tratamento de dados e da etapa de síntese. O Capítulo 4 mostra os resultados da utilização da ferramenta em uma coleção de dados reais e a avaliação em três etapas, análises qualitativa, de convergência e quantitativa. Este capítulo apresenta, também, a aplicação dos componentes intermediários para tratamento das trajetórias e dos resultados finais da solução proposta quando aplicada aos dados de teste. Finalmente, o Capítulo 5 faz algumas considerações finais sobre o trabalho. 


\section{Capítulo 2}

\section{Trabalhos Relacionados}

Apresentamos nesse capítulo uma revisão da literatura com foco nas pesquisas relacionadas à construção da ferramenta proposta.

\subsection{Comportamento de Indivíduos em Multidões}

Segundo Zhan et al. (2008), a análise comportamental de multidões é essencial para uma ampla variedade de aplicações, como gerenciamento de multidões em grandes eventos, design de espaços públicos, desenvolvimento de ambientes virtuais, vigilância e desenvolvimento de ambientes interativos inteligentes.

Segundo Junior et al. (2010), podemos descrever multidões considerando quatro características principais:

- Domínio do espaço da imagem: contempla desafios como a rastreabilidade de pessoas, estimativa de densidade de uma multidão e detecção de eventos e anomalias.

- Domínio sociológico: diz respeito à compreensão do comportamento das pessoas em multidões e explora o comportamento de indivíduos e de grupos.

- Nível de serviços: considera questões relacionadas ao design de espaços e enfoca a caracterização das pessoas em termos de atributos como densidade, fluxo e deslocamento.

- Computação gráfica do domínio: se concentra em construir a representação gráfica através do uso de modelos de simulação que apresentem comportamento similar ao real.

O objeto de estudo deste trabalho é a compreensão e análise do comportamento individual em uma multidão Moussaïd et al. (2016a). Alguns traços comportamentais identificados em estudos anteriores Zhan et al. (2008) são apresentados a seguir:

- Hipótese do Menor-Esforço: em geral, os indivíduos tendem a escolher caminhos que os conduzam aos seus objetivos de uma maneira que minimize o esforço;

- Formação de Filas: esta característica é um derivado de Hipótese de Menor-Esforço e indica que indivíduos, com a intenção de não ter que fazer desvios em suas rotas para evitar colisões, freqüentemente procuram seguir outra pessoa; e

- Efeito Gargalo: devido a restrições no ambiente e o número de pessoas no local, as pessoas mudam sua velocidade de caminhada. 
Outros aspectos podem ser relevantes, de acordo com o contexto e a localidade estudada. Alguns aspectos estão relacionados a determinadas características pessoais que influenciam o comportamento dos indivíduos: (i) distância pessoal do conforto; (ii) velocidade de caminhada; (iii) aspectos culturais; e iv) nível de mobilidade.

No trabalho de Gorrini et al. (2016), a característica (ii) é claramente identificada na análise do comportamento dos pedestres em um cruzamento. Basicamente, percebe-se a diferença na velocidade e distância de conforto das pessoas em relação a três fases de cruzamento: aproximação, avaliação e cruzamento. Outro aspecto percebido na análise refere-se à diminuição das habilidades locomotoras dos idosos, que caminham em média $22 \%$ mais devagar que os adultos mais jovens.

\subsection{Escalas de Análise}

A modelagem de indivíduos que compartilham espaços públicos, como corredores em estações de trem, pode ser classificada em três escalas diferentes de acordo com sua densidade: baixa, alta e média. Outro critério de classificação encontrado na literatura (Zhou et al. (2010)) considera o tamanho da multidão usando a seguinte escala: tamanho grande para milhares, tamanho médio para centenas e tamanho pequeno para dezenas. Consideramos que ambos os critérios indicados são equivalentes e adotamos, no presente trabalho, o termo escala. Nos parágrafos a seguir, mostraremos algumas cenas ilustrativas que nos ajudam a entender os principais desafios de modelagem encontrados em cada um desses ambientes.

Em cenas de baixa densidade (microescala), cada indivíduo pode ter seu próprio conjunto de objetivos: caminhar para o trabalho, desfrutar de momentos de lazer, engajar-se em interações sociais etc. Se o número médio de indivíduos por metro quadrado, referido como densidade neste documento, for relativamente baixo, a diversidade de interesses e metas individuais torna-se relevante para modelar decisões individuais, ações e interações, que por sua vez são necessárias para construir modelos de comportamento de grupo. Neste cenário, as técnicas de modelagem de Sistemas Multiagentes são mais adequadas. Nessas técnicas, os indivíduos são modelados de acordo com princípios de racionalidade, ações estratégicas e comportamento agregado, obtido como a composição do comportamento dos indivíduos. Modelos realistas podem ser produzidos considerando-se, por exemplo, critérios de racionalidade limitada e teoria dos jogos comportamental como fundamentos para o comportamento individual (Parsons e Wooldridge (2002)).

Em cenas de alta densidade (escala macro), onde a densidade é relativamente alta, as ações individuais são limitadas pela configuração de uma multidão, levando a cenários em que a diversidade de indivíduos é inerentemente reduzida. Nesses cenários, os modelos do comportamento global da multidão são aproximações suficientemente boas de fenômenos realistas e também são tratáveis do ponto de vista computacional, mesmo que o número de indivíduos seja grande. Esse pode ser o caso, por exemplo, de cenários de evacuação de emergência em um aeroporto densamente povoado. Nesses cenários, os modelos desenvolvidos geralmente levam em conta as ideias fundamentais utilizadas na dinâmica dos fluidos, que levam em conta apenas o comportamento de toda a turma, perdendo a particularidade dos comportamentos individuais.

Em cenas com densidade média encontramos fenômenos na meso-escala, normalmente encontrados em locais públicos como estações de trem e aeroportos, em que a densidade é suficientemente alta para se tornar relevante, mas não tão alta a ponto de restringir escolhas, ações e interações individuais. Para estas situações, existem técnicas de modelagem híbrida que combinam características usadas tanto em modelagem microscópica como em modelagem macroscópica. Uma modelagem em escala meso também pode encontrar aplicações práticas em outros domínios, como o gerenciamento do tráfego de carros, especialmente em 
ambientes urbanos e pastoreio de animais em fazendas.

Um critério de classificação menos conhecido e apontado por Zhou et al. (2010) classifica multidões usando a escala de tempo como longo ou curto prazo. No primeiro caso, encontramos aplicações que incluem aferições de influências e sua disseminação em opiniões. No curto prazo, onde a análise é geralmente da ordem de minutos a horas, os sistemas existentes se concentram na investigação de como a multidão se comporta em reação a vários eventos, como situações de emergência e ameaças.

A maioria das abordagens para gestão de multidões se concentra na modelagem de curto prazo. Por este motivo, também focamos, no presente trabalho, o critério de densidade de multidões no escopo da análise de curto prazo.

Nas próximas seções estão apresentadas as principais técnicas utilizadas em cada uma destas escalas e as principais questões de pesquisa que ainda carecem de ferramentas mais sofisticadas e precisas para a compreensão do comportamento humano em multidões.

\section{Micro}

Modelos para problemas de micro-escala têm recebido atenção especial nos últimos anos, principalmente pela sua robustez em representar diferentes aspectos do comportamento de indivíduos. Nesta seção delineamos as abordagens mais bem sucedidas encontradas na literatura:

- Modelo de Força Social (Helbing e Molnar (1998)) que é classificado como um modelo de partículas. Neste modelo, a dinâmica do movimento dos indivíduos é alcançada através de forças de atração e repulsão. Este modelo tem representatividade considerável para descrever vários comportamentos coletivos implementando apenas três regras simples. Nesta abordagem, a representação do tempo e do espaço é contínua.

- Modelos de autômatos celulares (Burstedde et al. (2001)). Basicamente, eles são baseados na discretização de tempo e espaço. Cada indivíduo é representado por um estado em uma célula e a dinâmica do movimento ocorre através de regras de transição que realizam a mudança da localização do indivíduo para uma célula vizinha usando alguns critérios pré-estabelecidos. Existem diversas variações de modelos de autômatos celulares. Particularmente, a combinação com a abordagem baseada em floor field é bem sucedida, pois permite que aspectos relacionados a uma multidão, globais e dinâmicos, sejam considerados pelas regras de transição locais. Desta forma, os modelos permitem caracterizar aspectos locais relacionados apenas as células adjacentes Ali e Shah (2008), em composição com aspectos globais.

- Modelos baseados em velocidade (Fiorini e Shiller (1998), Van Berg et al. (2008)), que têm sido amplamente utilizado na indústria de jogos para evitar colisões de personagens virtuais com obstáculos estáticos e em movimento. A ideia principal é baseada na composição de dois fatores-chave: escolher a direção mais direta para o destino e evitar o primeiro obstáculo ou indivíduo na direção escolhida.

- Modelos baseados em sistemas multiagentes têm sido bem-sucedidos na implementação de comportamentos psicológicos complexos, permitindo que os indivíduos sejam dotados de atributos e processos de tomada de decisão individualizados. Existem várias variações dessa abordagem para diferentes contextos e aplicações Kullu et al. (2017) Almeida et al. (2013) Gu e Deng (2013).

Modelos refinados de agentes podem ser construídos com base nesses conceitos. Dependendo da sofisticação desses modelos, no entanto, a escalabilidade para grandes conjuntos de agentes pode ser um 
desafio, pois pode requerer a definição de vários parâmetros, operações e mecanismos para transições de estados. Além disto, apesar da sofisticação dos modelos existentes na literatura, conforme constatado por Haghani e Sarvi (2017), existe uma enorme incerteza sobre a aplicabilidade e representatividade prática dos resultados destes estudos. Muitas vezes a parametrização realizada pode levar a conclusões equivocadas em relação ao que acontece nas situações reais.

\section{Meso}

Em cenários de meso escala, o uso de modelos híbridos busca superar as dificuldades dos cenários de modelagem com densidades significativamente maiores e observar o comportamento individual e coletivo com um tempo razoável de execução.

De acordo com Ijaz et al. (2015), podemos classificar os modelos híbridos da seguinte forma:

- Modelos baseados em zonas, que dividem o ambiente estudado em zonas. Algumas áreas são analisadas do ponto de vista macroscópico e outras do ponto de vista microscópico. Essa técnica é especialmente usada em simulações de planos de tráfego e evacuação. Uma das desvantagens dessa técnica é que os possíveis rumos do movimento da multidão são limitados, o que torna menos favorável a simulação de grandes eventos sociais em espaços abertos. Há também uma grande dificuldade técnica em simular as zonas de transição entre os dois tipos diferentes de modelos para torná-las suave. Essa técnica é conhecida como agregação e desagregação;

- Modelos baseados em camadas, que consideram cada escala em uma camada separada. Por exemplo, uma camada pode simular os movimentos da multidão através de um modelo macroscópico e fornecer informações para a outra camada, que pode ser responsável pela simulação do comportamento individual com base em um modelo microscópico. A vantagem dessa técnica é poder considerar comportamentos individuais complexos com a junção de informações resultantes de modelos macroscópicos e microscópicos.

- Modelos sequenciais, que também implementam as abordagens micro e macro para toda a multidão. Primeiro, o modelo macroscópico é executado para simular o movimento da multidão com base na relação velocidade-densidade. Sequencialmente, esses resultados são transferidos para o modelo microscópico para a simulação do comportamento individual. Esta técnica requer um método de sincronização para transferir os estados dentro do mesmo intervalo de tempo de simulação. Uma de suas variantes, denominada abordagem multi-resolução, foi criada para combinar os modelos macro e micro de forma interativa, melhorando a eficiência da simulação.

Nesse contexto de cenários de meso escala, a literatura existente não aborda adequadamente comportamentos sociais, físicos e psicológicos complexos para os indivíduos. Além disso, até onde sabemos, não há alternativas que considerem o perfil dos indivíduos para uma representação mais realista do comportamento das pessoas. Neste trabalho, tentamos preencher esta lacuna.

\section{Macro}

Abordagens em macro-escala referem-se à análise e simulação de interações de agentes em cenários em que o número de agentes é grande, agentes compartilham algumas (embora não necessariamente todas) motivações para ações e a densidade de agentes é tal que o comportamento de cada agente é dirigido pela 
presença de outros agentes, especialmente aqueles que estão próximos a ele (em problemas nos quais as noções de distância e vizinhança fazem sentido físico). Um cenário prototípico é composto por agentes distribuídos em um ambiente físico e que se movimentam em torno desse ambiente, compartilhando motivações para se movimentar, de forma que os movimentos de cada agente são constrangidos e dirigidos pela presença e pelos movimentos de outros agentes.

A técnica de modelagem mais promissora encontrada na literatura é a abordagem baseada no fluxo, onde a multidão é tratada como um fluxo contínuo e homogêneo. Esta técnica não considera o comportamento individual que limita seu uso a apenas situações com um grande número de pessoas. Além disso, como essa abordagem não representa os indivíduos de maneira realista, ela é geralmente usada em simulações apenas com o objetivo de medir o fluxo de pessoas, por exemplo, em planos de evacuação. Algumas dessas abordagens podem ser encontradas em Ronchi (2017) que expõe as principais pesquisas em gestão de multidões, com ênfase particular nos modelos de evacuação.

\subsection{Tipos de Estudos}

Na seção anterior, discorremos sobre os diferentes tipos de escala que podem ser aplicadas a estudos de comportamento de multidões. Nestes estudos, consegue-se notar a relação entre a escala da região estudada e o grau/poder de detalhamento do modelo utilizado (p. ex., quanto menos denso o cenário analisado maior o nível de especificidade do modelo aplicado).

Outra forma de se organizar as pesquisas existentes é classificar os estudos dentre empíricos e teóricos.

De uma forma bem simplificada, baseada no nosso âmbito de pesquisa, podemos dizer que os estudos teóricos se baseiam na construção de modelos a partir de conceitos e teorias, enquanto as pesquisas empíricas se baseiam em experimentos e observações de dados em campo.

Podemos ainda nos aprofundar um pouco mais e dividir as pesquisas empíricas de acordo com os tipos distintos de dados: dados empíricos obtidos por meio de atividade experimental e dados resgatados do cotidiano. O primeiro caso, que chamaremos de pesquisas com experimentos, comumente ocorre em situações controladas como locais fechados e ambientes artificiais. O segundo caso, que chamaremos de pesquisas de campo, se refere a observações em ambientes reais.

A separação das pesquisas em escalas de análise é de aplicação imediata aos estudos teóricos, visto que na concepção do modelo, já se é observado qual o intuito, objeto de análise, situação micro, meso ou macro. No entanto, quando se trata de estudos empíricos de campo, não se consegue por antecipação determinar a densidade de pessoas que irão se reunir no cenário estudado e, neste caso, a quantidade de pessoas no contexto pode variar da escala micro para a escala macro, e vice-versa.

Outro aspecto comum em estudos de campo em cenários reais é a predominância dos cenários de micro escala. Um dos principais motivos deste viés está nas limitações oriundas da capacidade de se capturar informações individuais através dos dispositivos existentes, como câmeras de segurança. Ainda que existam outras formas de rastreamento de pessoas em locais públicos como, por exemplo, dados de GPS, conexão wi-fi e Bluetooth, existe uma predominância de monitoramento através de câmeras de segurança, que constituem um mecanismo pouco invasivo e abrangente, em que todas as pessoas se tornam suscetíveis ao rastreamento, em vez de apenas as que têm um dispositivo móvel conectado.

Em se tratando de estudos experimentais, precisamos levar em consideração que muitas vezes os resultados podem ser questionáveis, pois os indivíduos envolvidos nas atividades experimentais podem se comportar diferentemente de quando estão expostos à situações não controladas, devido ao fato de sabe- 
rem que estão sendo avaliados, ou mesmo pelo desconforto de terem que utilizar algum aparato extra para fazer medições como, por exemplo, óculos com rastreamento de olhar Croft e Panchuk (2017) ou outros dispositivos para medir a velocidade.

Optamos, neste trabalho, por uma pesquisa empírica com dados de campo para estudar, investigar e analisar situações reais existentes em terminais metroviários fechados monitorados por câmeras de segurança. Estes ambientes possuem grande quantidade de aplicações, visto que a maioria dos terminais já contam com dispositivos de monitoramento através de câmeras. Além disto, os resultados obtidos através desta pesquisa teriam aplicação imediata em rodoviárias e aeroportos os quais incorporem as características mencionadas.

O direcionamento desta pesquisa para cenários de meso-escala tem as seguintes motivações:

- Não identificamos pesquisas especializadas em prover, tratar e analisar informações de forma eficiente em cenários em condições de oclusão entre indivíduos, ou seja, em cenários em que alguns indivíduos têm sua imagem temporariamente encoberta Maheshwari e Heda (2016);

- Existe uma grande variedade de ambientes com estas características, que poderiam se beneficiar de um método robusto de análise da situação em questão, melhorando o atendimento, conforto e segurança do público Kone (2005);

- Os trabalhos da área de processamento de imagens não disponibilizam uma informação sintetizada que possa ser aplicada de forma imediata por engenheiros e arquitetos a projetos e intervenções em cenários;

- Os trabalhos de análise, têm se limitado a analisar informações existentes, sem trabalhar possíveis inconsistências e imprecisões, o que pode levar a conclusões equivocadas Zhong et al. (2015).

- Muitos trabalhos de análise têm um viés voltado ao comportamento coletivo agregado em oposição à análise individualizada dos pedestres Haghani e Sarvi (2017); Teknomo et al. (2016).

\subsection{Análise do Movimento de Pedestres}

A análise de multidões tem aplicação direta em áreas como: monitoramento real de câmeras de segurança, avaliação de níveis de serviços de espaços públicos e testes de projetos de espaços para grandes eventos e situações de evacuação.

Existem diversos estudos com o intuito de analisar o comportamento de pedestres. Estes estudos enfrentam diferentes problemas, de acordo com o método empregado para a realização da análise. Alguns estudos utilizam amostras de pessoas em terminais, outros utilizam técnicas de simulação com aplicação de análise What-if, que permite averiguar os efeitos causados pela alteração de variáveis no comportamento de um sistema, ou a análise de dados obtidos diretamente de câmeras de segurança.

Neste trabalho são utilizadas técnicas para análise do comportamento de pedestres através da utilização de dados obtidos por câmeras de segurança. As próximas seções organizam os principais trabalhos de análise e suas divisões por ramos de pesquisa.

\subsubsection{Processamento de Imagens}

A extração de movimento de informação a partir de vídeos é estudada pelos pesquisadores de Visão Computacional e Processamento de Imagens. A principal questão é determinar, dado o ângulo da câmera, 
resolução etc., valores para parâmetros e técnicas para segmentação e análise de imagens. Outra dificuldade reside na oclusão de indivíduos em ambientes muito densos, conforme apontado por Grant e Flynn (2017); Zitouni et al. (2016)

Maheshwari e Heda (2016) divide os algoritmos de análise de multidão baseada em dados de câmeras de segurança em três grupos: (1) contagem de pessoas, (2) rastreamento de pessoas e (3) análise de comportamento de multidões. As técnicas de processamento de imagens são mais comumente utilizadas para estimativa de densidade de multidões, detecção de movimentos de multidões, rastreamento de multidões e reconhecimento de comportamento de multidões.

A extração de informações para análise de comportamentos passa por três etapas Maheshwari e Heda (2016):

1. Pré-processamento: extração de características dos quadros de vídeos

2. Rastreamento de objetos: diferenciação entre objetos e a multidão

3. Reconhecimento de eventos/comportamentos: busca de padrões de movimentos como direção, velocidade etc.

O objetivo dos algoritmos de rastreamento é combinar os pontos entre os quadros, estimando a quantidade de pedestres para cada ponto em cada quadro. Dois pontos em dois quadros consecutivos são correspondidos se e somente se os dois pontos representarem um mesmo pedestre (Teknomo et al. (2016)).

Apesar de existirem várias técnicas que focam no rastreamento de objetos, ainda são escassos os estudos especializados no rastreamento de objetos baseados em características antropométricas e do comportamento de pedestres. O mesmo ocorre nas etapas de reconhecimento de eventos e comportamentos, que enfatizam a detecção de padrões coletivos em detrimento da análise individualizada. Algoritmos de rastreamento de pedestres direcionam esforços para analisar a densidade de multidões de maneira agregada. Atualmente, ainda existe uma carência de um método robusto para o rastreamento preciso de pedestres de forma individualizada.

\subsubsection{Métodos de Análise Empírica}

Uma análise criteriosa de atributos importantes relacionados aos efeitos de aglomeração nas estações LRT (Light Rail Transit) em Hong Kong foi realizada por Lam et al. (1999), com os dados recolhidos em duas estações LRT selecionadas para estudar diferentes efeitos de aglomeração. Os graus de congestionamento nas plataformas LRT foram examinados através da observação direta de características operacionais da estação como número de passageiros chegando, embarcando, desembarcando; chegada, partida e tempo de permanência dos trens. O conceito de Nível de Serviço (LOS) foi aplicado para estudar os graus de congestionamento nas plataformas LRT. Finalmente, as respostas dos passageiros devido ao desconforto em veículos lotados e plataformas congestionadas são investigadas através da condução de pesquisas de preferência para estudar os efeitos do desconforto de passageiros em veículos lotados e plataformas congestionadas. Os resultados proveram dados para nortear o projeto e planejamento de plataformas das estações de LRT em Hong Kong.

O monitoramento de desempenho em estações de trem baseados em dados do sistema de cobrança automática foi desenvolvido por Heuvel e Hoogenraad (2014). Essa forma apresenta um baixo custo em relação a vários métodos que tem sido empregados de contagem manual ou aplicação de pesquisas. Além 
disso, através de contagens manuais é muito difícil conseguir inferir tendências no fluxo de passageiros, causas de gargalos e o tempo gasto nas estações.

Vários desafios associados ao fluxos de pedestres em estações de trem são discutidos utilizando-se como exemplo a estação ferroviária de Lausanne no trabalho de Hänseler et al. (2015). A pesquisa explorou diversas fontes de dados, incluindo pesquisas de viagens, contagens de pedestres e trajetórias.

\subsubsection{Análises Experimentais}

Vários estudos empenham-se em ampliar a compreensão a respeito de motivações e decisões fundamentais no que se refere as características comportamentais da direção de deslocamento, velocidade de marcha e prevenção de colisões com outros pedestres ou obstáculos.

Particularmente, Croft e Panchuk (2017) estudou algumas características relacionadas à prevenção de colisões, como contato visual entre pedestres, variações de velocidade e direção em cruzamentos com interferentes perpendiculares a direção de caminhada. Neste estudo, foram testados os comportamentos de oito pedestres diferentes em uma situação de possível colisão com um interferente que atravessa perpendicularmente a direção de caminhada. As medições foram todas realizadas em ambiente artificial observado.

\subsubsection{Estudos Teóricos de Simulação e Síntese}

Abordagens que utilizam modelos para estimar o fluxo de pedestres em plataformas de embarque são amplamente estudadas, como em Ahn et al. (2017), onde foi desenvolvida uma aplicação em relação à estação JR Takatsuki, que continha uma plataforma de ilha estreita que atendia a grandes volumes de embarque, desembarque e transferência de passageiros. Neste caso, o objetivo do projeto foi desenvolver um método de previsão de padrões de fluxo de pedestres dentro de uma estação ferroviária para um novo layout proposto para aliviar o elevado fluxo entre as plataformas e links de interconexão. O núcleo da metodologia utiliza padrões de origem-destino para pedestres para estimar medidas de esforço de caminhada de pedestres. Além da técnica de modelagem analítica, uma aplicação de um modelo de simulação foi realizada para fornecer uma apreciação visual da operação futura dos saguões ferroviários.

\subsection{Parâmetros de Referência}

Nesta sessão abordamos alguns aspectos relacionados a medidas e parâmetros de referência no que tange a aspectos antropométricos e aos padrões de caminhada das pessoas. Estes parâmetros foram utilizados no método proposto como referência tanto no método para corrigir problemas dos algoritmos de rastreamento como na segregação de informações individuais para análise.

\subsubsection{Medidas Antropométricas}

A profundidade do corpo e a largura dos ombros são as medidas humanas primárias usadas pelos projetistas de espaços e instalações para pedestres, onde a largura dos ombros é o fator que afeta a capacidade prática. A vista plana de um corpo humano masculino adulto médio ocupa uma área de cerca de $0,14 \mathrm{~m}^{2}$, mas o envelope de desenho adotado é uma elipse de $45,8 \mathrm{~cm}$ por $61 \mathrm{~cm}$, com área de $0,21 \mathrm{~m}^{2}$ (ver Figura 2.2.). Este espaço é usado para determinar a capacidade prática para pedestres em pé, permitindo que muitos pedestres carreguem artigos pessoais, considerando preferências psicológicas naturais para evitar contato corporal (Austroads (1995)). 


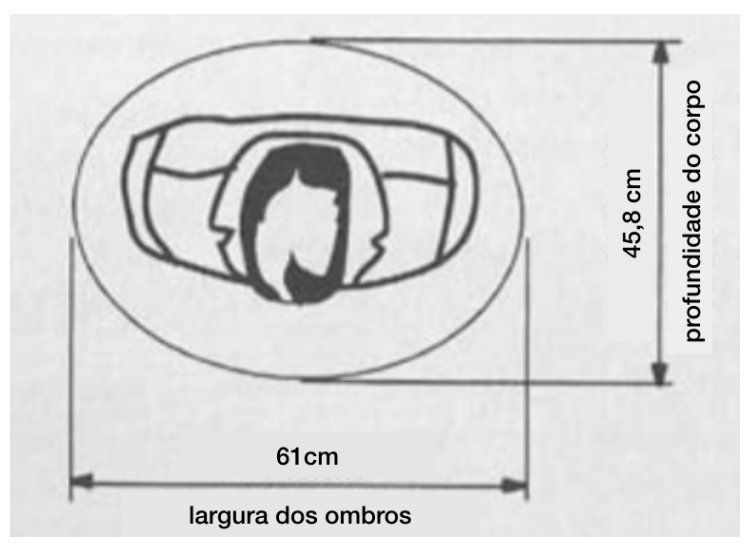

Figura 2.1: Elipse corporal. Adaptado de Austroads (1995)

Em estações e terminais de trem/metrô é comum aos pedestres estarem carregando uma bolsa ou bagagem. A Tabela 2.1 apresenta a largura do pedestre de acordo com o tipo de bagagem.

\begin{tabular}{|c|c|c|c|c|c|c|}
\hline & & & & Primei & não & \\
\hline & Bagagem & Percentis & Vazia & Pequena & Média & Grande \\
\hline \multirow{8}{*}{ 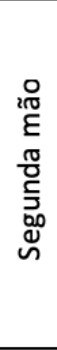 } & \multirow{2}{*}{ Vazia } & $50 \%$ & 64 & 73 & 73 & 89 \\
\hline & & $85 \%$ & 73 & 81 & 80 & 100 \\
\hline & \multirow{2}{*}{ Pequena } & $50 \%$ & & 75 & 72 & 78 \\
\hline & & $85 \%$ & & 83 & 80 & 84 \\
\hline & \multirow{2}{*}{ Média } & $50 \%$ & & & 74 & 85 \\
\hline & & $85 \%$ & & & 81 & 95 \\
\hline & \multirow{2}{*}{ Grande } & $50 \%$ & & & & 79 \\
\hline & & $85 \%$ & & & & 84 \\
\hline
\end{tabular}

Tabela 2.1: Percentis de 50\% e 85\% da largura dos pedestres dependendo da bagagem. Valores em $\mathrm{cm}$. Adaptado de Buchmueller e Weidmann (2006)

\subsubsection{Velocidade de Caminhada}

A velocidade de caminhada de indivíduos em fluxos de pedestres desimpedidos tende a ter uma distribuição normal, com média estimada de $1,34 \mathrm{~m} / \mathrm{s}$ e desvio padrão de $0,37 \mathrm{~m} / \mathrm{s}($ Daamen (2004)).

Segundo Kone (2005), ao projetar um espaço para terminal de transporte, deve-se utilizar como referência para a velocidade de caminhada o valor de $1,25 \mathrm{~m} / \mathrm{s}$, sendo que a velocidade média observada em terminais de transporte varia entre 0,7 e $2,0 \mathrm{~m} / \mathrm{s}$, ainda que existam observações indicando que ela está ficando mais rápida, especialmente nas grandes cidades. Várias características influenciam variações nestes valores, geralmente os homens tendem a andar mais rápido que as mulheres. Pessoas com deficiência andam mais devagar.

Segundo Buchmueller e Weidmann (2006), a velocidade de caminhada específica para pedestres é determinada por vários fatores de influência como:

- Condições físicas dos pedestres:

- Diferenças culturais e raciais

- Idade

- Gênero 
- Altura corporal/tamanho do passo

- Obstáculos

- Bagagens

- Propósito da viagem

- Condições do ambiente:

- Temperatura

- Clima

- Horário

- Características do caminho:

- Áreas inclinadas

- Escadas

- Escadas rolantes

De acordo com o próposito da viagem, Weidmann (1993) aponta diferentes velocidades de caminhada conforme indicado abaixo:

- Trabalho: $1.45 \mathrm{~m} / \mathrm{s}$

- Habitual: $1.34 \mathrm{~m} / \mathrm{s}$

- Compras: $1.04 \mathrm{~m} / \mathrm{s}$

- Lazer: $0.99 \mathrm{~m} / \mathrm{s}$

As velocidades médias de caminhada para os diferentes níveis de serviço são apresentadas na Tabela 2.2. Com um nível de serviço alto, as pessoas podem andar livremente o quanto quiserem. Quanto mais rápido as pessoas andam, maior o espaço ocupado em torno de si mesmas. Em ambientes lotados, as pessoas são forçadas a reduzir sua velocidade.

\begin{tabular}{|c|c|c|}
\hline $\begin{array}{c}\text { Níveis de } \\
\text { serviços }\end{array}$ & Definição & $\begin{array}{c}\text { Velocidade de caminhada } \\
\text { horizontal }(\mathrm{m} / \mathrm{s})\end{array}$ \\
\hline $\mathrm{A}$ & Zona de circulação livre & 1,3 \\
$\mathrm{~B}$ & Zona de circulação restrita & 1,25 \\
$\mathrm{C}$ & Zona de conforto pessoal & 1,22 \\
$\mathrm{D}$ & Sem zona toque & 1,15 \\
$\mathrm{E}$ & Zona de toque & 0,77 \\
$\mathrm{~F}$ & Elipse corporal & $<0,77$ \\
\hline
\end{tabular}

Tabela 2.2: Definições de níveis de serviços para velocidade de pedestre em caminhadas horizontais. Adaptado de Kone (2005) 


\subsubsection{Indicadores de Engenharia de Tráfego}

A engenharia de tráfego se dedica ao planejamento, monitoramento, projeto geométrico e operações de tráfego, para que pessoas e bens se movam de forma segura, rápida e eficiente. Os parâmetros fundamentais de tráfego fornecem informações que auxiliam a detecção de qualquer variação das características de fluxo (NPTEL (2007)). Os conceitos dos principais parâmetros adotados pela área de engenharia de tráfego são apresentados abaixo:

\section{Velocidade}

A velocidade é considerada como uma medida de qualidade, pois os analistas consideram preponderantemente a velocidade do percurso como aspecto de design. A velocidade é definida como a taxa de movimento em distância por unidade de tempo. Matematicamente, a velocidade $v$ é dada por

$$
v=d / t
$$

onde, $v$ é a velocidade do veículo em $\mathrm{m} / \mathrm{s}$, $d$ é a distância percorrida em metros no tempo $t$ segundos.

\section{Densidade}

A densidade é definida como o número de pedestres que ocupam determinada área. Pode-se fotografar uma extensão da região analisada $r$, contar o número de pedestres, $n p$, naquele momento e obter a densidade $k$ como

$$
k=n p / r
$$

A densidade também é tão importante quanto o fluxo como medida diretamente relacionada à demanda por espaço. Ela mede a proximidade dos pedestres no fluxo, que por sua vez, afeta a liberdade de deslocamento e a percepção de conforto.

\section{Fluxo}

O fluxo é o número de pessoas que passam por determinada faixa ou área durante um intervalo de tempo. A medição é realizada contando o número de pedestres, $n p$, passando uma região particular em um período definido $t$. O fluxo que é expresso em pedestres/metros.minuto, pode ser expresso a partir da densidade $k$ e velocidade média $v m$ conforme

$$
q=k \times v m
$$

Expressaremos, neste trabalho, as medições do fluxo tomando um minuto como a medida do tempo.

\subsubsection{Níveis de Serviços}

Dentre as principais razões para se estudar o movimento de pedestres está avaliar se os recursos de um terminal atendem a determinados padrões de projeto. Neste trabalho, adotamos o padrão de níveis de serviço criado por Fruin (1987), que classifica as diferentes instalações de acordo com o espaço disponível 
para indivíduos (por exemplo, locais lotados têm um nível de serviço mais baixo). A classificação em níveis de serviços é aplicada de acordo com o espaço disponível para os indivíduos e podem ser usados como uma das variáveis de decisão ao planejar estações de trânsito, onde as classes variam da letra $\mathrm{A}$ até a letra $\mathrm{F}$ (Kone (2005)). Nesta escala, a classe A corresponde à situação em que as pessoas têm muito espaço ao seu redor. No outro extremo, a classe F significa congestionamento. A Tabela 2.3 mostra a definição de nível de serviço criada por Fruin (1987) e a Figura 2.5.4 mostra exemplos da classificação nos diferentes níveis de serviços existentes.

\begin{tabular}{|c|c|c|c|c|}
\hline \multirow{2}{*}{$\begin{array}{c}\text { Níveis de } \\
\text { serviços }\end{array}$} & Definição & \multicolumn{3}{|c|}{ Espaço do pedestre $\left(\mathrm{m}^{2} /\right.$ pessoa) } \\
& $\begin{array}{c}\text { Esteiras } \\
\text { rolantes }\end{array}$ & Escadas & $\begin{array}{c}\text { Áreas de } \\
\text { espera }\end{array}$ \\
\hline A & Zona de circulação livre & $\geq 3,3$ & $\geq 1,9$ & $\geq 1,21$ \\
B & Zona de circulação restrita & $2,3-3,3$ & $1,4-1,9$ & $0,93-1,21$ \\
C & Zona de conforto pessoal & $1,4-2,3$ & $0,9-1,4$ & $0,65-0,93$ \\
D & Sem zona toque & $0,9-1,4$ & $0,7-0,9$ & $0,28-0,65$ \\
E & Zona de toque & $0,5-0,9$ & $0,4-0,7$ & $0,19-0,28$ \\
F & Elipse corporal & $<0,5$ & $<0,4$ & $<0,19$ \\
\hline
\end{tabular}

Tabela 2.3: Classificação em níveis de serviços em relação ao espaço disponível em diferentes áreas. Adaptado de Kone (2005), baseado no trabalho de Fruin (1987)

Um critério alternativo, criado para se determinar o desempenho do fluxo de pedestres baseado em dados obtidos de algoritmos de rastreamento, é o Pedestrian Performance Index - PI, que é a média das medições individuais do indicador para todo o cenário. $\mathrm{O}$ indicador individual é resultado de uma combinação linear do atraso e desconforto, como proposto por Teknomo e Takeyama (2016).

\subsection{Conclusões}

Este capítulo apresentou as principais pesquisas que se propõem a investigar o comportamento de pedestres em terminais de transporte. A maioria destas técnicas focam apenas na análise de densidade, fluxo e velocidade das caracteristicas da multidão de forma agregada, negligenciando assim características individuais relevantes para o gerenciamento de espaços públicos. O próximo capítulo apresenta um método inovador, que demonstra vantagens para a análise de terminais de transporte em termos de precisão, considerando não apenas aspectos e medições do público de forma agregada, mas levando-se em consideração características individuais. 
Nível de serviço $A$

Velocidade de caminhada livre; inexistência de conflitos com outros pedestres.

\section{Nível de serviço B}

Velocidade de caminhada livre; pedestres respondem a existência de outros pedestres.

Nível de serviço $\mathbf{C}$

Velocidade de caminhada livre; poucos conflitos para movimento reverso ou cruzado.

\section{Nível de serviço D}

Liberdade para escolha da velocidade de caminhada e restrição para passar por outras pessoas; alta possibilidade de conflitos para movimento reverso ou cruzado.

\section{Nível de serviço E}

Restrição para escolha da velocidade de caminhada e para passar por outras pessoas para todos os pedestres; movimento reverso ou cruzado são extremamente difíceis.

\section{Nível de serviço $F$}

Restrição severa da velocidade de caminhada; o contato com os outros é frequente e inevitável; movimento reverso ou cruzado são virtualmente impossíveis.

Figura 2.2: Exemplos de níveis de serviços. Adaptado de Kone (2005), baseado no trabalho de Fruin (1987) 


\section{Capítulo 3}

\section{Análise Baseada em Contexto do Movimento de Pedestres em Terminais de Transporte}

Nesta seção, é apresentada uma nova ferramenta para analisar as trajetórias de pedestres a partir de dados obtidos do processamento de imagens de vídeos. $\mathrm{Na}$ área de visão computacional, o uso de algoritmos de rastreamento para a aquisição de informações de cenários reais é frequente, em função do seu baixo custo e alta abrangência. No entanto, ainda existem obstáculos para garantir a acurácia destes algoritmos. $\mathrm{O}$ que é proposto como contribuição neste trabalho é a utilização de informações do contexto para solucionar impasses do rastreamento de pedestres. Algoritmos genéricos de rastreamento não consideram o significado dos dados. Desta forma, muitas vezes os rótulos de pedestres falham e levam a distorções. A solução apresentada traz mais acurácia e precisão, fazendo uso de informações do contexto.

Na seção 3.1 são apresentados os dados de entrada utilizada pelo método, bem como a etapa de pré processamento necessária para ajuste da informação proveniente de vídeos. Na seção 3.2 apresentamos o metódo de pesquisa adotado neste trabalho. Na seção 3.3 apresentamos uma visão geral da aplicação da primeira etapa da ferramenta. Na seção 3.3.1 são apresentados os principais parâmetros utilizados pela ferramenta. Na seção 3.3.2, são apresentadas as contribuições em relação à remoção de anomalias na direção de caminhada, considerando os padrões típicos de caminhada dos pedestres no contexto de terminais de transporte. Na seção 3.3.3, é apresentada a contribuição em relação à contagem de pedestres com a correção de erros de duplicidade de rastreamento baseada em referências antropométricas associadas ao contexto. Na seção 3.3.4, é tratada a completude na determinação do caminho percorrido pelos pedestres. Finalizamos este capítulo com a seção 3.4, onde são apresentados os relatórios criados na ferramenta com a finalidade de sintetizar e analisar os dados obtidos pela aplicação da etapa de tratamento de dados.

\subsection{Coleta de Dados e Pré-processamento: Conversão dos Paramêtros de Vídeo para a Representação do Ambiente}

Sistemas de monitoramento de vídeo são comumente usados como fontes importantes de informações. A partir das imagens adquiridas é possível produzir métricas sobre o cenário em estudo. O uso de câmeras para o monitoramento de cenários reais tem ganhado importância devido ao barateamento destes dispositivos e ao aumento da capacidade de processamento de imagens. 
Um aspecto que sempre deve ser considerado ao se utilizar os dados provenientes dos algoritmos de processamento de imagens é a questão da distorção. Existem vários aspectos que afetam a distorção geométrica das imagens, os quais podem ser divididos em internos, aqueles relacionados com a arquitetura da câmera, e externos, nos quais se enquadra a distorção de perspectiva Mikhail et al.. A distorção de perspectiva ocorre quando a imagem é obtida com visão oblíqua, como ocorre no caso da maioria das câmeras de monitoramento de espaços públicos. A rigor, toda imagem aérea possui distorção projetiva, devido ao fato dos raios de luz provenientes do objeto convergirem para um único ponto no sensor - o centro de perspectiva Roberto et al. (2017). A consequência deste fato na imagem é que os objetos mais distantes parecem menores, e a perda do paralelismo, como demonstrado na Figura 3.1.

Para resolver este problema, neste trabalho é tratada a distorção de perspectiva pela transformação das posições em pixels obtidas da imagem de vídeo para posições em metros, de acordo com as medidas de projeto do ambiente. Esta etapa de pré-processamento das informações é primordial para garantir a acurácia das análises feitas a partir das informações quantitativas obtidas do processamento das imagens de vídeo do cenário analisado.

Nesta camada, aplica-se uma técnica de normalização dos dados obtidos das imagens extraídas de câmeras de vídeo. $\mathrm{O}$ conceito de normalização adotado neste artigo refere-se à transformação das posições em pixels da perspectiva distorcida da imagem capturada para posições em metros do ambiente real.

Para transformação de perspectiva, é utilizado o método do OpenCV que faz a transformação das posições com perspectiva distorcida nas imagens para o plano ortogonal in OpenCV (2019). Primeiramente, é necessário encontrar essa matriz de transformação, que pode ser obtida a partir de quatro pontos na imagem de entrada e os pontos correspondentes na imagem de saída, assumindo que três dos pontos não sejam colineares. Em seguida, obtemos as coordenadas da imagem no plano ortogonal aplicando-se a matriz de transformação $3 \times 3$, encontrada no primeiro passo.

Existem diversos modos de seleção dos quatro pontos de coordenadas de origem para a transformação de perspectiva. Por exemplo, muitos algoritmos de transformação de perspectiva detectam programaticamente quatro pontos de origem em uma imagem com base na detecção de borda ou canto e analisam atributos como cor e pixels adjacentes. Neste trabalho, são selecionados os cantos do ambiente de forma manual, visto que toda a análise é feita através das imagens obtidas de um único dispositivo e a configuração do ambiente é estática. A calibração manual dos cantos e medidas do ambiente é, em determinado aspecto, mais segura em garantir generalizações para diferentes ambientes. Sendo assim, nos experimentos, esta informação poderá ser verificada de forma explícita.

Os parâmetros pelos quais a imagem é normalizada devem ser determinados conforme indicado abaixo:

- Vídeo original: posições dos quatro cantos em pixels - $C_{1,2,3,4}$ do ambiente que pode variar de acordo com o ângulo de posicionamento da câmera.

- Layout do ambiente real: dimensões de largura e altura em metro.

A partir dos parâmetros de entrada, a conversão de perspectiva é executada, como demonstrado na Figura 3.1, usando-se os métodos que estão disponíveis em in OpenCV (2019) (cv.getPerspectiveTransform e cv.warpPerspective).

A notação, utilizada nos algoritmos e na Figura 3.1, é definida conforme se segue. Basicamente, a multidão no cenário é composta pela soma de vários movimentos individuais, ou abreviadamente, um conjunto de trajetórias - $T$. Formalmente, os movimentos de um determinado pedestre - $i$ são representados através da trajetória $t_{i}$ e sua representação correspondente em um vídeo. A trajetória $t_{i}$ é composta por uma lista de 



tempo.

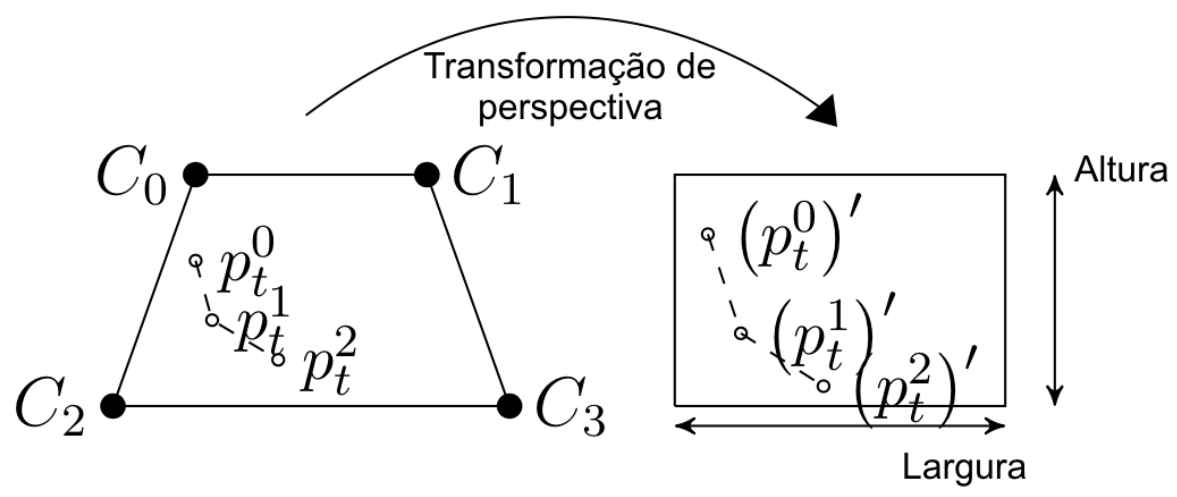

Figura 3.1: Entrada e saída da etapa de pré-processamento dos dados para conversão dos paramêtros de vídeo (pixels e frames) para a representação do ambiente (metros e segundos)

Nesta etapa, além da normalização da perspectiva e normalização do tempo, que é a conversão do tempo de vídeo dado em quadros por segundo para o tempo em segundos. No final deste estágio de normalização, é possível fazer cálculos de distâncias e velocidades de pedestres sem distorções de perspectiva e tempo.

\subsection{Método de Pesquisa}

A metodologia de pesquisa adotada neste trabalho foi a pesquisa descritiva. $\mathrm{O}$ intuito desta pesquisa foi identificar características e variáveis relacionadas aos problemas decorrentes da obtenção de dados de cenários reais para criar novos mecanismos que ampliem a capacidade de captura de dados de cenários reais.

Os mecanismos propostos neste trabalho foram obtidos a partir dos seguintes procedimentos de pesquisas:

- Seleção de uma amostra de trajetórias obtidas de um cenário real;

- Análise das caraterísticas destas trajetórias;

- Apuração da ocorrência de erros destas trajetórias na representação dos pedestres no cenário;

- Identificação das correções possíveis de serem realizadas baseadas no conhecimento do significado e contexto dos dados;

- Automatização das correções por meio da criação dos algoritmos para extrapolação para todo o domínio.

A pesquisa descritiva nos permitiu a ampliação do conhecimento para a criação de uma ferramenta que provê mecanismos para a correção de diferentes falhas provocados pelos algoritmos de rastreamento conforme apresentado na próxima seção.

\subsection{Tratamento dos Dados}

A etapa de tratamento utiliza uma arquitetura composta por três componentes que funcionam de forma independente e se propõem a superar algum revés relacionado ao rastreamento de pedestres através de informações geradas de imagens de vídeos. Desta forma, o método permite que os componentes possam ser 
utilizados de forma independente. Isto provê flexibilidade para adaptações a coleções de dados de outros cenários que podem não apresentar todas as falhas tratadas pelo método. Os componentes são implementados separadamente e suportam diferentes níveis de abstração que podem variar de acordo com a qualidade das informações e os impasses gerados por um algoritmo de rastreamento específico. A estruturação desta solução, por sua vez, proporciona flexibilidade e extensibilidade a diversas aplicações.

A arquitetura geral desta solução é mostrada na Figura 3.2. Nesta abordagem, cada componente trata um diferente impasse da obtenção de dados através dos algoritmos de rastreamento.

\section{Análise de pedestres baseada em contexto}

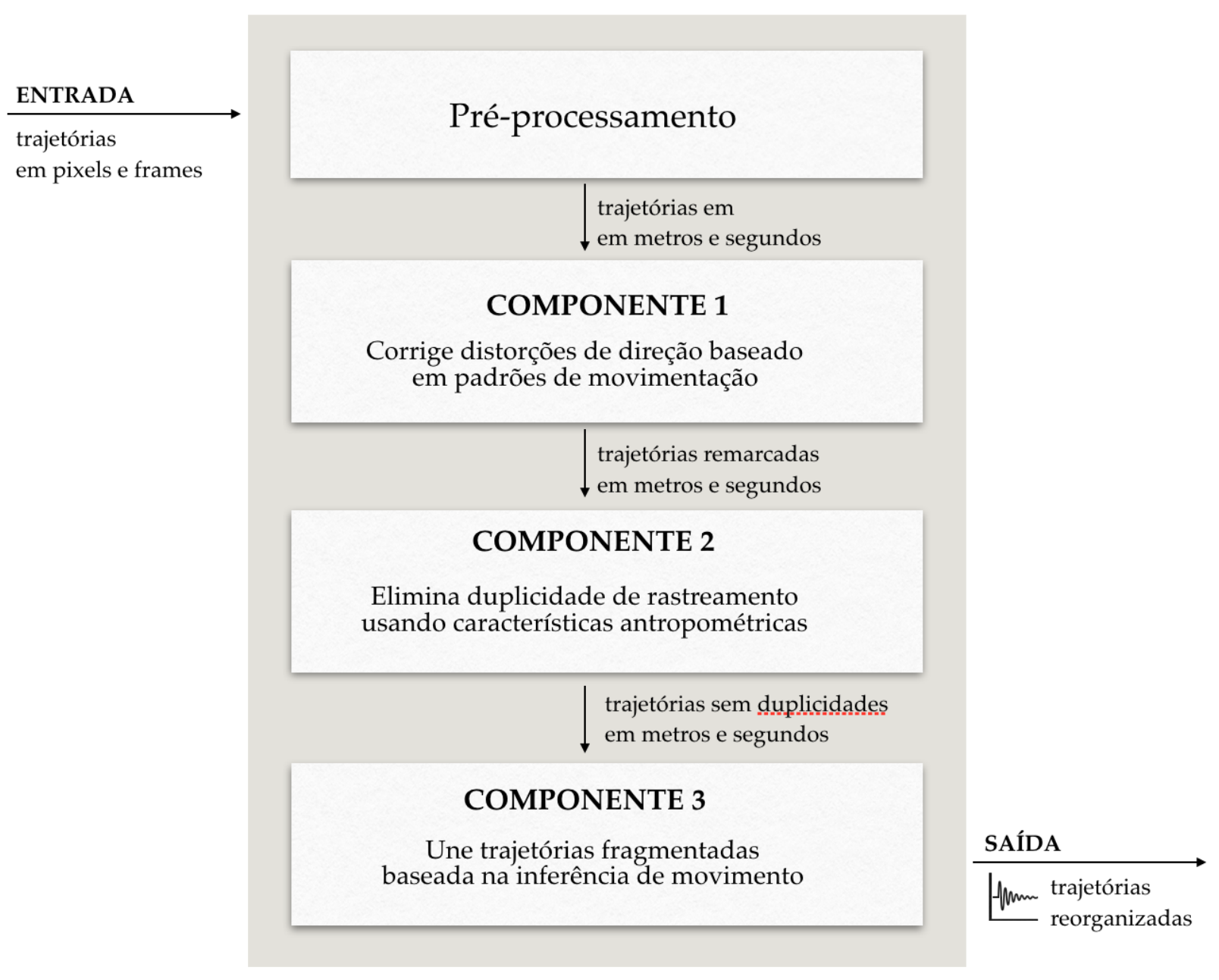

Figura 3.2: Esquema representativo da etapa de tratamento de dados

Na próxima seção são apresentados os parâmetros contextuais utilizados na ferramenta e nas seções seguintes, os principais detalhes de cada componente são explicados de modo a demonstrar uma visão abrangente da solução.

\subsubsection{Sumário dos Parâmetros Contextuais Utilizados pela Ferramenta}

Os componentes que serão apresentados nesta seção efetuam a correção de dados baseada em parâmetros contextuais que devem ser ajustados de acordo com o cenário a ser analisado. A identificação destes parâmetros foi realizada na etapa de análise dos dados e o seu uso nos componentes é fundamental para a obtenção de trajetórias mais aderentes a realidade através do tratamento dos dados. Vale ressaltar que al- 
guns parâmetros são comuns a mais de um dos componentes. Apresentamos na Tabela 3.1 um resumo dos parâmetros identificados por tipo, escopo de uso, referência e representação visual.

Tabela 3.1: Parâmetros contextuais por tipo e escopo de utilização nos componentes

\begin{tabular}{|c|c|c|c|c|c|}
\hline \multirow{2}{*}{ Parâmetro } & \multirow{2}{*}{ Tipo } & Escopo de uso & \multicolumn{2}{|c|}{ Referência } \\
\cline { 2 - 5 } anguloLimiarDeOclusao & Comportamental & $\mathrm{X}$ & - & - & $\begin{array}{l}\text { Deslocamento de movimentação má- } \\
\text { ximo comum ao cenário (Fig. 3.3) }\end{array}$ \\
\hline distanciaMinimaLimiar & Antropométrico & $\mathrm{X}$ & $\mathrm{X}$ & $\mathrm{X}$ & Figura 3.4 \\
\hline tempoLimiarMinimo & Antropométrico & $\mathrm{X}$ & $\mathrm{X}$ & $\mathrm{X}$ & Figura 3.5 \\
\hline larguraLimiar & Antropométrico & - & $\mathrm{X}$ & $\mathrm{X}$ & \multicolumn{1}{|c|}{ Figura 3.6 } \\
\hline alturaLimiar & Antropométrico & - & $\mathrm{X}$ & $\mathrm{X}$ & Figura 3.6 \\
\hline velocidadeLimiar & Comportamental & - & $\mathrm{X}$ & $\mathrm{X}$ & $\begin{array}{l}\text { Variação média de velocidade do cená- } \\
\text { rio }\end{array}$ \\
\hline mudancaDeDirecaoLimiar & Comportamental & - & $\mathrm{X}$ & $\mathrm{X}$ & $\begin{array}{l}\text { Deslocamento de movimentação mé- } \\
\text { dio comum ao cenário (Fig. 3.3) }\end{array}$ \\
\hline limiarDeSimilaridade & Dispositivo de captura dos dados & - & $\mathrm{X}$ & - & $\begin{array}{l}\text { Oscilações de posição de referência do } \\
\text { algoritmo de rastreamento (Fig. 3.7) }\end{array}$ \\
\hline
\end{tabular}

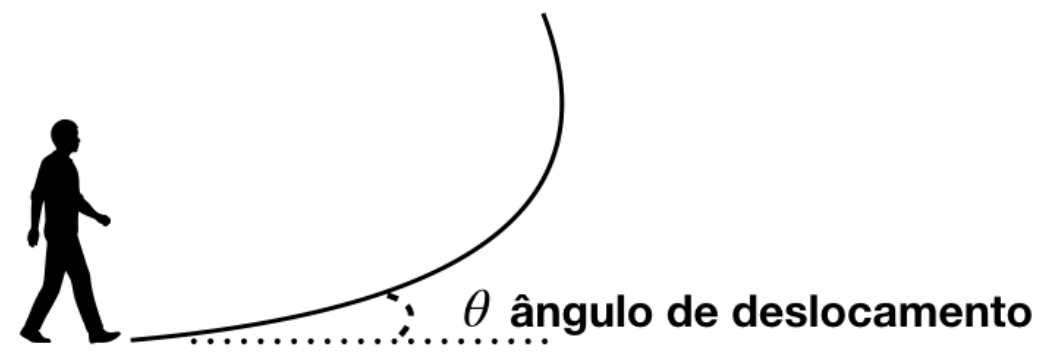

Figura 3.3: Parâmetros ângulo limiar de deslocamento/mudança de direção

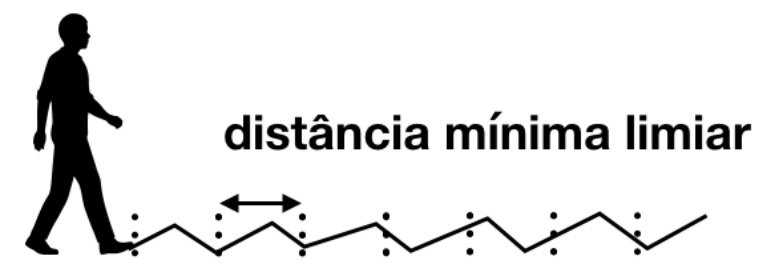

Figura 3.4: Parâmetro distância mínima

\subsubsection{Componente 1: Corrige distorções de direção baseado nos padrões comportamentais de movimentação para melhorar o percurso de pedestres}

\section{Problema}

Essa camada foca especialmente na melhoria de rótulos de percursos de pedestres quando a rotulação é imperfeita no que se refere ao erro na atribuição de um único rótulo de pedestre para dois ou mais pedestres distintos. Um exemplo típico dessa situação ocorre quando duas pessoas se cruzam em suas trajetórias 


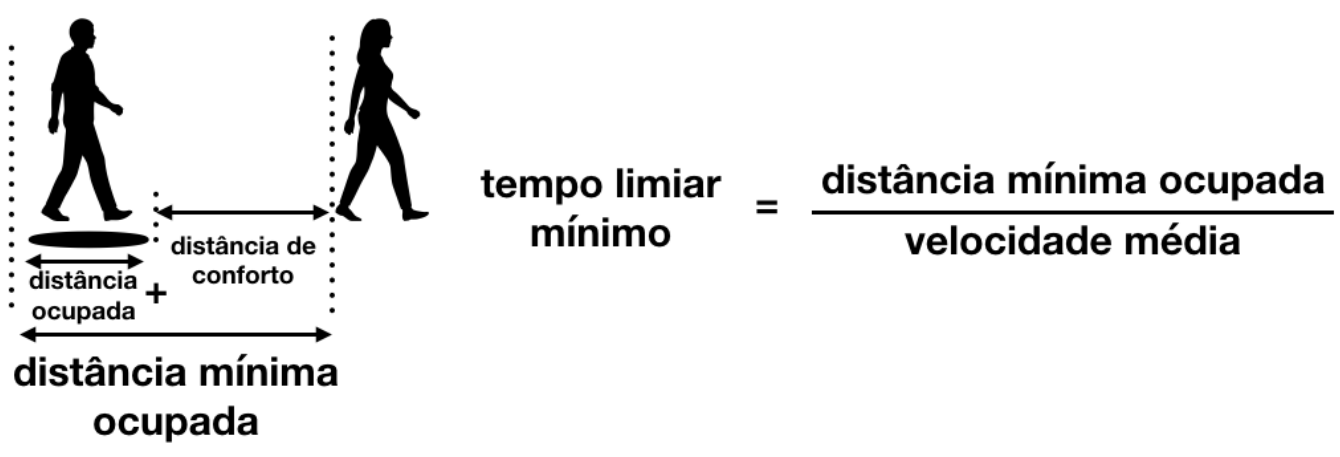

Figura 3.5: Parâmetro tempo mínimo

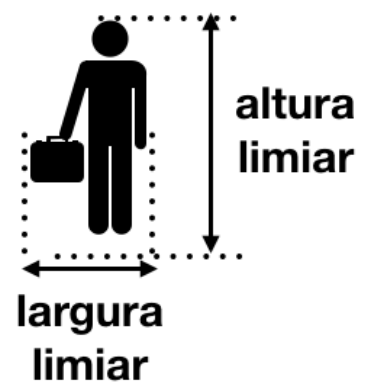

Figura 3.6: Parâmetros largura e altura

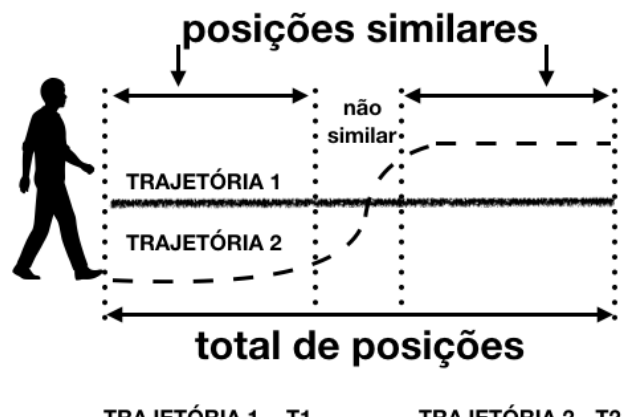

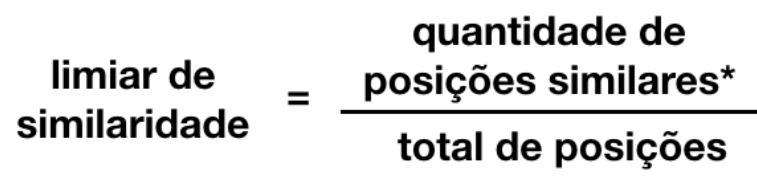

*Caso a diferenças dos valores dos atributos das posições de T1 e T2 para um mesmo tempo for < limiar, esta posição é considerada como similar e somada a quantidade ( $\forall$ atributo: velocidade, direção distância x e y)

Figura 3.7: Parâmetro similaridade

e o algoritmo de rastreamento falha em continuar o curso da pessoa original, rastreando outro indivíduo após a travessia em função da oclusão de imagens. Para minimizar o ruído causado por este problema foi desenvolvido o componete que identifica e altera o rótulo nos pontos de cruzamento.

\section{Descrição}

O algoritmo implementado neste componente corrige o rótulo com base na identificação de trajetórias que têm um ângulo - $\theta$ que representa uma mudança abrupta de direção. Sendo assim, afirmamos que esse ângulo não é devido a uma mudança de direção do pedestre, mas a uma falha do algoritmo em atribuir o rótulo da trajetória de um pedestre para o outro pedestre que a atravessou. Este é um parâmetro contextual, pois baseia-se no comportamento típico de pedestres em terminais de transporte que é dar preferência por uma rota de tamanho mínimo (Princípio do menor esforço, Zipf (1949)) que se revela pelo descolamento retílineo na ausência de obstáculos. Nestes cenários as pessoas tendem a se deslocar pelo caminho de menor 
esforço, ou seja, caminho mais curto, que geralmente é em linha reta, salvo situações onde há obstáculos ou é necessário evitar colisões com outros pedestres. Nesse caso, estabelecemos que um ângulo de mudança de direção $\theta$ deve ser maior que um determinado limiar para ser considerado como tendo um erro na definição do rótulo. $\mathrm{O}$ valor a ser atribuído a este parâmetro é definido de forma experimental de acordo com o contexto.

A identificação do ângulo de mudança de direção deve evitar alguns problemas oriundos do rastreamento de pedestres. Em várias situações, os algoritmos de rastreamento identificam de forma não consistente o indivíduo por uma parte específica do seu corpo como, por exemplo, a cabeça, as mãos ou os pés. Isto pode levar a oscilações em formato de zig-zag. Apesar de o pedestre seguir em movimento em linha reta, seu percurso fica com imperfeições (ruídos de deslocamento) no rastreamento, as quais podem prejudicar o cálculo de indicadores de movimentação. Para mitigar este problema, adotamos uma distância mínima para efetuar os cálculos de mudança de direção e velocidade que são utilizados nos algoritmos dos componentes $1,2 \mathrm{e}$ 3. Este parâmetro é considerado antropométrico, pois se baseia em uma medida relacionada às dimensões do corpo humano.

O pseudo-código do procedimento para o cálculo dos indicadores locais das trajetórias está descrito no algoritmo 1 .

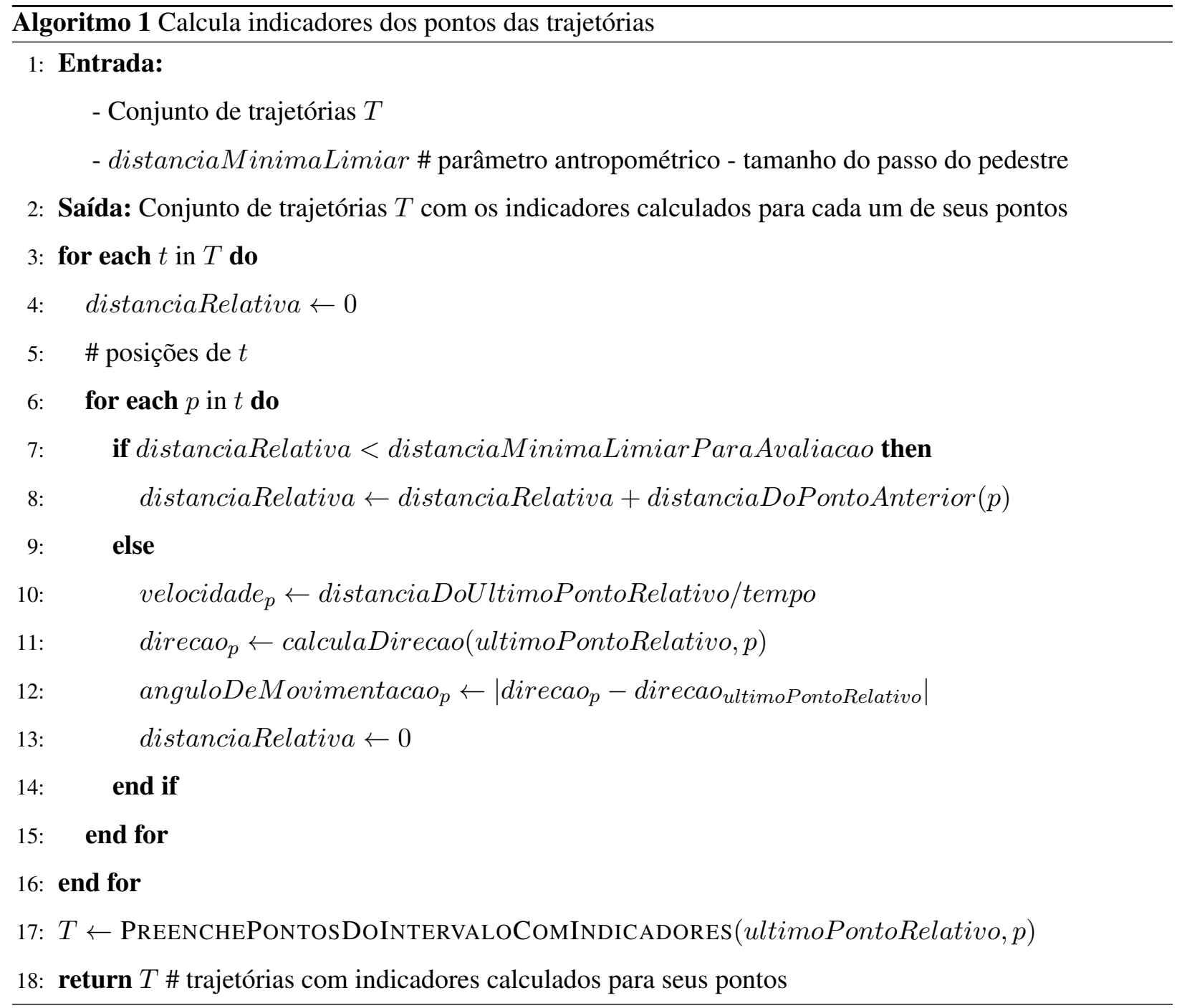

Após a realização destes cálculos, é possível alterar os rótulos atribuídos aos pedestres pelo algoritmo de rastreamento baseado nos valores obtidos para o ângulo de mudança de direção que é a diferença entre 
a direção de movimentação de pontos subsequentes. $\mathrm{O}$ algoritmo 2 utilizado no componente 1 se baseia na premissa de que ocorreu um problema de rastreamento do pedestre devido a oclusão de imagens em pontos com a mudança incomum de direção "mudança brusca". Esta assunção é inspirada no princípio do menor esforço que diz que pedestres optam por percorrer o menor caminho em espaços abertos, ou seja, tendem a seguir em linha reta.

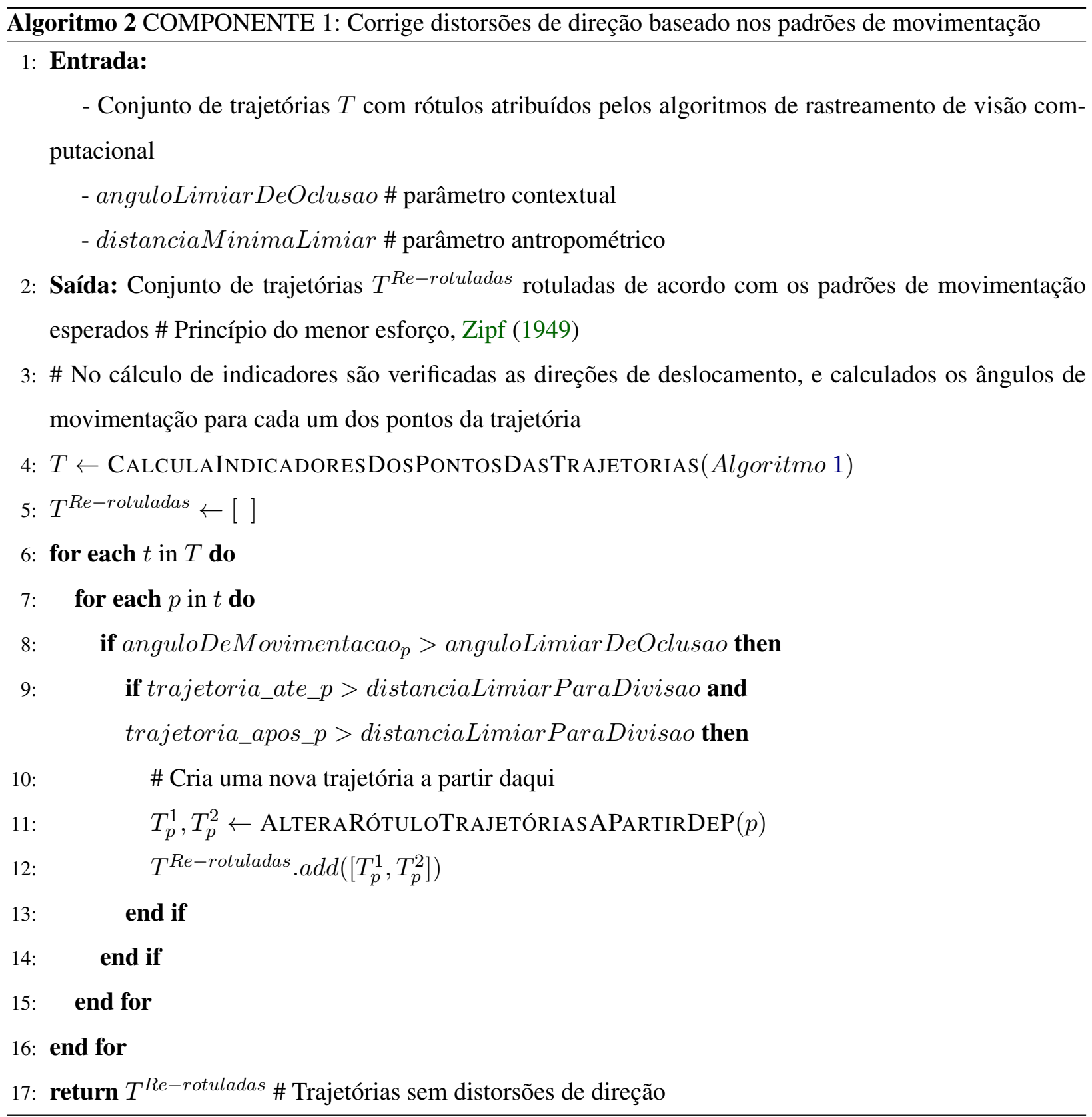

A Figura 3.8 ilustra a trajetória $t_{a}$ com o ponto de mudança abrupta de direção $t_{a}^{3}$, a trajetória original $t_{a}$ é dividida em duas trajetórias - $t_{a^{\prime}}$ e $t_{a^{\prime \prime}}$, até o ponto de mudança onde as etiquetas de identificação são mantidas, e após o ponto de conflito, onde é criado um novo rótulo para identificar a parte restante a trajetória. 




Entrada: $t_{a} \quad$ Saída: $t_{a^{\prime}}$ e $t_{a^{\prime \prime}}$

Figura 3.8: Entrada e saída do algoritmo que desagrega trajetórias adivindas de oclusão

\section{Resultados}

A aplicação do algoritmo deste componente aumenta o número de trajetórias no cenário, mas também reduz o número de percursos inconsistentes, possibilitando a identificação mais precisa do fluxo dos pedestres. Um dos benefícios dessa fase de filtragem é o cálculo mais preciso do fluxo de pessoas que passam pela cena. O resultado permite que a componente 3, Une trajetórias fragmentadas baseada na inferência de movimento, tenha um resultado muito mais eficaz na reparação de trajetórias incompletas.

\subsubsection{Componente 2: Elimina duplicidade de rastreamento baseado em características an- tropométricas para melhorar a contagem de pedestres}

\section{Problema}

A detecção de pedestres através da análise de imagens de vídeo sofre de várias dificuldades, incluindo a granularidade da detecção. Alguns algoritmos buscam identificar pedestres por partes específicas do corpo, como a cabeça. Nesses algoritmos, pode haver falhas, como a detecção de objetos semelhantes como bolsas e sapatos, identificando esses objetos como se fossem outro indivíduo. Esse problema é comum em cenários onde a densidade de pedestres é média ou alta, como no caso de terminais de transporte metroviários, o que prejudica a precisão da análise e o cálculo da densidade de pedestres no cenário.

\section{Descrição}

Essa camada busca reduzir ruídos baseada em um espaço mínimo de conforto que existe entre os pedestres, que é violado nos casos de pedestres que geram três trajetórias de rastreamento paralelo, por terem sido identificados, por exemplo, por pés, bolsa e cabeça. A rota gerada por tal problema de detecção é impossível na prática, devido à distância entre um ponto e outro, com uma distância mínima para as pessoas se moverem em paralelo.

A correção realizada nesta etapa é baseada em paramêtros antropométricos e padrões de caminhada, conforme apresentados no algoritmo 3. As verificações podem ser divididas em 4 passos: 1) tempo para certificar que as trajetórias análogas estão no mesmo intervalo com uma variação máxima do tempo que um pedestre demora para percorrer o espaço ocupado por um pedestre; 2) medidas antropométricas de um pedestre - altura e largura; 3) características do padrão de movimentação - velocidade e direção, e 4) oscilações do algoritmo de rastreamento. Após estas verificações são avaliadas características de caminhada que possam ser consideradas equivalentes, as quais devem resultar de ambigüidade na detecção dos pedestres. Nestes casos, a trajetória de menor tamanho é eliminada. 


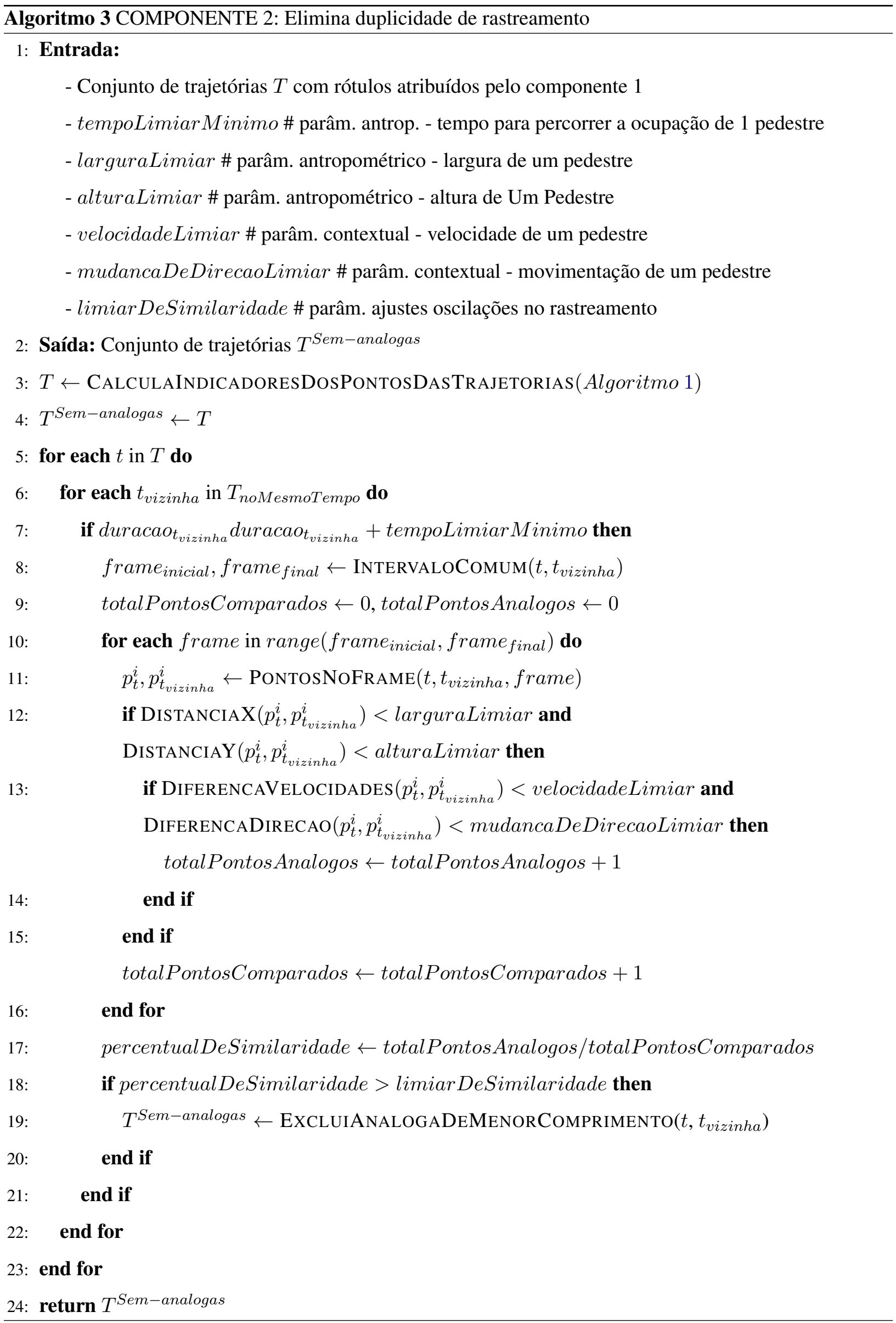




\section{Resultados}

Um dos benefícios da aplicação deste componente é a contagem mais precisa do número de pessoas no ambiente. As trajetórias identificadas como análogas são excluídas.

\subsubsection{Componente 3: Une trajetórias fragmentadas com base na inferência de movimento}

\section{Problema}

Essa camada busca minimizar os ruídos relacionados à segmentação de trajetórias que podem ocorrer tanto pela incapacidade dos algoritmos de rastreamento em detectar a trajetória completa dos pedestres quanto pelas falhas desses algoritmos em atribuir os rótulos corretos aos pedestres das trajetórias.

\section{Descrição}

O algoritmo para junção realiza um procedimento iterativo de busca com o intuito de completar uma trajetória parcial na direção em que ela se dirigia, unindo-a a outros fragmentos de trajetórias. De maneira geral, este procedimento busca trajetórias parciais que iniciam próximo ao final da trajetória original e faz a união de trajetórias, caso os traços comportamentais da trajetória original sejam mantidos. Como traços comportamentais consideramos direção e velocidade da trajetória original. Este procedimento funciona repetidamente até que não seja encontrada trajetória com os mesmos padrões da trajetória original.

A reparação dessas trajetórias é fundamentada em 3 passos. Primeiramente, é definido o espaço de busca que é próximo ao final da trajetória no tempo e espaço. O segundo passo utiliza o Constant Velocity Model (ConVelocity) (Kim et al., 2015) para estimar a posição futura baseada na direção e velocidade de movimentação mais recentes. Este método se mostra simples mas eficaz. Por outro lado, por ser baseado nas duas últimas posições de deslocamento, ele é sensível aos erros de medição. O uso deste método foi adaptado para ser utilizado pelo nosso algoritmo, ao invés de nos basearmos na direção e velocidade das duas últimas posições do histórico, nos baseamos nas duas últimas posições que tenham uma distancia mínima entre elas abaixo de distancia Mínima Limiar (definida posteriormente no capítulo de experimentos), conforme calculado no algoritmo 1. Após verificarmos a existência de uma trajetória vizinha próxima à posição estimada, é realizado o último passo do algoritmo, que é a averiguação se a junção das trajetórias mantém a mesma direção de deslocamento da trajetória origem não gerando movimentos anômalos. O procedimento deste componente está detalhado no algoritmo 4, que é composto pelos algoritmos 5 e 6 . Este procedimento foi segregado em mais de um algoritmo, exclusivamente, com o intuito de melhorar a legibilidade.

\section{Resultados}

A junção dos fragmentos de trajetórias possibilita que se possa realizar uma análise mais robusta do percurso realizado pelo pedestre o que melhora o entendimento da dinâmica da estação/ambiente bem como a determinação do fluxo percorrido. Após a aplicação deste componente ocorre uma redução do número total de trajetórias, pois trajetórias de um mesmo pedestre que anteriormente possuiam 2 ou mais rótulos distintos, são agora atribuídas um único rótulo. 


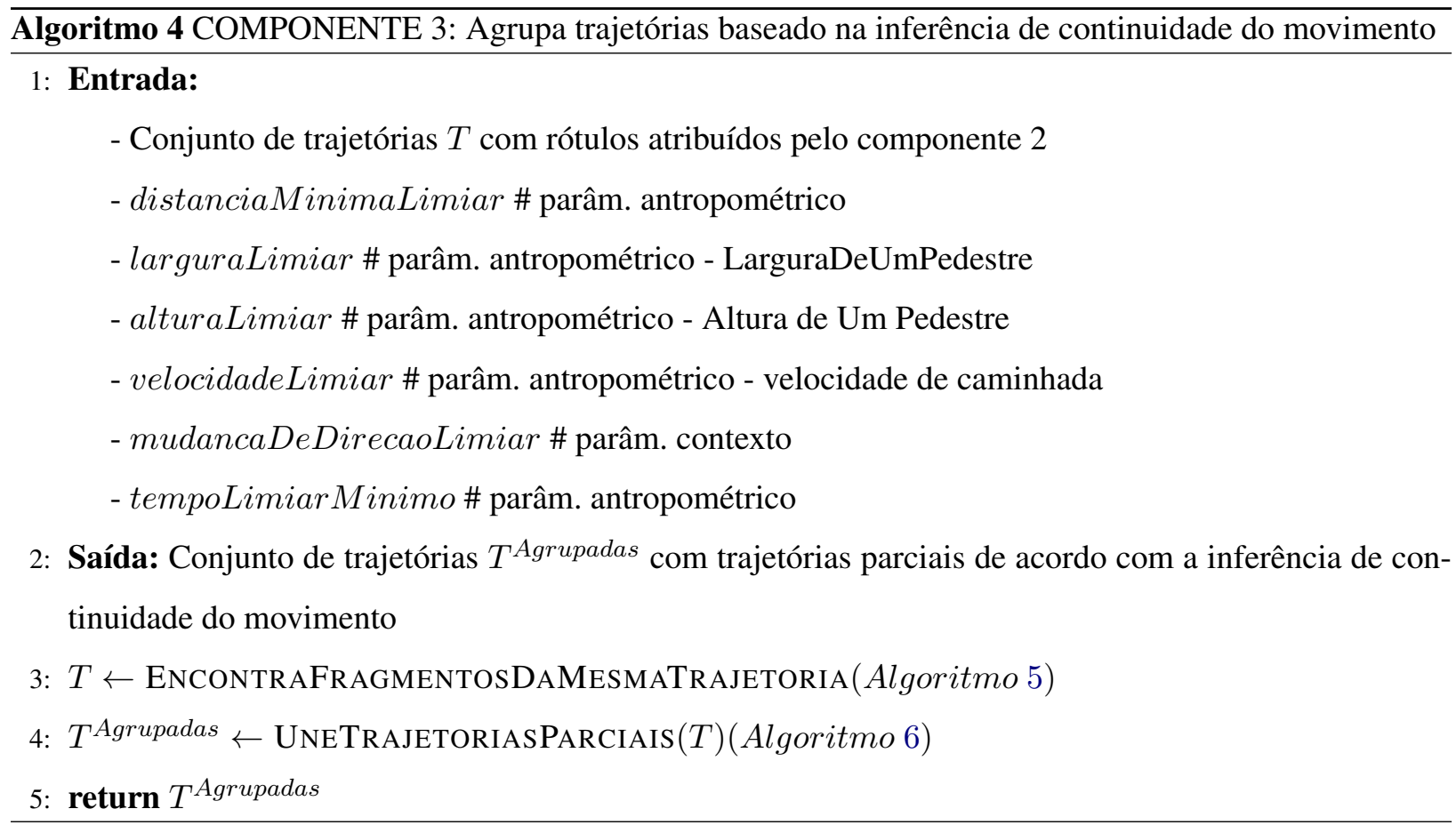




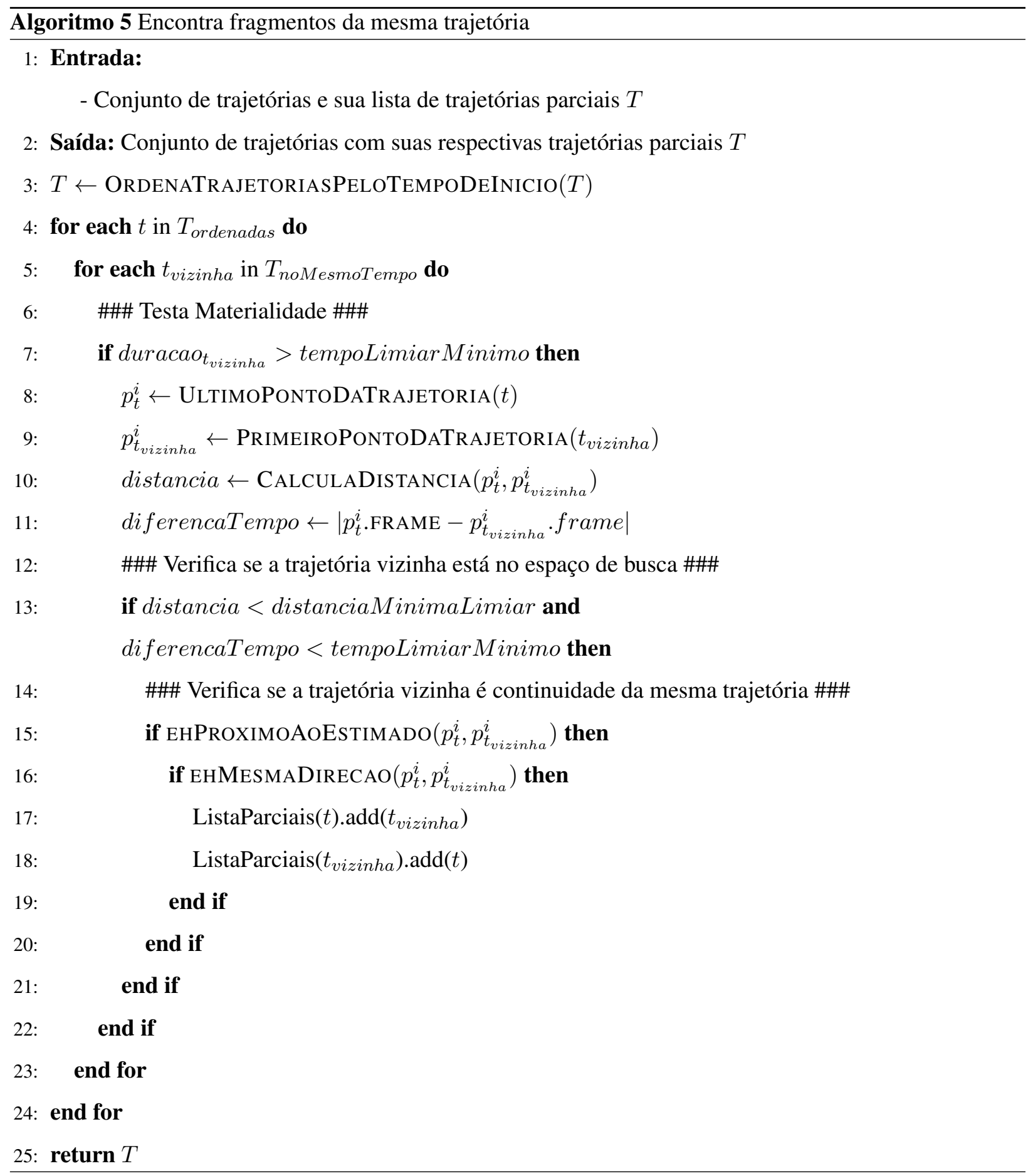




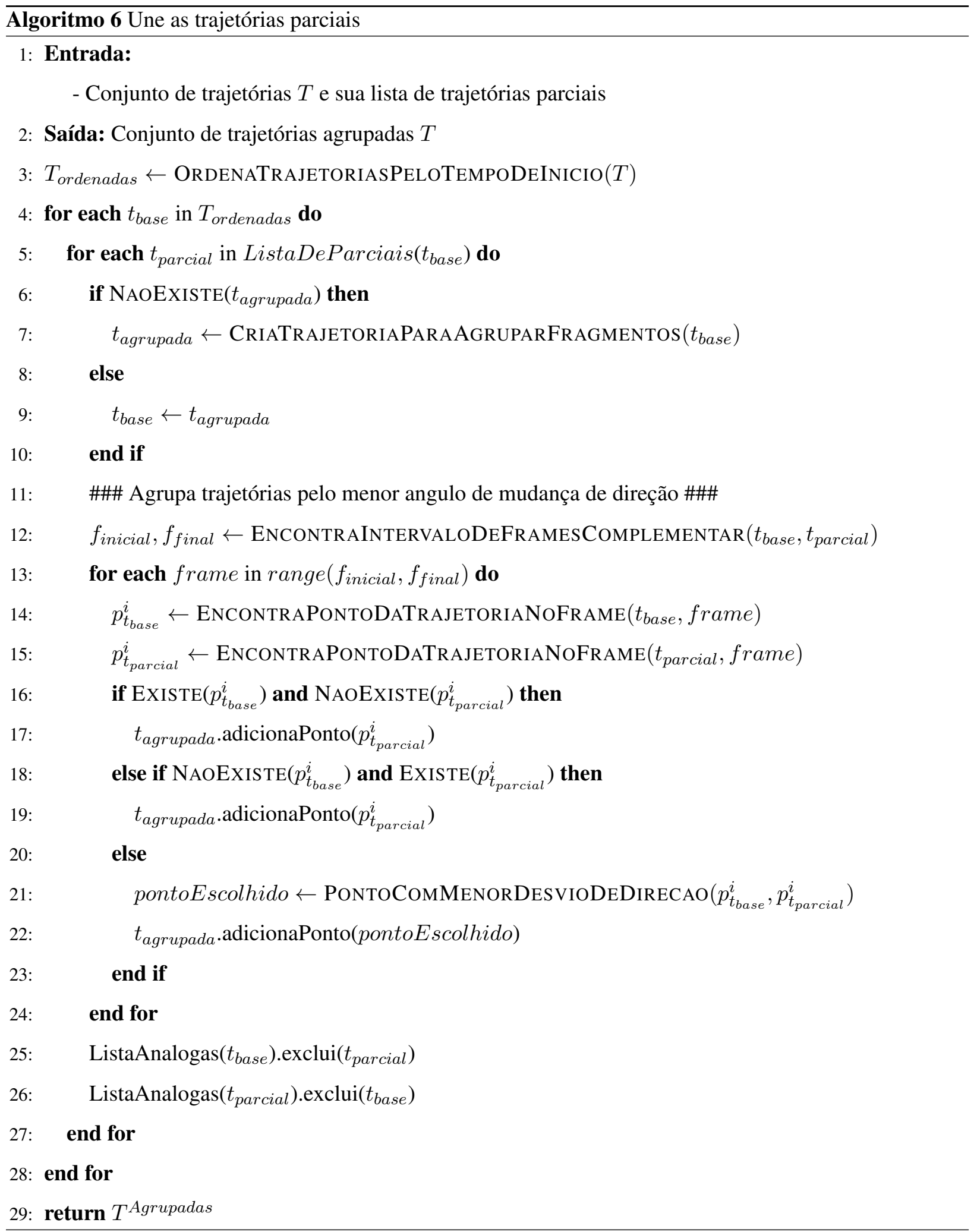




\subsubsection{Sequência de Aplicação dos Componentes}

A arquitetura da ferramenta propõe que a aplicação dos componentes propostos sigam a ordem proposta, para obtermos o resultado mais abrangente da solução. O exemplo da Figura 3.9 ilustra a importância da realização das correções na ordem proposta.



(a) Exemplo de Trajetórias Originais Oriundas do Algoritmo de Visão Computacional

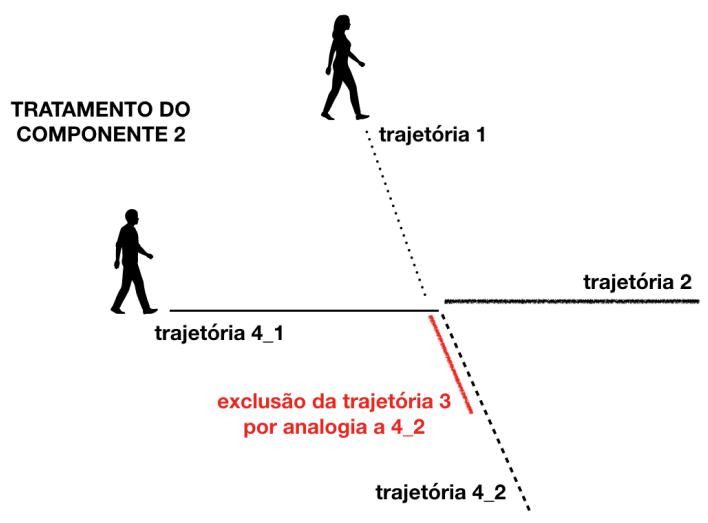

(c) Correção realizada pelo componente 2

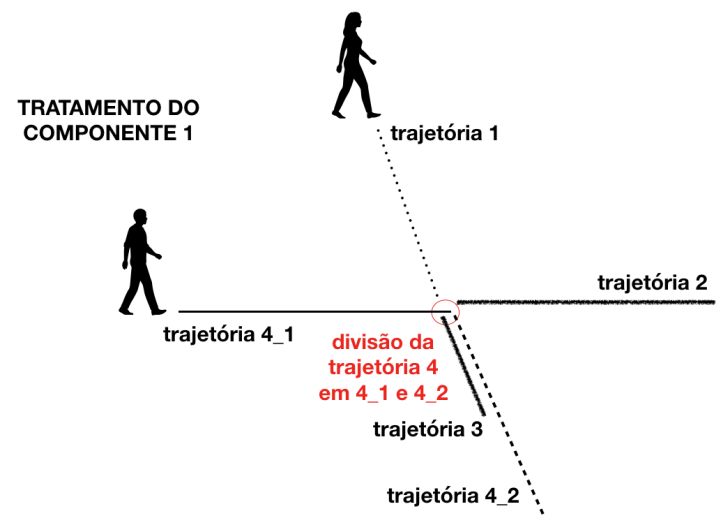

(b) Correção realizada pelo componente 1

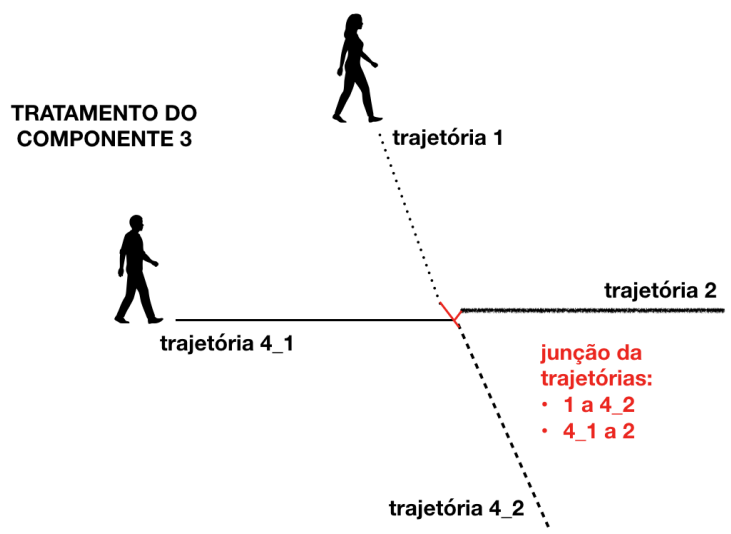

(d) Correção realizada pelo componente 3

Figura 3.9: Solução proposta pela ferramenta

Conforme pode ser observado no exemplo da Figura 3.9, caso o componente 1 fosse aplicado após o componente 2 ou 3, não seria possível identificar que a trajetória 3 e a trajetória $4 \_2$ são análogas, ou a continuidade da trajetória 1 como a trajetória 4_2. Tendo como premissa a utilização do componente 1, se o componente 3 fosse aplicado antes do componente 2, a trajetória 1 poderia ter se conectado à trajetória análoga 3, em vez da trajetória 4, que é mais completa e representa de forma mais completa o percurso da pedestre.

\subsection{Síntese dos Dados}

Nesta seção apresentamos uma das funcionalidades da ferramenta proposta que é a síntese das informações da movimentação de pedestres que foram processadas pela etapa de análise baseada em contexto. $\mathrm{O}$ objetivo desta funcionalidade é prover informações tanto da dinâmica de pedestres no cenário real quanto para realização do ajuste dos paramêtros de entrada de cada um dos componentes. 
A etapa de síntese é composta por vários relatórios distintos que objetivam prover informações sobre diferentes aspectos da dinãmica do ambiente e do impacto da parametrização na correção de trajetórias falhas. Os relatórios apresentados a seguir foram produzidos a partir das informações da coleção de dados do Grand Central Terminal de Nova York (Zhong et al., 2015), que será apresentada, posteriormente, na seção 4.1.

\section{Relatório 1: Visualização das trajetórias antes a depois da aplicação de cada componente}

O primeiro relatório provê uma forma de visualização das trajetórias originais vs. trajetórias modificadas pela aplicação dos componentes de tratamento dos dados. Neste caso, para trajetórias escolhidas manualmente, ou para uma quantidade amostral pré-determinada, são fornecidas imagens do impacto da aplicação de cada um dos componentes em separado.

A Figura 3.10 (a) representa a trajetória, identificada pelo rótulo 30026, advinda do algoritmo de processamento de imagens . Esta trajetória mostra um movimento inverídico provocado pelo falha do algoritmo de processamento de imagens em atribuir o rótulo do pedestre a sua imagem correspondente. Este movimento é, de fato, composto pela trajetória de 3 pedestres distintos, que tiveram a sobreposição de suas imagens no vídeo quando se cruzaram. Em (b) observa-se o resultado da aplicação do componente 1, que corrige o problema fazendo a dissociação da trajetória original em 3 trajetórias distintas, como efetivamente ocorreu.

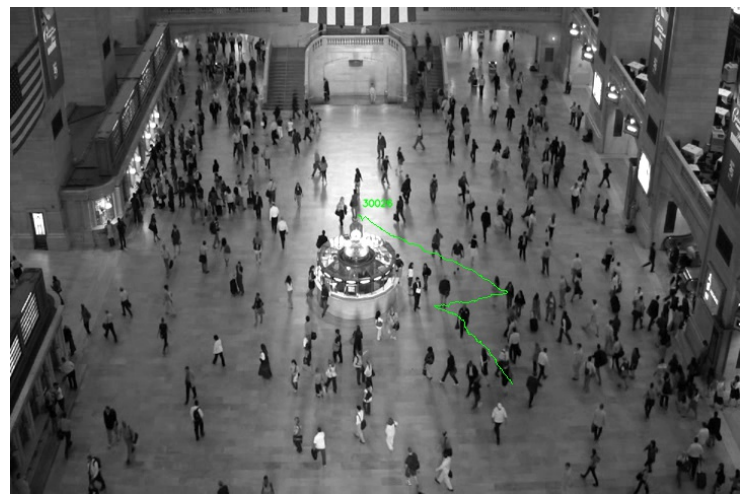

(a) Trajetória original: 30026

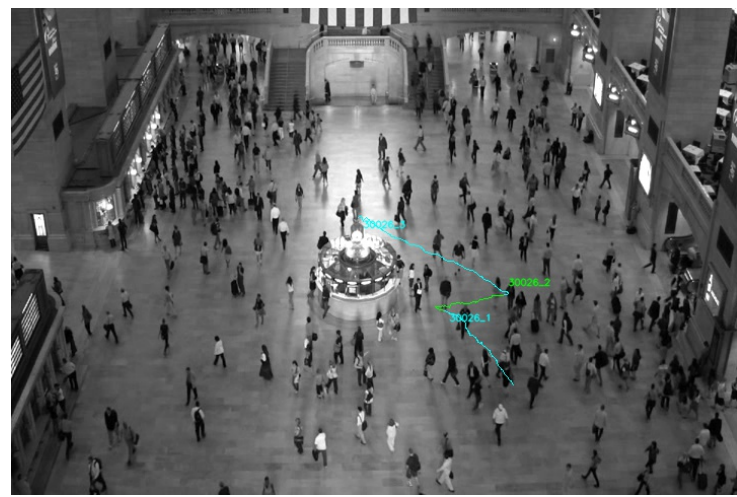

(b) Trajetórias resultantes: 30026_1, 30026_2 e 30026_3

Figura 3.10: Relatório de visualização das trajetórias obtidas pela aplicação do Componente 1 da ferramenta divididas em 3 novas trajetórias

\section{Relatório 2: Registro das modificações de rótulos de trajetórias realizadas pela ferramenta}

O segundo relatório fornece arquivos texto com o registro das modificações realizadas pelos algoritmos com a informação dos rótulos das trajetórias originais vs. rótulos atríbuídos pela ferramenta. O nome dos arquivos e as informações fornecidas para cada um dos componentes estão detalhados abaixo:

- Divididas_C1: Registro do de...para dos rótulos atribuídos pelo componente 1 vs. rótulos originais

- Mantidas_C1: Registro dos rótulos das trajetórias originais sem modificações realizadas pelo componente 1

- Excluidas_C2: Registro das trajetórias análogas excluídas pelo componente 2 
- Mantidas_C2: Registro dos rótulos das trajetórias originais sem modificações realizadas pelo componente 2

- Agrupadas_C3: Registro das trajetórias originais que foram agrupadas pelo componente 3 em uma nova trajetória

- Mantidas_C3: Registro dos rótulos das trajetórias originais sem modificações realizadas pelo componente 3

\section{Relatório 3: Análise quantitativa de trajetórias modificadas pelos componentes da ferra- menta}

Este relatório provê dados quantitativos do volume de trajetórias obtido após a aplicação de cada um dos componenetes. Nele são apresentadas informações como: quantidade de trajetórias oriundas do algoritmo de visão computacional, quantidade de trajetórias corrigidas e a variação da quantidade de trajetórias após a aplicação de cada um dos componentes da ferramenta. As Tabelas 4.2 e 4.3 apresentam as informações que são disponibilizadas através deste relatório.

\section{Relatório 4: Visualização das trajetórias em vídeo}

Este relatório permite a verificação visual das trajetórias processadas pela ferramenta no video do cenário real e os efeitos da aplicação dos componentes. Desta forma, o relatório possibilita que a verificação posterior dos efeitos da ferramenta por um especialista, de forma a evidenciar a aderência dos resultados apresentados pela ferramenta em relação aos resultados produzidos pelos algoritmos de rastreamento de visão computacional.

A visualização dos resultados sobre o vídeo do cenário real permite a validação dos resultados no contexto em que se encontram (tempo e espaço) e a verificação dos efeitos da aplicação dos componentes. A Figura 3.11 é uma amostra de um frame produzido por este relatório para um conjunto de trajetórias. Note que em (a) são apresentadas 2 trajetórias análogas que correspondem a um único pedestre. Em (b) é possível visualizar a trajetória resultante da aplicação do componente 2, que identificou a analogia das trajetórias apresentadas em (a) e excluiu a trajetória análoga menos representativa.

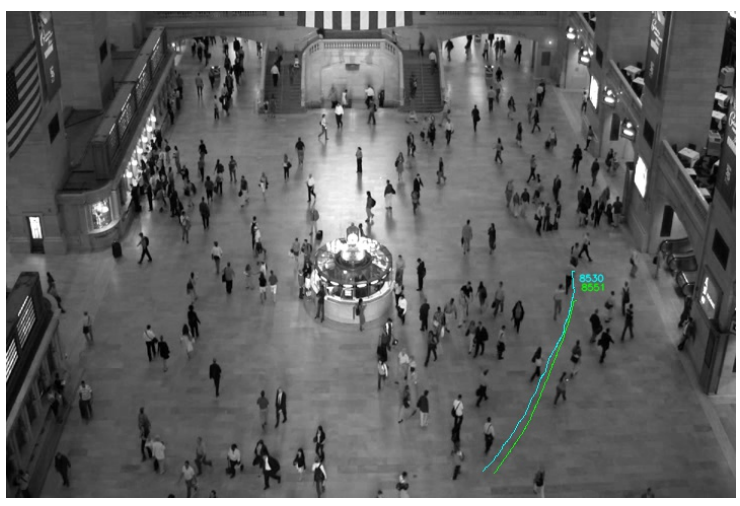

(a) Antes da aplicação da ferramenta



(b) Depois a aplicação da ferramenta

Figura 3.11: Frame produzido para um conjunto de trajetórias antes e depois a aplicação dos componentes 


\section{Relatório 5: Indicadores quantitativos das trajetórias}

Este relatório provê dados quantitativos da trajetória sobre características da movimentação de pedestres no cenário. Os indicadores fornecidos neste relatório possibilitam a contagem de pedestres no tempo, o cálculo de suas velocidades e características de movimentação, como o ponto de maior desvio de direção.

Uma amostra do arquivo de indicadores de trajetórias, produzido pela ferramenta, é apresentada na Tabela 3.2. Nesta tabela, cada linha representa uma trajetória específica, são apresentadas as principais informações referentes as trajetórias do cenário como: a velocidade, duração, distância percorrida, frame de início e o deslocamento de direção médio da trajetória.

Tabela 3.2: Amostra do arquivo com os indicadores de trajetórias produzidos pela ferramenta

\begin{tabular}{|c|c|c|c|c|c|}
\hline Rótulo & $\begin{array}{c}\text { Velocidade } \\
\text { em m/s }\end{array}$ & $\begin{array}{c}\text { Duração } \\
\text { em segundos }\end{array}$ & $\begin{array}{c}\text { Distância } \\
\text { em metros }\end{array}$ & $\begin{array}{c}\text { Tempo de início } \\
\text { em segundos }\end{array}$ & $\begin{array}{c}\text { Angulo de } \\
\text { deslocamento médio }\end{array}$ \\
\hline 0 & 1,64 & 1,21 & 1,98 & 1 & 13,0 \\
1 & 1,34 & 0,96 & 1,28 & 1 & 41,7 \\
2 & 1,38 & 1,21 & 1,66 & 1 & 16,2 \\
3 & 1,04 & 2,04 & 2,12 & 1 & 16,1 \\
4 & 1,32 & 3,54 & 4,69 & 1 & 14,6 \\
5 & 1,28 & 12,08 & 15,42 & 1 & 13,7 \\
6 & 1,15 & 7,62 & 8,75 & 1 & 14,7 \\
\hline
\end{tabular}

As informações produzidas pela ferramenta são essenciais para munir engenheiros de transporte e segurança pública sobre aspectos do contexto real e possibilitam a visualização de informações como as demostradas nas Figuras 3.12 e 3.13.


Figura 3.12: Contagem de pedestres e velocidade x tempo de vídeo

A Figura 3.12 apresenta que os períodos de maior ocupação ocorrem no início do vídeo entre o frame 0 e 500 e próximo ao frame 1500 . Nesta mesma figura, pode-se perceber que a velocidade média é por volta de 1.34 e tem uma maior variação, no período onde a ocupação é menor, entre o frame 500 e 1500 . A Figura 3.13 apresenta o cálculo da densidade do cenário considerando o tempo total do vídeo. Note que a maior concentração de pedestres ocorre na porta direita mais inferior ao vídeo, que é o local onde se concentram as escadas rolantes.

Neste capítulo apresentamos uma ferramenta que possibilita uma análise mais robusta de cenários reais através do uso de informações de contexto. No próximo capítulo será demonstrado como a ferramenta pode ser utilizada para melhorar a qualidade dos dados obtidos de algoritmos de rastreamento. 


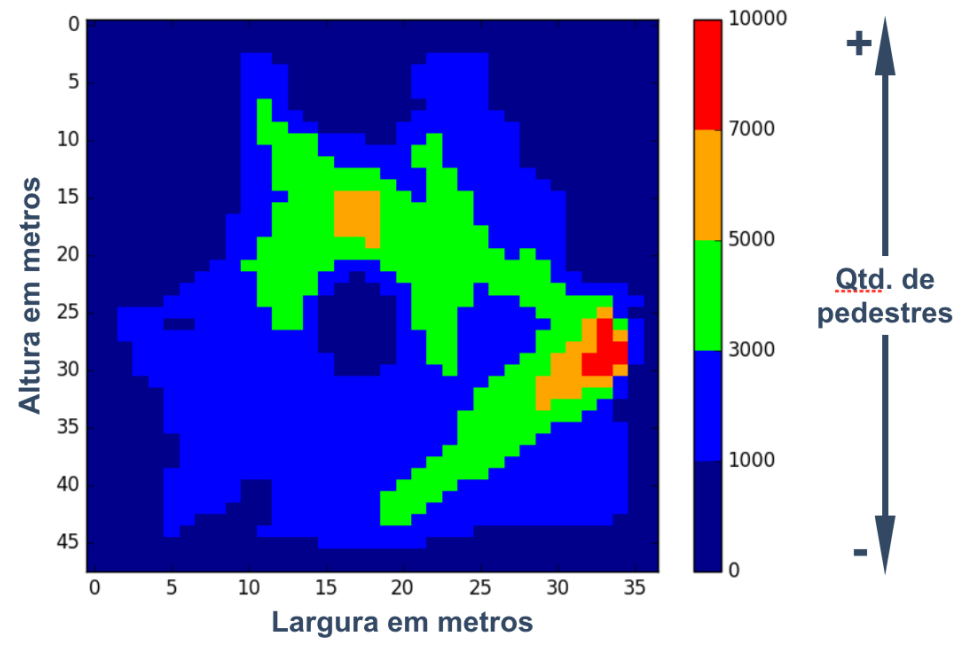

Figura 3.13: Mapa de densidade para verificação das regiões de gargalo 


\section{Capítulo 4}

\section{Resultados e Discussões}

No Capítulo 3 foi apresentada uma nova ferramenta para tratar dados imprecisos oriundos do processamento de imagens de vídeos de estações de transporte em situações onde não é possível identificar as trajetórias completas dos pedestres. Desta forma, avançamos na qualidade das informações obtidas com o ganho de informação propiciado pelo conhecimento do contexto, o que possibilita uma análise mais robusta do cenário.

Neste capítulo, mostraremos a aplicação da ferramenta proposta em uma coleção de dados reais obtido de um terminal de transporte de passageiros. A implementação da ferramenta proposta neste trabalho foi desenvolvida em Python e utiliza a biblioteca Opencv para visualização das trajetórias originais e obtidas pela ferramenta a partir do vídeo real.

Os experimentos realizados demonstram como a ferramenta proposta pode ser aplicada e ajustada para ampliar a análise de cenários reais. Para isto, aplicamos a ferramenta à coleção de dados abertos e disponíveis a respeito do Grand Central Terminal de Nova York - GCTNY (Zhou et al., 2012).

A avaliação de desempenho da ferramenta foi feita em 3 fases: 1) Primeiramente, demonstramos de forma qualitativa como o uso da ferramenta modifica os resultados dos algoritmos de rastreamento. 2) Em seguida, demonstramos a estabilidade da ferramenta com testes de convergência para demonstrar os resultados obtidos pela ferramenta quando aplicada de forma recursiva. 3) Por fim, é feita uma análise quantitativa para mensurar a melhora dos resultados obtidos pela ferramenta tomando algumas situações de referência.

Este capítulo está organizado da seguinte forma: na seção 4.1 apresentamos uma visão geral da coleção de dados que vamos usar para aplicação da ferramenta. Na seção 4.2 explicamos o processo de inicialização dos parâmetros utilizados pelos componentes da ferramenta. Na seção 4.3 demonstramos como a ferramenta modifica a interpretação dos dados dos algoritmos de rastreamento, após ser ajustada de forma conveniente ao comportamento dos pedestres no contexto analisado. Na seção 4.4 aplicamos a ferramenta de forma recursiva para demonstrar a sua estabilidade. Na seção 4.5 medimos quantitativamente o ganho da ferramenta para algumas situações exemplo. Por último, na seção 4.6 discutimos o potencial da ferramenta para avaliação de cenários reais e algumas limitações.

\subsection{Coleção de Dados}

Existem muitas coleções de dados públicos que podem ser usadas para testar a solução proposta. Dentre as mais conhecidas estão o conjunto de dados de tráfego do Massachusetts Institute of Technology - MIT, que contém uma coleção de vídeos de cruzamentos de avenidas Wang et al. (2009); e o vídeo do GCTNY, que é 
um vídeo de uma estação de trem Zhou et al. (2012). Zitouni et al. (2016) apresenta um resumo sistemático de várias coleções de dados que estão disponíveis para a realização de estudos e análises de multidões de pedestres.

A principal motivação para a escolha da coleção de dados, publicada no trabalho de Zhou et al. (2012), decorre do fato deste conjunto de dados ser caracterizado por uma densidade média, que apresenta vários desafios para o processo de análise, como veremos nos experimentos realizados. Além disto, esta coleção é de uma representatividade considerável para um terminal de transporte, pois foi obtida de um vídeo de vigilância de uma das principais estações existentes em um grande centro urbano, que é o GCTNY.

Uma outra vantagem desta coleção é que ela tem uma duração suficiente para permitir perceber variações no fluxo de pedestres. O vídeo tem duração de 33 minutos, com cerca de 40.000 trajetórias extraídas. O algoritmo de visão computacional utilizado para a extração das trajetórias do vídeo foi o KLT keypoint tracker (Tomasi e Kanade, 1991). Esta coleção de dados fornece todas as informações de entrada necessárias para demonstrarmos o potencial de nossa solução.

O terminal tem oito regiões de entrada/saída, que proporcionam ao cenário analisado a existência de 56 diferentes combinações de fluxos, ou pares origem-destino, de passageiros desprezando-se as combinações de entrada e saída pela mesma porta. A análise de padrões de movimento e as principais áreas de entrada/ saída não foi considerada neste trabalho. Este tipo de análise pode ser encontrada na literatura como, por exemplo, em Jodoin et al. (2013) que apresenta um método para extrair padrões de movimento dominantes de vídeos de vigilância. A Figura 4.1 ilustra o centro de cada uma das portas.

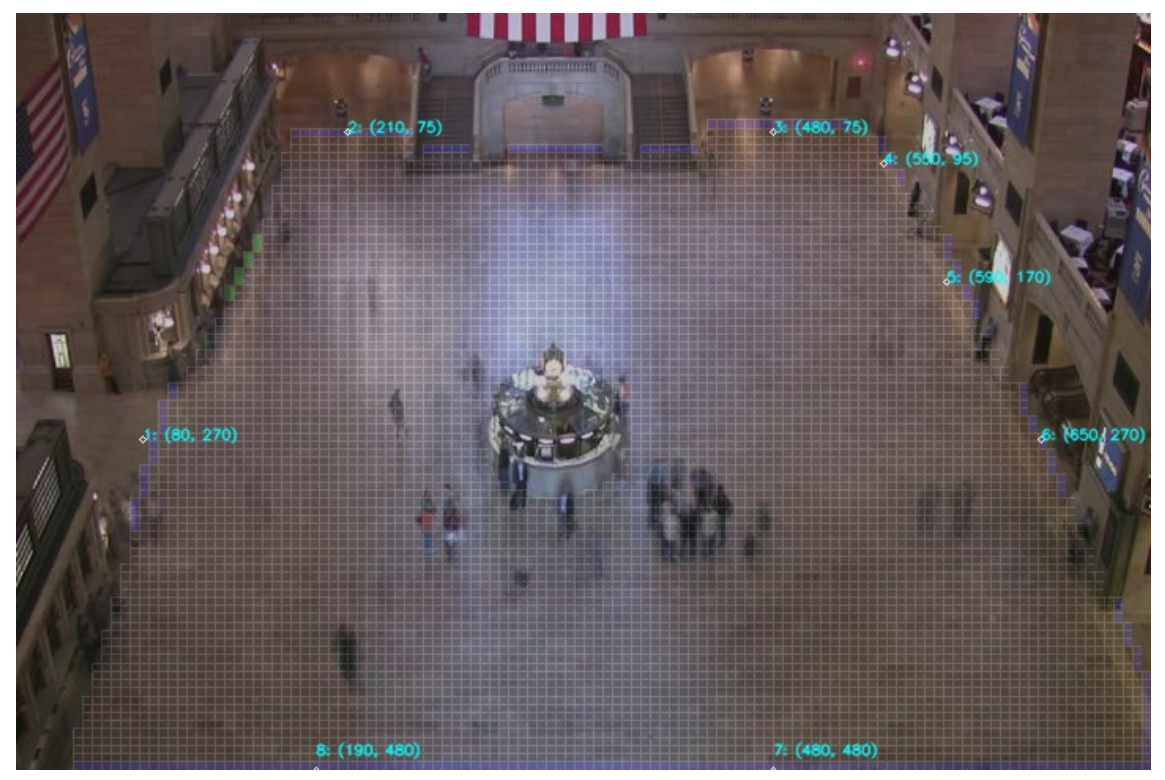

Figura 4.1: Portas de entrada e saída de pedestres do Grand Central Terminal de Nova York

Todas as trajetórias extraídas dos 33 minutos de vídeo por Zhou et al. (2012) são apresentadas em (a) na Figura 4.2. Em (b) apresentamos 10 trajetórias selecionadas aleatóriamente. Em (c) e (d) mostramos as 10 trajetórias mais longas e com maior angulo de desvio, respectivamente.

A Figura 4.2 possibilita a identificação visual de alguns dos problemas existentes no processo de extração das trajetórias de pedestres das imagens de vídeo em cenários com uma significativa densidade de pedestres. Em (b) fica evidente que existe um predomínio de trajetórias fragmentadas no processo de extração de trajetórias. Em (c) observa-se a escassez na obtenção de trajetórias completas de pedestres com 
origem e destino a partir das regiões das portas. Em (d) percebe-se como a oclusão de pedestres influencia a obtenção de trajetórias. Quando ocorrem situações em que alguns pedestres se cruzam muito próximos aos outros, o algoritmo de rastreamento muitas vezes falha na definição do trajeto real, gerando trajetórias totalmente dissociadas das trajetóras reais por ter determinado como uma trajetória única a associação de trajetórias de diferentes pedestres.

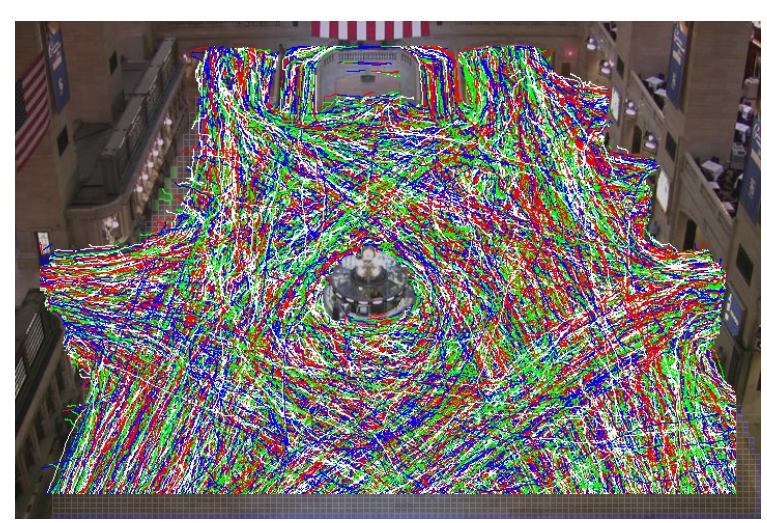

(a) Trajetórias oriundas do algoritmo de visão computacional

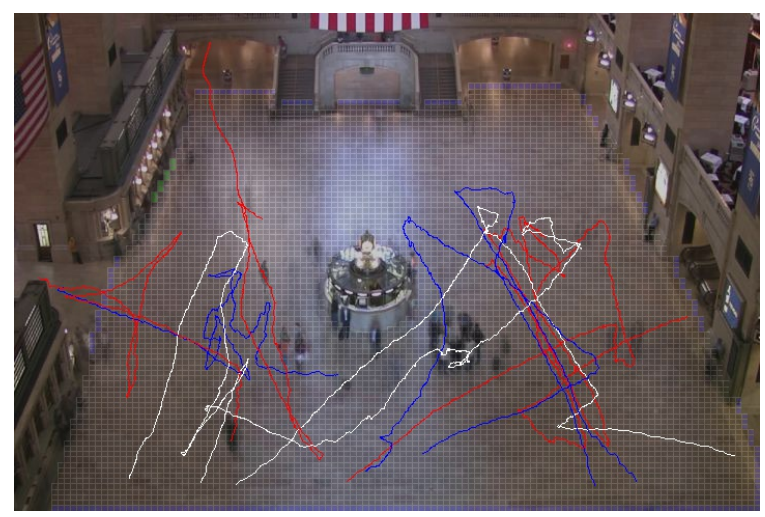

(c) Top 10 das trajetórias mais longas

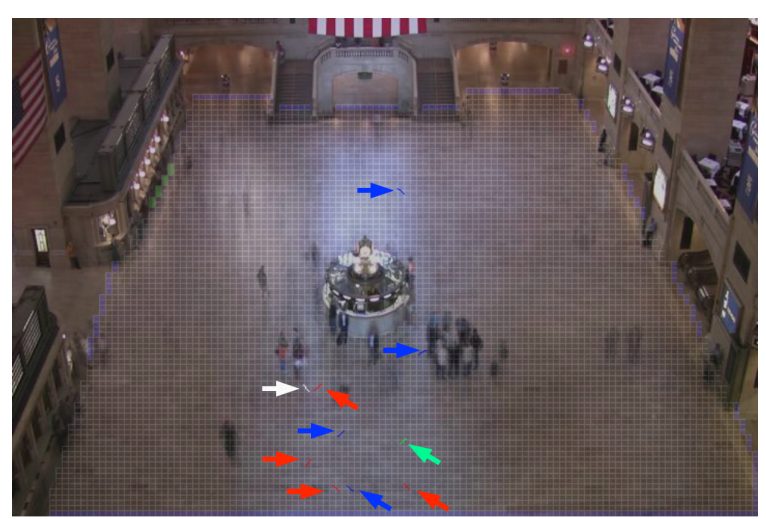

(b) Top 10 das trajetórias mais curtas

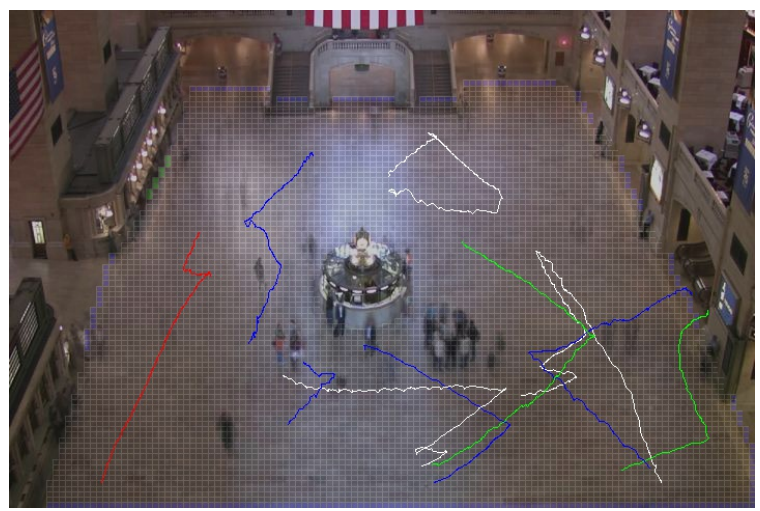

(d) Top 10 das trajetórias com maiores ângulos de desvio

Figura 4.2: Dados obtidos do cenário real

\subsection{Inicialização dos Parâmetros}

Esta seção apresenta o processo de inicialização dos parâmetros utilizados nos componentes. A Tabela 4.1 indica como foi efetuada a escolha dos parâmetros. Para a escolha dos parâmetros foram adotados dois métodos distintos:

- Referência: os parâmetros atribuídos por referência são basicamente parâmetros antropométricos que estão relacionados não apenas ao ambiente específico que está sendo analisado, mas sim ao público que circula no ambiente.

- Experimental: os parâmetros que usam este método de atribuição estão diretamente relacionados a dinâmica do cenário que está sendo analisado e ao comportamento característico dos pedestres neste ambiente, por isto, o ajuste destes parâmetros realiza-se em três etapas ou fases: a) análise preliminar 
dos indicadores das trajetórias dos cenário baseada nas informações da Tabela 3.2, b) experimentos com a atribuição de diferentes valores baseados na análise preliminar dos parâmetros, e c) mensuração da efetividade dos valores atribuídos para uma amostra da coleção de dados, conforme indicador proposto na seção 4.5.1.

Tabela 4.1: Valoração dos parâmetros para a coleção Grand Central Terminal de Nova York

\begin{tabular}{|c|c|l|c|}
\hline Parâmetro & Método de Atribuição & \multicolumn{1}{|c|}{ Justificativa } & Valor \\
\hline anguloLimiarDeOclusao & Experimental & $\begin{array}{l}\text { Lei do menor esforço (evita desloca- } \\
\text { mentos desnecessários e caminham em } \\
\text { linha reta }\end{array}$ & $65^{\circ}$ \\
\hline distanciaMinimaLimiar & Referência & $\begin{array}{l}\text { Tamanho do passo do pedestre que é o } \\
\text { ponto de maior deslocamento do corpo }\end{array}$ & 0.72 metros \\
\hline tempoLimiarMinimo & Referência & $\begin{array}{l}\text { Tempo para percorrer o espaço ocu- } \\
\text { pado de um pedestre }\end{array}$ & 1.04 segundos \\
\hline distanciaXLimiar & Referência & $\begin{array}{l}\text { Largura do pedestre com com bolsa } \\
\text { pequena }\end{array}$ & 0.73 metros \\
\hline distanciaYLimiar & Referência & Altura média cidadão americano & 1.68 metros \\
\hline velocidadeLimiar & Referência & Desvio padrão da velocidade & 0.37 metros/segundo \\
\hline mudancaDeDirecaoLimiar & Experimental & Pedestres tendem a andar em linha reta & $30^{\circ}$ \\
\hline limiarDeSimilaridade & Experimental & $\begin{array}{l}\text { Ocorrem oscilações no ponto rastreado } \\
\text { que alteram a rota mesmo para pedes- } \\
\text { tres caminhando em linha reta }\end{array}$ & $85 \%$ \\
\hline
\end{tabular}

Os parâmetros com a atribuição efetuada por referência se basearam na localização da coleção de dados, que é um importante terminal ferroviário e metroviário localizado na região central da cidade de Nova York. Abaixo mencionamos as fontes utilizadas na atribuição para cada um destes parâmetros:

- distanciaMinimaLimiar: para o cenário analisado verificamos que ao longo do deslocamento dos pedestres no terminal a situação que teve a maior oscilação de posicionamento foi para pedestres que estavam sendo rastreados pela posição dos pés. Por isto, foi adotada como valor de referência o comprimento do passo. O comprimento do passo é a distância entre o ponto de contato inicial de um pé e o ponto de contato inicial do pé oposto. Na marcha normal, os comprimentos dos passos direito e esquerdo são semelhantes. Adotou-se o valor de 0.72 metros para o comprimento médio do passo, que é a média dos valores médios da passada do homem - 0.79 metros e da mulher - 0.66 metros, segundo Murray et al. (1970). Também foram identificadas outras situações de oscilações pelo rastreamento pela posição das mãos com o uso do celular ao caminhar e também pelo uso de malas de rodinha, o que sugere que caso a análise fosse realizada em cenários como aeroportos, este parâmetro possa ser considerado como valor de referência com a atribuição da largura total ocupada pelo pedestre com uma mala grande.

- tempoLimiarMinimo: atribuímos o tempo de 1.04 segundos, que é o tempo gasto para percorrer a distância mínima ocupada pelo pedestre caminhando na velocidade média (1.47/1.42). A distância mínima ocupada por um pedestre é de 1.47 metros que é a soma do espaço ocupado por um pedestre caminhando, que é o tamanho médio do passo - 0.72 metros - com a distância média de conforto que as pessoas usualmente mantém dos demais pedestres para evitar colisões - 0.75 metros, segundo Corbetta et al. (2018). O valor médio da velocidade foi obtido da análise da própria coleção de dados de GCTNY através do relatório 3.4, conforme apresentado na Figura 4.3, foi de 1.42 metros por segundo. 
- distaciaXLimiar: este parâmetro se refere a largura dos pedestres identificados. Como o cenário é uma estação em um grande centro metropolitano, observamos que a maioria dos pedestres transportava uma bolsa pequena em uma das mãos. Logo, utilizamos o valor de 0.73 metros que é a referência para pedestres com uma bolsa pequena em uma das mãos, como mostrado na Figura 2.1.

- distanciaYLimiar: este parâmetro se refere a altura dos pedestres identificados, como a estação é localizada nos Estados Unidos. O valor utilizado foi de 1.68 metros que é a média entre a estatura do homem - 1.75 metros e da mulher americana - 1.61 metros, segundo Fryar et al. (2016).

- velocidadeLimiar: consideramos o desvio padrão da velocidade de 0.37 metros por segundo como possíveis oscilações e variações nos valores de velocidade das trajetórias. Este dado, assim como a velocidade, foi obtido da própria coleção de dados através do relatório 3.4, conforme Figura 4.3.

A Figura 4.3 apresenta o valor médio da velocidade dos pedestres em relação ao tempo de vídeo obtido do cenário analisado. O valor médio obtido de $1.42 \mathrm{~m} / \mathrm{s}$ é próximo ao valor médio de $1.45 \mathrm{~m} / \mathrm{s}$ atribuído por Weidmann (1993) para pedestres com o propósito de trabalho.

\section{Velocidade em $\mathrm{m} / \mathrm{s}$ média: 1.42 e desvio: 0.37}

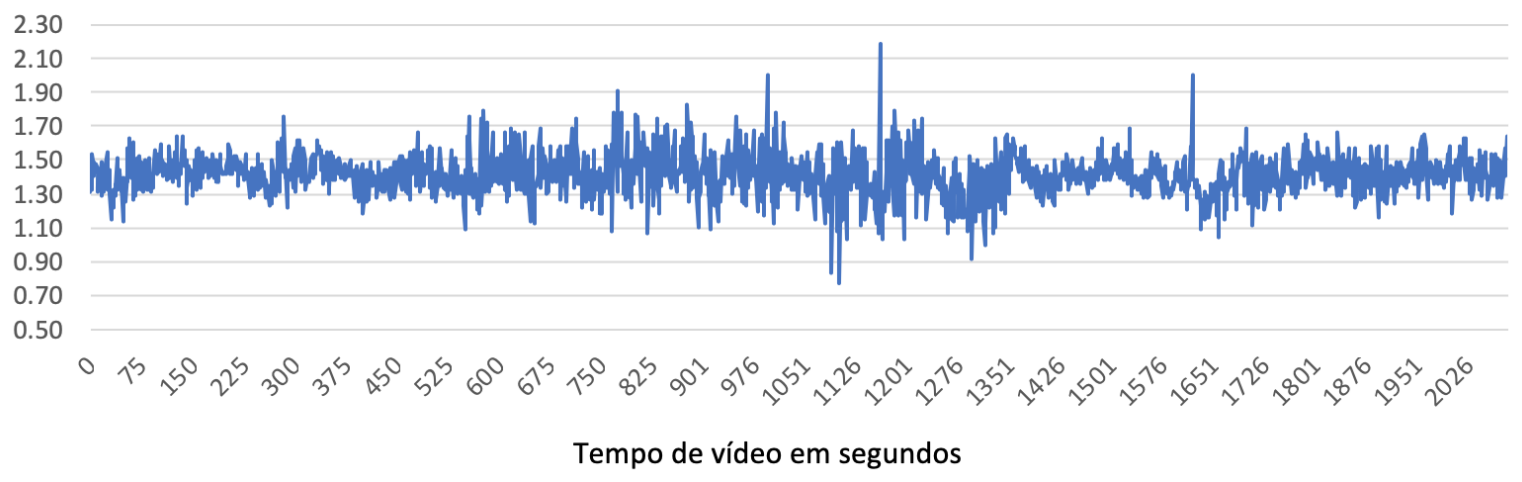

Figura 4.3: Velocidade média $\mathrm{m} / \mathrm{s}$ por tempo de vídeo em segundos

O procedimento de atribuição experimental dos parâmetros foi realizado conforme elucidado na seção 4.5.1. Os valores obtidos do processo de experimentação realizado são apresentados na Tabela 4.1.

\subsection{Testes Qualitativos}

Para demonstrar a efetividade do nosso método de inferência de trajetórias individuais, escolhemos algumas situações amostrais e confrontamos os resultados da aplicação do método com o vídeo real, apresentando os movimentos individuais obtidos após a aplicação do método com os movimentos brutos obtidos do algoritmo de rastreamento.

Esta seção demonstra qualitativamente, com a apresentação visual das trajetórias, o resultado da ferramenta que usa informações do contexto para melhorar a qualidade dos dados obtidos do cenário real, com modificações e exclusões de algumas trajetórias. Para isto, foram escolhidas algumas situações amostrais e confrontados os resultados da aplicação de cada um dos componentes com as trajetórias obtidas pelo algoritmo de visão computacional. 
De maneira geral, estas situações estão ilustradas, nas subseções 4.3.1, 4.3.2 e 4.3.3, por duas figuras posicionadas lateralmente da seguinte maneira: a primeira figura apresenta as trajetórias originais e rótulos identificadores fornecidos pela coleção de dados (Zhou et al., 2012), a segunda figura apresenta as trajetórias e seus respectivos rótulos identificadores atribuídos pela aplicação do componente da ferramenta proposta. Para cada uma das componentes foi criada uma subseção específica com o intuito de conseguirmos apresentar de forma separada o resultado da aplicação de cada uma das camadas da ferramenta.

\subsubsection{Componente 1}

As imagens apresentadas nas Figuras 4.4, 4.5 e 4.6 evidenciam como as trajetórias obtidas por algoritmos de rastreamento de visão computacional obtém trajetórias anômalas de pedestres com características altamente diferentes do comportamento de pedestres em estações de trem.

Por outro lado, observa-se como o tratamento de dados do componente 1, que considera o perfil de caminhada dos pedestres nos ambientes, foi capaz de detectar e corrigir estas anomalias, pelo fato de explorarem características do contexto analisado.

A aplicação do componente 1 aumenta a quantidade de trajetórias a medida que encontra movimentos de mudança de direção que estejam fora de um limiar esperado para o contexto do ambiente analisado. Um ponto a ser observado, neste caso, é que o aumento no número de rótulos de trajetórias de pedestres não afeta a contagem de pedestres em um determinado tempo, pois a divisão da trajetória original é realizada a partir de determinado momento de seu percurso.

O resultado da divisão desta trajetória contribui para que a cálculo do fluxo no cenário seja realizado de forma mais assertiva. Note que a junção de trajetórias de pedestres distintos em uma única trajetória prejudica a contabilização do fluxo para a totalidade das trajetórias existentes.

A Figura 4.6 mostra como a aplicação do componente 1 pode trazer contribuições significativas para determinação dos fluxos de movimentação de pedestres em cenários reais. Neste caso, observa-se que as trajetórias de 3 pedestres distintos se fundiam em uma única trajetória, o que pode levar a determinação equivocada do fluxo do cenário.

$\mathrm{Na}$ literatura é possível encontrar métodos que lidam com informações parciais para determinação de fluxos Zhong et al. (2015). No entanto, para cada trajetória original rastreada, é atribuído um único par origem-destino. Por este motivo, para as trajetórias advindas de oclusão, o resultado da atribuição do fluxo é comprometido. A correção realizada por este componente, combinada com métodos para estimativa de fluxo em cenários reais, pode contribuir significatimente para a obtenção de dados mais precisos de fluxo. 


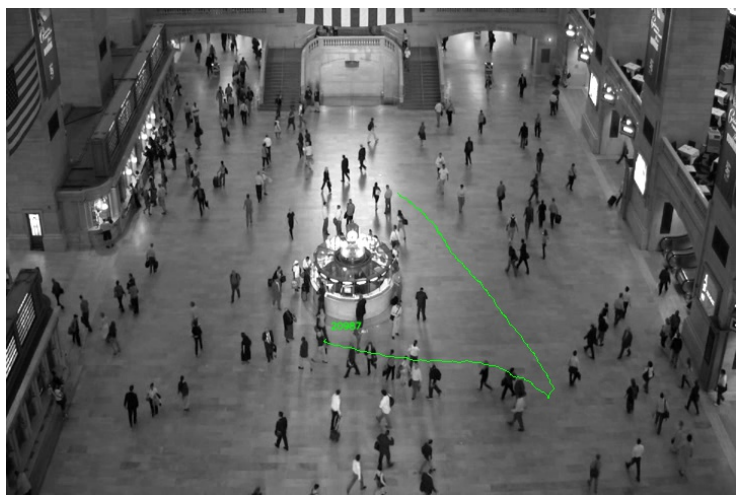

(a) Trajetória original: 20987

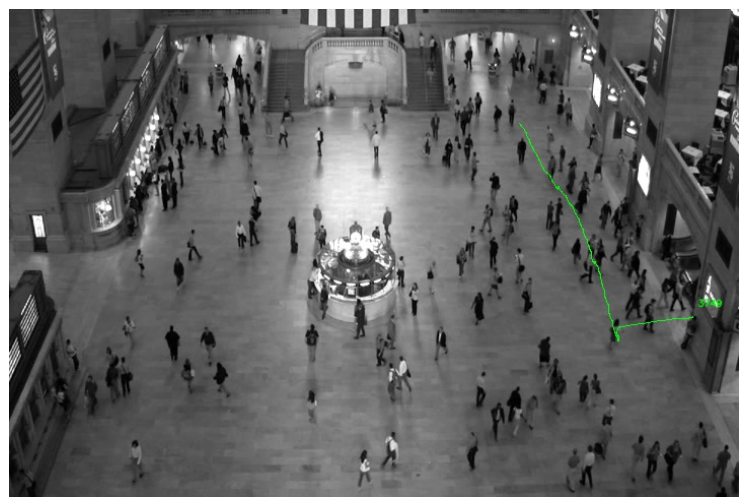

(c) Trajetória original: 3749

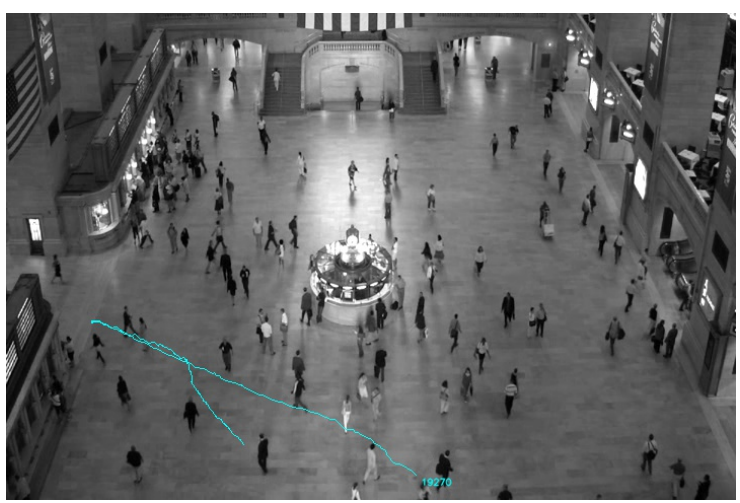

(e) Trajetória original: 19270

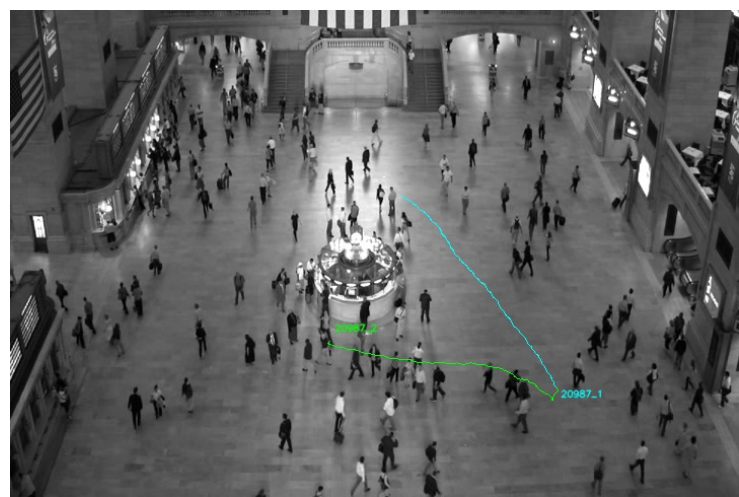

(b) Trajetórias resultantes: 20987_1 e 20987_2

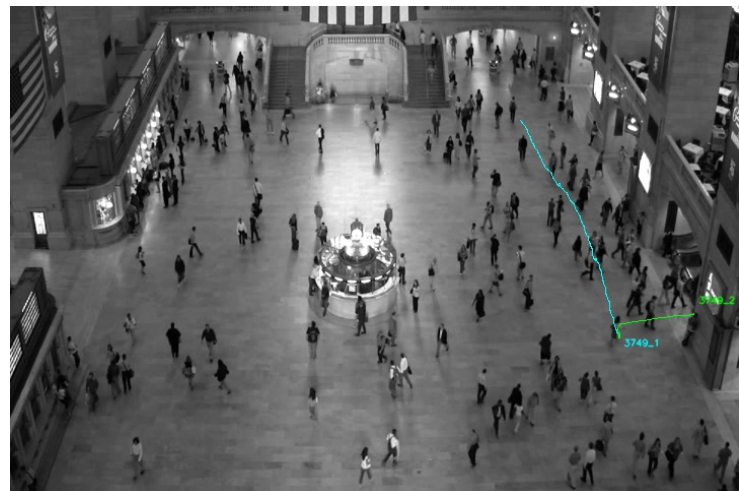

(d) Trajetórias resultantes: 3749_1 e 3749_2

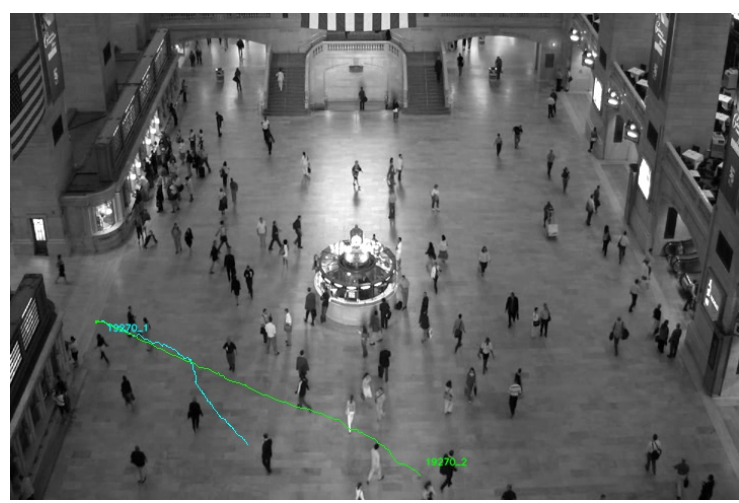

(f) Trajetórias resultantes: 19270_1 e 19270_2

Figura 4.4: Visualização das trajetórias obtidas pela aplicação do Componente 1 com uma divisão da trajetória original 


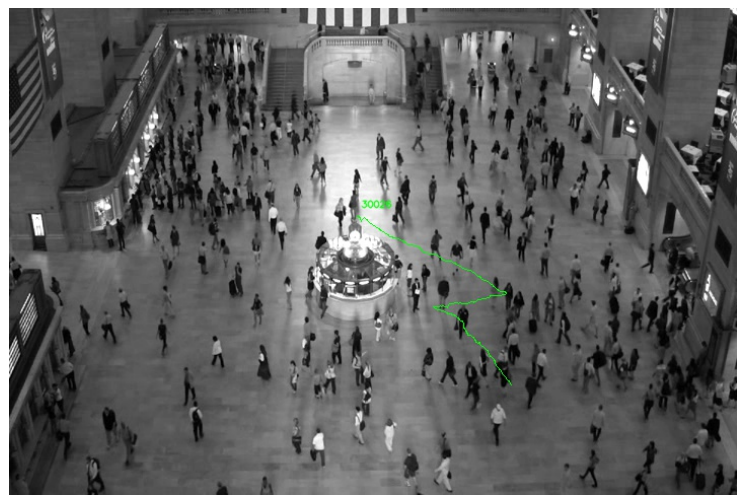

(a) Trajetória original: 30026

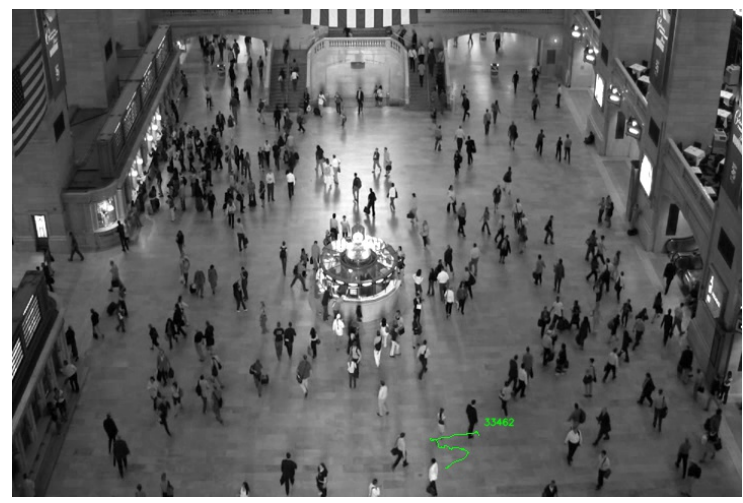

(c) Trajetória original: 33462

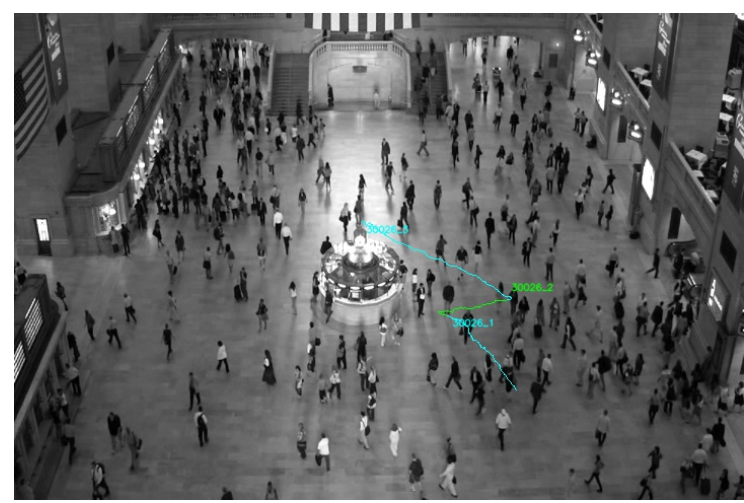

(b) Trajetórias resultantes: 30026_1, 30026_2 e 30026_3

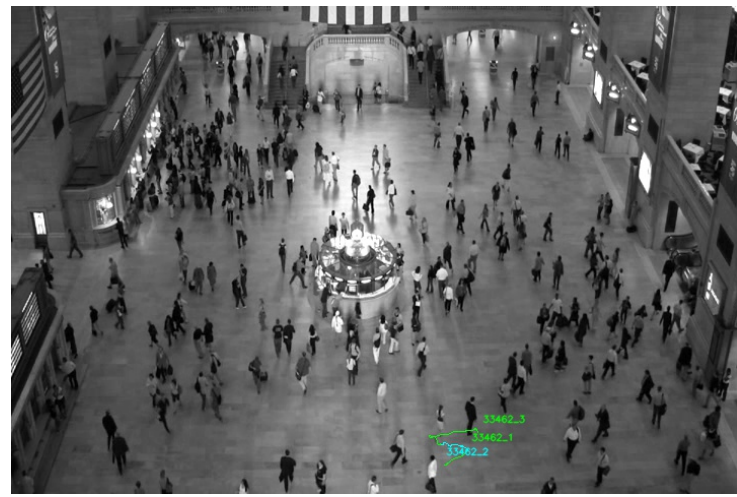

(d) Trajetórias resultantes: 33462_1, 33462_2 e 33462_3

Figura 4.5: Visualização das trajetórias obtidas pela aplicação do Componente 1 com duas divisões da trajetória original



(a) Trajetória original: 38236

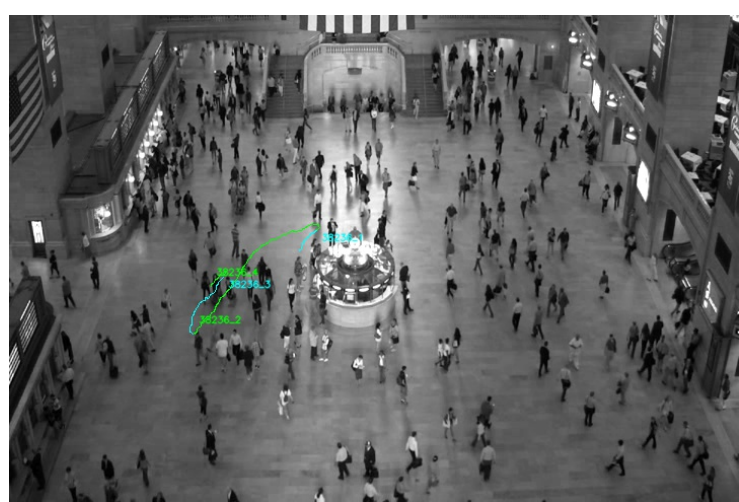

(b) Trajetórias resultantes: 38236_1, 38236_2 e 38236_3

Figura 4.6: Visualização das trajetórias obtidas pela aplicação do Componente 1 com três divisões da trajetória original

\subsubsection{Componente 2}

A correção realizada pela aplicação deste componente diminui a quantidade de trajetórias, traz benefícios imediatos e contagem mais precisa da quantidade de pedestres no ambiente, ao passo que identifica o multirastreamento de um único pedestre por mais de uma trajetória. A Figura 4.7 mostra casos onde um único pedestre é representado por ao menos duas trajetórias, e a representação final do pedestre por uma única trajetória após a remoção das trajetórias menos representativas. 


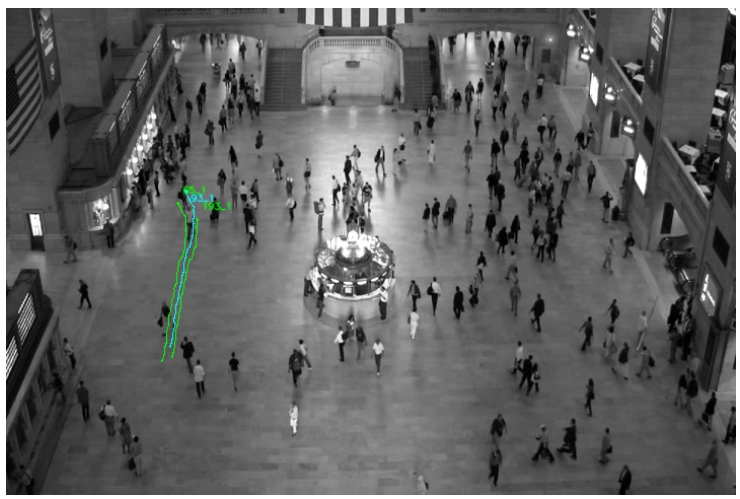

(a) Três trajetórias originais: 65_1,93_1 e 193_1

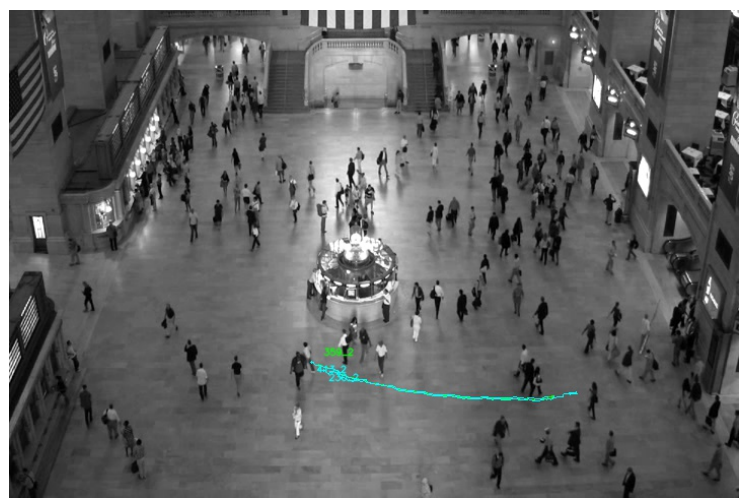

(c) Trajetórias originais: 138_3, 230_2, 359_2, 413_2

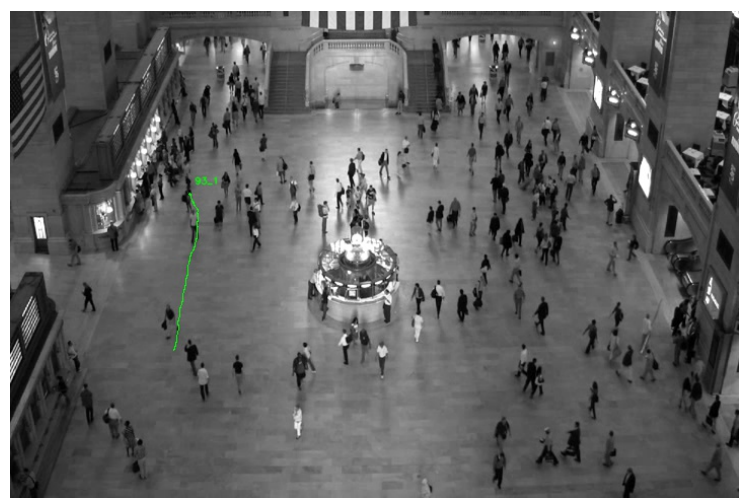

(b) Trajetória obtida pelo Componente 2: 93_1



(d) Trajetória obtida pelo Componente 2: 230_2

Figura 4.7: Visualização das trajetórias obtidas pela aplicação do Componente 2

\subsubsection{Componente 3}

A aplicação do último componente leva à obtenção de percursos mais completos do pedestre a medida que conecta os fragmentos de trajetórias parciais obtidos da identificação do pedestre e os une para a formação de uma única trajetória. Esta junção de trajetórias reduz o número total de trajetórias, mas difere do impacto do componente 2, pois não traz impacto na contagem de pedestres no tempo. Ao contrário do componente 2, que remove trajetórias existentes em um mesmo tempo, este componente reduz a quantidade de trajetórias pela identificação da existência de trajetórias parciais de um único pedestre em momentos diferentes. A Figura 4.8 mostra a junção de fragmentos parciais de um mesmo pedestre com a atribuição de um rótulo único para a trajetória oriunda desta união. 




(a) Trajetórias originais: 21913_1 e 21841

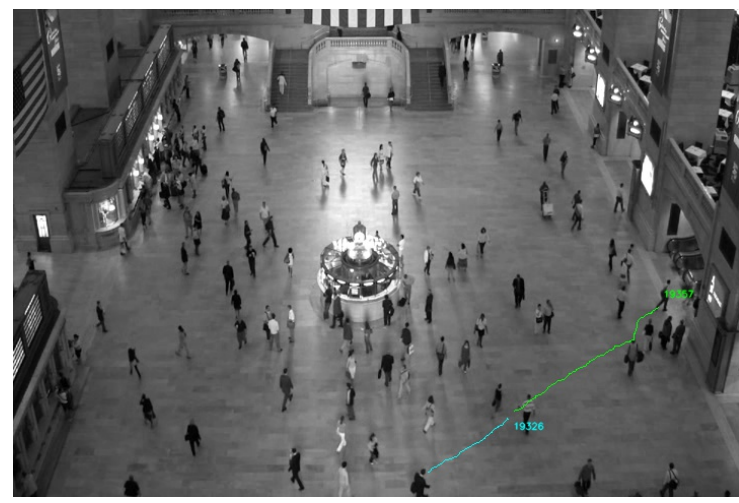

(c) Trajetórias originais: 19326 e 19357

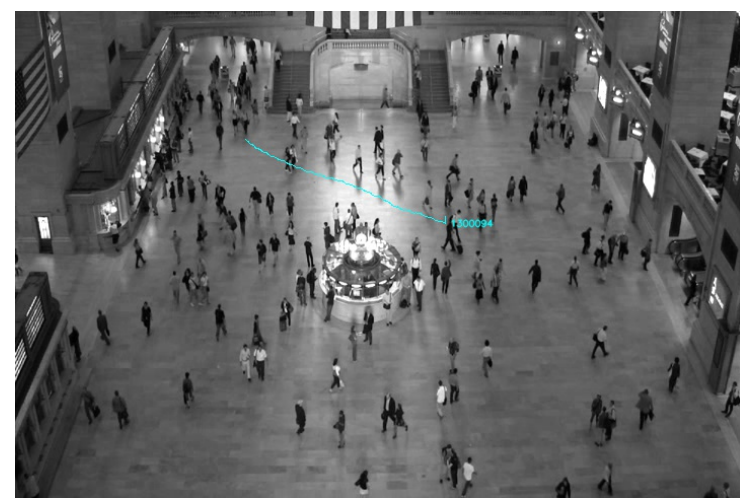

(b) Trajetória obtida pelo Componente 3: 1300094

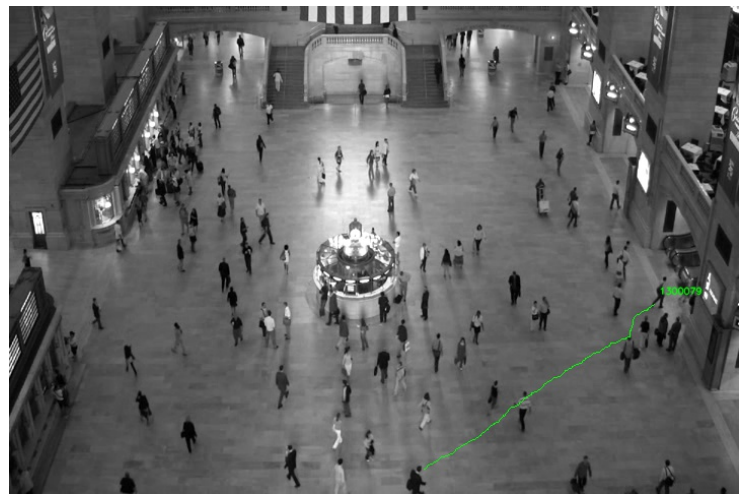

(d) Trajetória obtida pelo Componente 3: 1300079

Figura 4.8: Visualização das trajetórias obtidas pela aplicação do Componente 3

A próxima seção apresenta o resultado dos testes realizados para a averiguação da convergência e estabilidade da ferramenta proposta.

\subsection{Testes de Estabilidade}

A proposta desta etapa de testes foi verificar a estabilidade do método em relação às modificações realizadas nas trajetórias. O intuito das componentes da ferramenta é obter trajetórias mais precisas. Esta melhora é alcançada pela incorporação de informações do contexto aos algoritmos da ferramenta. Note que, espera-se que após a aplicação e uso desta informação ocorra a convergência dos resultados para trajetórias mais precisas e que estas trajetórias, em determinado momento, não sejam mais modificadas pelos componentes de tratamento de dados, confirmando a estabilidade da ferramenta.

Os testes de estabilidade foram feitos em duas etapas. Primeiramente foi realizado a repetição da aplicação de cada um dos componentes de forma individual até a estabilização, situação que ocorre quando não ocorre alteração em nenhuma trajetória. Por fim, foi realizada a aplicação dos três componentes de forma sequencial e a repetição desta aplicação, até a estabilidade.

\subsubsection{Execução Individualizada dos Componentes}

A realização deste experimento começou com a execução apenas do componente 1 aplicado a coleção de dados original e com a sua repetição para cada conjunto de trajetórias tratada até que nenhuma nova trajetória fosse modificada, o que chamamos de estabilização. Após a obtenção deste conjunto de traje- 
tórias aplicamos o componente 2 até a estabilização, como mencionado anteriormente, e na sequência ao componente 3 .

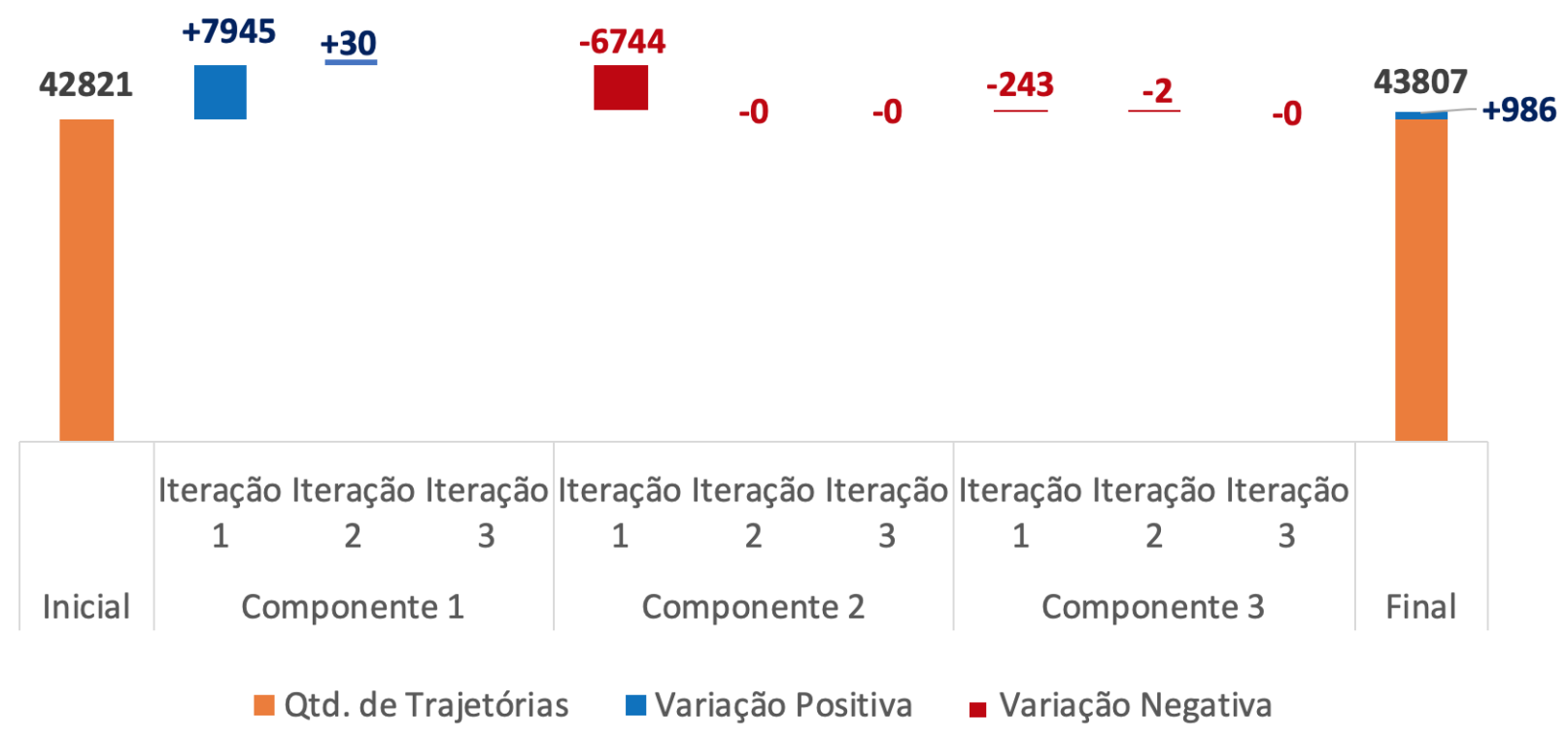

Figura 4.9: Variação do total de trajetórias pela execução individualizada de cada um dos componentes

A Figura 4.9 apresenta a variação total da quantidade de trajetórias, a quantidade total de trajetórias obtidas após a execução completa do teste teve um aumento de 986 trajetórias em relação a coleção de dados original. Este resultado foi obtido com a valoração de parametrização informada na seção 4.2. No entanto, é importante destacar que este valor poderia ser negativo. Existem dois aspectos que podem influenciar neste valor. São eles: a) as características da coleção de dados que pode conter mais falhas com uma determinada características; e b) a valoração dos parâmetros dos componentes que pode ser ajustada de acordo com a semântica do ambiente a ser estudado. Neste caso, podem ser aplicados critérios mais conservadores, com o intuito de obter uma maior corretude das correções, ou critérios mais relaxados, com o intuito de obter uma cobertura maior de correções a falhas, mas com eventuais erros de ajustes. Na seção 4.5.1 é proposto um novo indicador para ser usado como critério de ajuste dos parâmetros e avaliação dos resultados da ferramenta. 


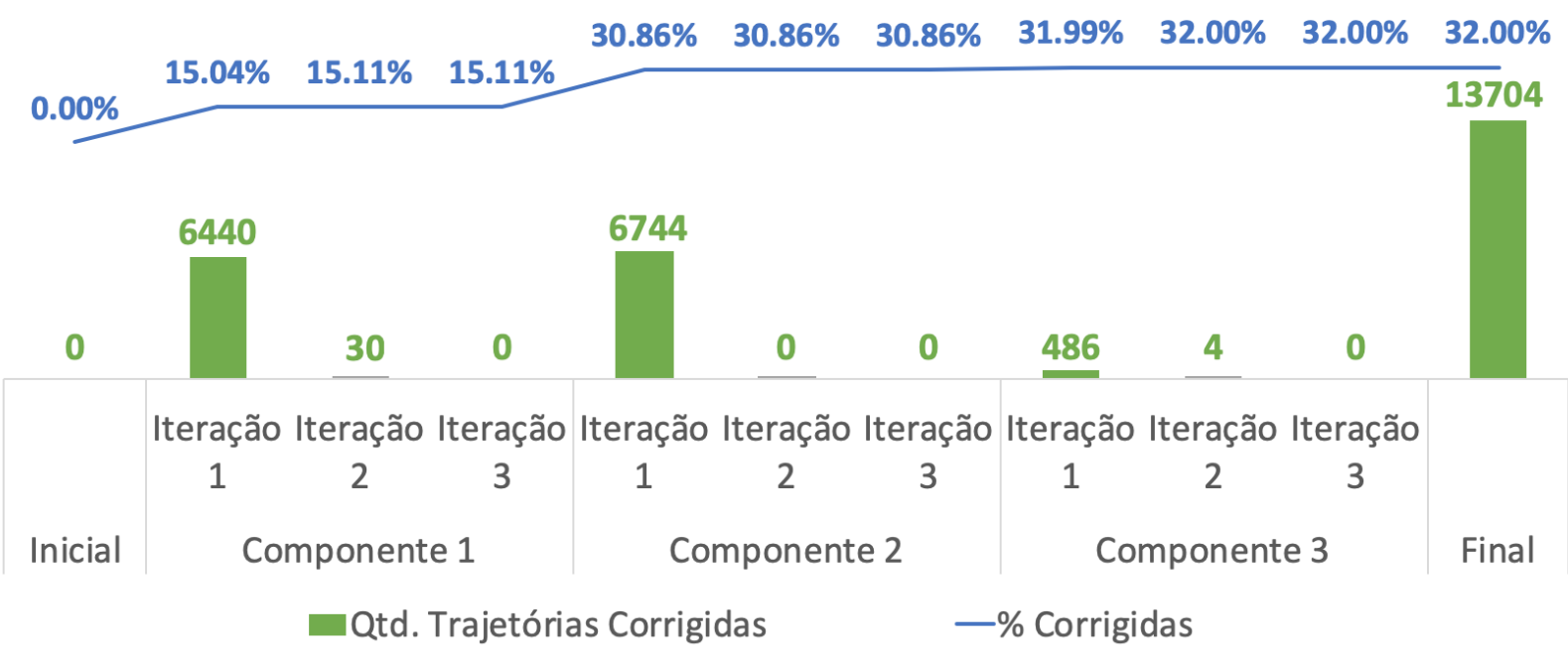

Figura 4.10: Quantidade de trajetórias corrigidas pela execução individualizada de cada um dos componentes

A Figura 4.10 apresenta a quantidade de trajetórias corrigidas pelo teste considerando como referência os rótulos de entrada dos componentes. Estes resultados indicam que a coleção de dados analisada possui muitas trajetórias com falhas decorrentes da oclusão de pedestres, pois 6.470 trajetórias foram corrigidas pelo componente 1. Na sequência, houve uma quantidade relevante de correções realizadas pela componente 2, 6.744 casos. Por último, em menor magnitude temos 490 trajetórias fragmentadas corrigidas pelo componente 3 .

Os detalhes da aplicação individualizada de cada componente até a sua estabilização estão demonstrados na Tabela 4.2. Os resultados demonstram uma rápida estabilização já na segunda iteração para os componentes 1 e 3 , e na primeira iteração para o componente 2 , sendo que as alterações realizadas na segunda iteração nos componentes 1 e 3 foram irrisórias $(0.06 \%$ e $0.005 \%$, respectivamente).

\begin{tabular}{|c|c|c|c|c|c|}
\hline & & COMPONENTE 1 & COMPONENTE 2 & COMPONENTE 3 & \\
\hline \multirow{4}{*}{ Iteração 1} & Qtd. Inicial deTrajetórias & 42.821 & 49.885 & 43.457 & \\
\hline & Qtd. Final deTrajetórias & 49.856 & 43.457 & 43.150 & \\
\hline & Variação & +7.035 & -6.428 & -307 & \\
\hline & \% Variação & $16,4 \%$ & $-12,9 \%$ & $-0,7 \%$ & \\
\hline \multirow{4}{*}{ Iteração 2} & Qtd. Inicial deTrajetórias & $\longrightarrow 49.856$ & 43.457 & 43.150 & \\
\hline & Qtd. Final deTrajetórias & 49.885 & 43.457 & 43.148 & \\
\hline & Variação & +29 & +0 & -2 & \\
\hline & \% Variação & $0,06 \%$ & $0 \%$ & $-0,005 \%$ & \\
\hline \multirow{4}{*}{ Iteração 3} & Qtd. Inicial deTrajetórias & 49.885 & 43.457 & 43.148 & \\
\hline & Qtd. Final deTrajetórias & 49.885 & 43.457 & 43.148 & \\
\hline & Variação & +0 & +0 & +0 & \\
\hline & \% Variação & $0 \%$ & $0 \%$ & $0 \%$ & TOTAL \\
\hline \multirow{4}{*}{ TOTAL } & Variação qtd. de trajetórias & +7.064 & -6.428 & -309 & +327 \\
\hline & Variação \% de trajetórias & $16,5 \%$ & $-12,9 \%$ & $-0,7 \%$ & $0,8 \%$ \\
\hline & Qtd. Correções realizadas & +7.064 & +6.428 & +309 & +13.801 \\
\hline & \% Correções realizadas & $16,5 \%$ & $12,9 \%$ & $0,7 \%$ & $32,2 \%$ \\
\hline
\end{tabular}

Tabela 4.2: Quantidades de trajetórias de entrada, saída e corrigidas obtidas pela execução individualizada de cada um dos componentes 
A quantidade total de correções realizadas, 13.704, corresponde a 32,0\% do total de trajetórias da coleção de dados inicial. Apesar da variação total na quantidade de trajetórias ser baixa, $2.3 \%$, o total de correções realizado sugere que as trajetórias da coleção de dados original possuem um elevado número de percursos com falhas.

O total de correções realizadas pelo componente 1 sugerem que exista uma elevada densidade no cenário estudado, pois foram identificadas várias situações de oclusão. Este indicativo também justifica o baixo desempenho do componente 3 em identificar a continuidade do movimento, visto que, em situações com uma maior densidade as alterações na direção e velocidade dos pedestres são comuns, o que viola as regras para as correções realizadas pelo componente 3 .

\subsubsection{Execução Sequencial dos Componentes}

A execução sequencial começou com a aplicação do componente 1, e na sequencia, aplicou-se os componentes 2 e 3 . O processo se repete até a estabilização. Os resultados da aplicação sequencial obtidos são apresentados nas Figuras 4.11, 4.12 e na Tabela 4.3.

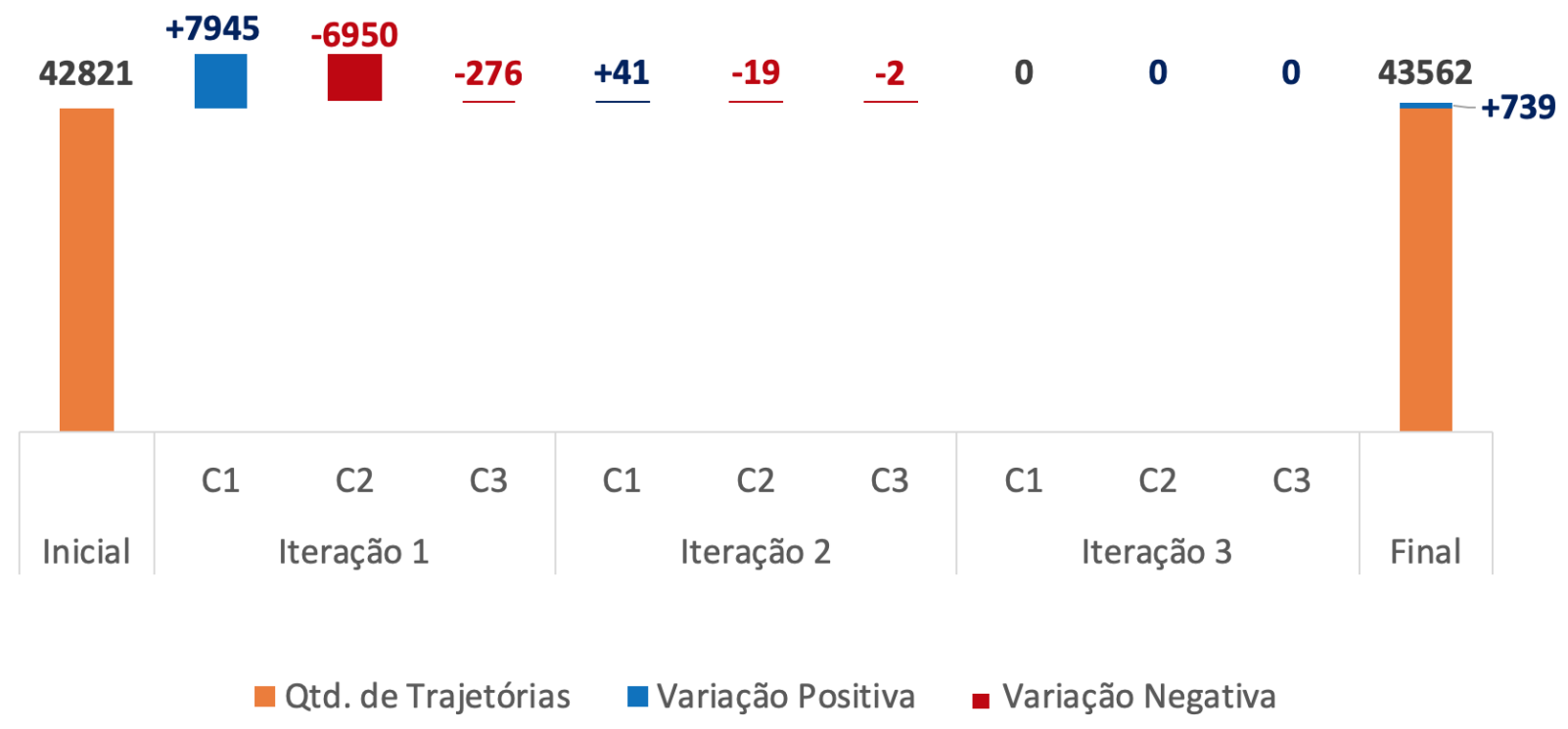

Figura 4.11: Variação do total de trajetórias pela execução sequencial dos componentes

De forma similar ao teste de estabilidade individualizada, a Figura 4.11 demonstra que ocorreu uma rápida estabilização já na segunda iteração para todos os componentes. Com relação ao total de trajetórias final e correções realizadas, também foram obtidos valores semelhantes. O teste indivializado obteve apenas 247 (individualizado: 986, sequencial: 739) trajetórias adicionais em relação ao teste de aplicação sequencial. Isto corresponde a $0.5 \%$ do total de trajetórias na coleção de dados original, conforme Figura 4.11. 


\begin{tabular}{|c|c|c|c|c|c|}
\hline & & Iteração 1 & Iteração 2 & Iteração 3 & \\
\hline \multirow{5}{*}{$\begin{array}{c}\text { COMPONENTE } 1 \\
\text { C1 }\end{array}$} & Qtd. Inicial deTrajetórias & 42.821 & 43.540 & 43.560 & \\
\hline & Qtd. Final deTrajetórias & 50.766 & 43.581 & 43.560 & \\
\hline & Qtd. Trajetórias Corrigidas & 6.440 & 41 & 0 & \\
\hline & Variação & +7.945 & +41 & +0 & \\
\hline & \% Variação & $18,6 \%$ & $0,09 \%$ & $0 \%$ & \\
\hline \multirow{5}{*}{$\begin{array}{c}\text { COMPONENTE } 2 \\
\text { C2 }\end{array}$} & Qtd. Inicial deTrajetórias & $\rightarrow 50.766$ & 43.581 & 43.560 & \\
\hline & Qtd. Final deTrajetórias & 43.816 & 43.562 & 43.560 & \\
\hline & Qtd. Trajetórias Corrigidas & 6.950 & 19 & 0 & \\
\hline & Variação & -6.950 & -19 & +0 & \\
\hline & \% Variação & $-13,7 \%$ & $-0,04 \%$ & $0 \%$ & \\
\hline \multirow{5}{*}{$\begin{array}{c}\text { COMPONENTE } 3 \\
\text { C3 }\end{array}$} & Qtd. Inicial deTrajetórias & 43.816 & 43.562 & 43.560 & \\
\hline & Qtd. Final deTrajetórias & 43.540 & 43.560 & 43.560 & \\
\hline & Qtd. Trajetórias Corrigidas & 552 & 4 & 0 & \\
\hline & Variação & -276 & -2 & +0 & \\
\hline & \% Variação & $-0,6 \%$ & $-0,005 \%$ & $0 \%$ & TOTAL \\
\hline \multirow{4}{*}{ TOTAL } & Variação qtd. de trajetórias & +719 & +20 & +0 & +739 \\
\hline & Variação \% de trajetórias & $1,7 \%$ & $0,05 \%$ & $0 \%$ & $1,7 \%$ \\
\hline & Qtd. Correções realizadas & +13.942 & +64 & +0 & +14.006 \\
\hline & \% Correções realizadas & $32,6 \%$ & $0,15 \%$ & $0 \%$ & $32,7 \%$ \\
\hline
\end{tabular}

Tabela 4.3: Quantidades de trajetórias de entrada, saída e corrigidas obtidas pelo teste de estabilidade sequencial

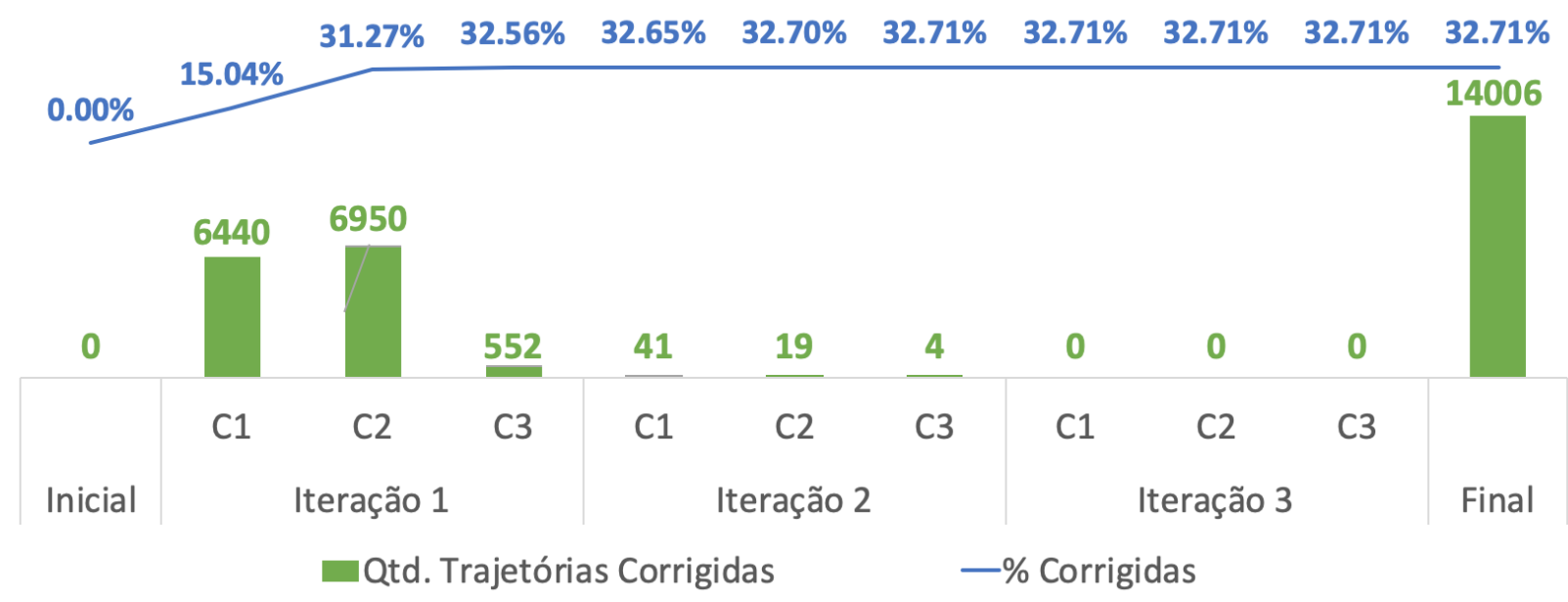

Figura 4.12: Quantidade de trajetórias corrigidas pela execução sequencial dos componentes

Com relação ao total de correções realizadas, a diferença foi de 302 (individualizado: 13.704, sequencial: 14.006), o que corresponde a $0.7 \%$ de correções adicionais realizadas pelo procedimento sequencial em relação ao individualizado, como apresentado na Figura 4.12..

Os resultados obtidos pelos testes de estabilidade, conforme Tabela 4.3, indicam que o desempenho na correção de falhas da ferramenta pelo processo sequencial, com apenas uma iteração (13.942), é superior ao obtido pelo processo individualizado até a estabilização (13.704). Além disto, o processo sequencial, em apenas uma iteração, produz $99,5 \%$ de correções em relação ao processo sequencial até a estabilização (14.006). Isto indica que a ferramenta pode ser usada por este processo sem prejudicar o desempenho. 


\subsection{Testes de Quantitativos}

Esta etapa de testes demonstra através de indicadores quantitativos a efetividade da ferramenta no tratamento das trajetórias para obtenção de informações mais precisas com relação ao comportamento observado dos pedestres no vídeo real.

Uma dos grandes desafios desta fase é que as coleções de dados oriundas de ambientes reais não possuem a referência verdadeira do percurso. Desta forma, é difícil mensurar com exatidão a completa dimensão do tratamento de correções das imprecisões e imperfeições dos dados. Para mitigar este problema, este trabalho propõe um indicador para mensurar a melhora obtida pela aplicação da ferramenta apresentada. Este indicador considera tanto a acurácia nas correções realizadas como também a quantidade de falhas da coleção de dados. A próxima seção descreve e exemplifica como o indicador proposto opera e pode ser utilizado na calibração de parâmetros para outros cenários.

\subsubsection{Definição do Indicador para Averiguar a Efetividade da Ferramenta}

Este trabalho propõe um indicador, denominado Fator de melhora, com o intuito de averiguar a efetividade das correções feitas pela ferramenta desenvolvida. Este indicador é essencialmente influenciado por dois fatores referentes às correções realizadas pela ferramenta. Um destes fatores é a abrangência, que mensura a quantidade de trajetórias que tiveram alguma falha e foram identificadas e corrigidas pela ferramenta em relação ao total de trajetórias da coleção de dados original. O outro fator é a corretude, que avalia a conformidade das correções realizadas. Formalmente, o indicador Fator de melhora - $f m_{c}$ do componente $c$ pode ser obtido pela seguinte equação:

$$
f m_{c}=p a_{c} \times p m_{c}
$$

onde $p a_{c}$ é o percentual de trajetórias com falhas identificadas e corrigidas pelo componente $c$ que se refere a abrangência, e $p m_{c}$ é o percentual de melhora do componente $c$ no que se refere a corretude das correções realizadas.

O percentual de abrangência pode ser obtido pela equação:

$$
p a_{c}=\frac{t c_{c}}{\tau}
$$

onde $t c_{c}$ é o total de trajetórias com falhas identificadas e corrigidas pela componente $c$, e $\tau$ é o total de trajetórias na coleção de dados original.

O procedimento para obtenção de $p m_{c}$ é baseado na verificação da conformidade das correções de dados. Esta verificação pode ser feita de forma automatizada ou manual, caso a coleção de dados possua o chão verdade ou não, respectivamente. Como a coleção de dados não possui os valores reais de referência, pode-se definir $p m_{c}$ a partir de uma amostra aleatória de tamanho $n$ das correções feitas pela seguinte equação:

$$
p m_{c}=p c_{c}-p i_{c}
$$

onde, $p c_{c}$ é o percentual de correções corretas realizadas, e $p i_{c}$ o percentual de incorretas. Considera-se como incorretas todas as correções que não estavam em conformidade:

$$
p i_{c}=1-p c_{c}
$$


Substituindo a equação 4.4 em 4.3 obtem-se

$$
p m_{c}=p c_{c}-\left(1-p c_{c}\right)
$$

isto é, o cálculo do percentual de correções corretas para a amostra de tamanho $n$ pode ser obtido pela média dos percentuais de correções corretas de cada trajetória corrigida. Seja $t c_{k}$ o total de correções realizado para uma única trajetória da amostra, e $c c_{k}$ o total destas correções realizadas que estavam em conformidade, $p c_{c}$ pode ser obtido pela média dos valores apurados pela seguinte equação:

$$
p c_{c}=\frac{1}{n} \sum_{k=1}^{n} \frac{c c_{k}}{t c_{k}}
$$

Desta forma, obtem-se o indicador Fator de melhora para a averiguação da qualidade dos resultados obtidos pela ferramenta. A Figura 4.13 apresenta possíveis resultados de serem obtidos para o indicador com a variação do percentual de abrangência $p a_{c}$ em relação ao percentual de correções corretas $p c_{c}$. $\mathrm{O}$ fator $p a_{c}$ teve a variação do valor mínimo possível - 0 (onde nenhuma trajetória é corrigida) até $100 \%$ (onde todas as trajetórias são corrigidas) com intervalos de $10 \%$. O outro fator $p c_{c}$ também sofreu o mesmo intervalo de variação, sendo 0 onde nenhuma correção estava em conformidade com a verdade de referência, e 100 onde todas as correções foram adequadas a situação real.

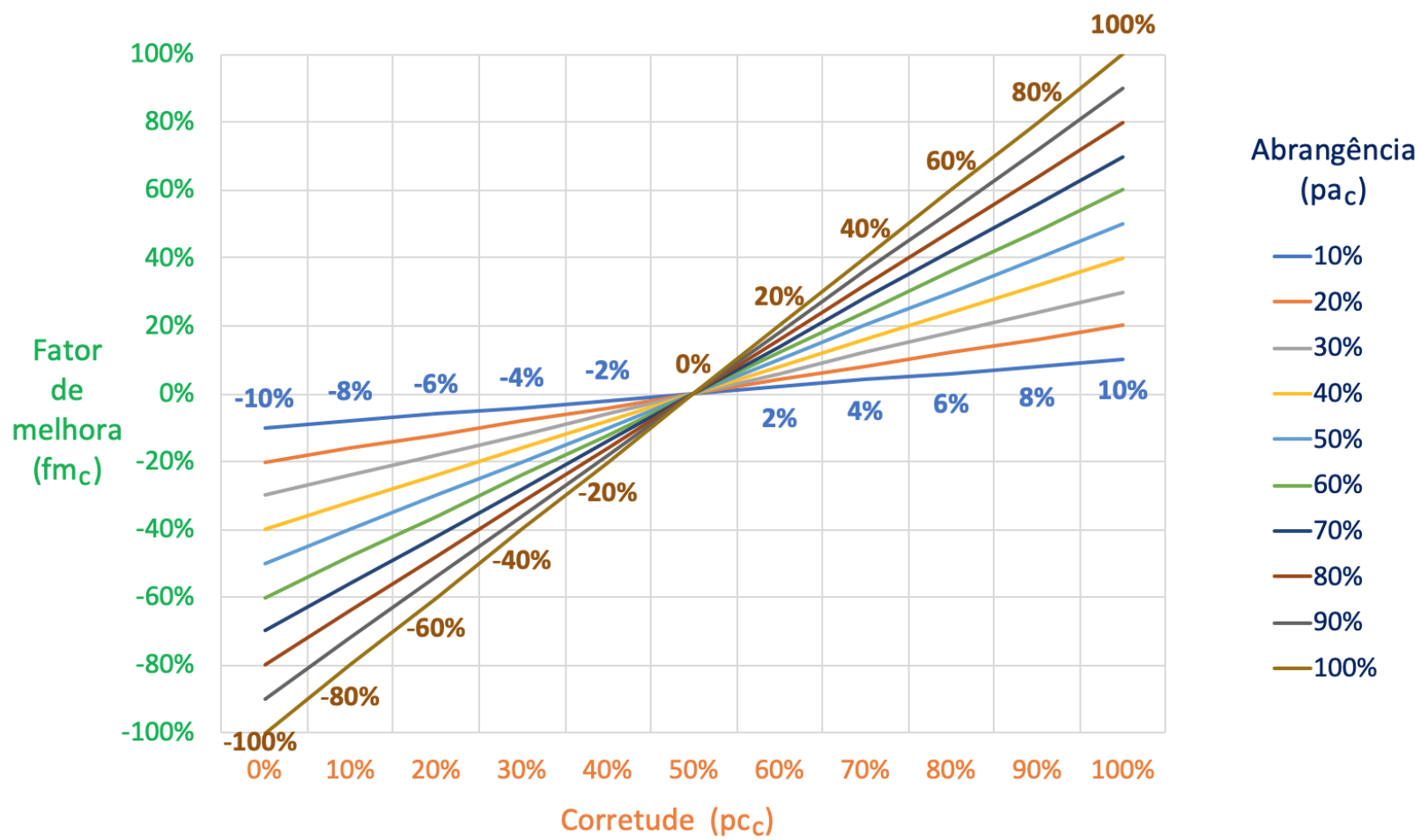

Figura 4.13: Variação do indicador proposto em relação as variáveis que o compõe

Para ilustrar como o indicador varia em razão das váriaveis que o compõe, pode-se observar algumas situações na Figura 4.13. Primeiro, considerando o ponto onde o fator de melhora $f m_{c}$ converge para 0 , verifica-se que sempre que as correções realizadas $p c_{c}$ tem $50 \%$ de corretude, o fator de melhora é zero. Note que, para cada ajuste feito em conformidade tivemos um ajuste feito de forma inadequada o que faz com que o $\mathrm{pm}_{c}$ seja igual à zero. 
Outro ponto a ser observado é o intervalo do fator de melhora, que é limitado pelo percentual de abrangência das falhas identificadas $p a$ e varia de $[-p a,+p a]$, ou seja, como observado para a abrangência de $10 \%$ que está destacada na figura na cor azul, o valor mínimo que o indicador pode receber é de $-10 \%$ para o caso de todas as correções realizadas terem sido inadequadas $\left(p c_{c}=0\right)$, e o valor máximo possível é de $10 \%$ para o caso de todas as correções terem sido apropriadas $\left(p c_{c}=1\right)$.

Partindo da definição do indicador mencionada, é necessário utilizar dois relatórios criados pela ferramenta para a atribuição do valores aos fatores que compõe o indicador. A valoração para o fator abrangência $\left(p a_{c}\right)$ é obtida de forma direta do relatório 3.4. O valor para a atribuição do fator de corretude $\left(p c_{c}\right)$ é obtido a partir da análise do relatório 3.4 .

O relatório 3.4 gera uma amostra aleatória de vídeos com exibição das trajetórias antes e depois do tratamento realizado pela ferramenta. Desta forma, pode ser feita a verificação manual da aderência das correções feitas ao comportamento observado dos pedestres no vídeo e a contabilização dos valores $c c_{k} \mathrm{e}$ $t c_{k}$ necessários para a obtenção do valor de $p c_{c}$, conforme equação 4.6. O tamanho da amostra definido como $\eta$ pode ser ajustado de acordo com critérios definidos de acordo com as necessidades do cenário específico que está sendo analisado. A amostra só inclui trajetórias originais que foram modificadas pela ferramenta. A partir da amostra, são gerados vídeos com os trajetos originais e resultantes da aplicação da ferramenta, para que, posteriormente, possa ser realizada a verificação da aderência dos resultados da ferramenta ao comportamento observado dos pedestres no vídeo.

A partir da obtenção destes fatores pelo processo mencionado é possível calcularmos o Fator de melhora para cada um dos componentes pela equação 4.1 utilizando-se o mesmo processo.

Com a atribuição dos valores $f m_{c}$ a cada um dos três componentes pode-se mensurar de forma composta o Fator de Melhora Total - FMT que o tratamento realizado pela ferramenta propiciou a coleção de dados original pela seguinte equação:

$$
F M T=\sum_{k=1}^{t} f m_{c}, \quad t=3
$$

Este fator de melhora significa que quanto maior o valor obtido, melhor é a performance da ferramenta na correção de imperfeiçoes e erros nas trajetórias da coleção de dados original. Por outro lado, pode-se considerar que menor é a qualidade dos dados obtidos do algoritmo de rastreamento.

As próximas seções apresentam a utilização do indicador proposto para a avaliação das correções realizadas pela ferramenta na coleção de dados de Grand Central Terminal. Esta coleção de dados não possui as referências reais dos rótulos das trajetórias. Logo, o cálculo do fator de corretude se baseou em uma amostra arbitrada de tamanho $\eta=30$ devido ao alto custo expendido no processo de verificação manual e as limitações de recursos do projeto.

Conforme sugerido na seção 4.4.2 foi utilizada a iteração 1 do processamento sequencial dos componentes para o cálculo do fator de melhora de cada um dos componentes e do total, visto que a contribuição das iterações adicionais é residual.

\subsubsection{Efetividade do Componente 1}

A Tabela 4.4 apresenta a apuração da equação 4.6 para a Componente 1, onde temos:

- $k$ : número identificador da amostra avaliada; 


\begin{tabular}{|c|c|c|c|}
\hline$k$ & $t c_{1}$ & $c c_{1}$ & $c c_{1} / t c_{1}$ \\
\hline 1 & 1 & 1 & $100 \%$ \\
\hline 2 & 1 & 1 & $100 \%$ \\
\hline 3 & 3 & 3 & $100 \%$ \\
\hline 4 & 1 & 1 & $100 \%$ \\
\hline 5 & 1 & 1 & $100 \%$ \\
\hline 6 & 2 & 2 & $100 \%$ \\
\hline 7 & 1 & 1 & $100 \%$ \\
\hline 8 & 1 & 1 & $100 \%$ \\
\hline 9 & 1 & 1 & $100 \%$ \\
\hline 10 & 1 & 1 & $100 \%$ \\
\hline 11 & 1 & 1 & $100 \%$ \\
\hline 12 & 1 & 1 & $100 \%$ \\
\hline 13 & 1 & 1 & $100 \%$ \\
\hline 14 & 1 & 1 & $100 \%$ \\
\hline 15 & 1 & 1 & $100 \%$ \\
\hline 16 & 1 & 1 & $100 \%$ \\
\hline 17 & 1 & 1 & $100 \%$ \\
\hline 18 & 2 & 2 & $100 \%$ \\
\hline 19 & 2 & 2 & $100 \%$ \\
\hline 20 & 1 & 1 & $100 \%$ \\
\hline 21 & 1 & 1 & $100 \%$ \\
\hline 22 & 1 & 1 & $100 \%$ \\
\hline 23 & 1 & 1 & $100 \%$ \\
\hline 24 & 2 & 2 & $100 \%$ \\
\hline 25 & 1 & 0 & $0 \%$ \\
\hline 26 & 1 & 1 & $100 \%$ \\
\hline 27 & 1 & 1 & $100 \%$ \\
\hline 28 & 1 & 1 & $100 \%$ \\
\hline 29 & 1 & 1 & $100 \%$ \\
\hline 30 & 1 & 0 & $0 \%$ \\
\hline
\end{tabular}

Tabela 4.4: Apuração da equação 4.6 para o Componente 1 e amostra de tamanho $\eta=30$

- $t c_{1}$ : total de correções realizadas para a trajetória da amostra. Cada ponto da trajetória original, onde é necessário realizar uma divisão, considera-se como uma correção;

- $c c_{1}$ : total de divisões realizadas na trajetória da amostra que de fato representavam trajetórias de pedestres diferentes; $\mathrm{e}$

- $p c_{1}$ : valor médio de correções realizadas em conformidade nas trajetórias da amostra.

A Tabela 4.5 mostra os cálculos das equações parciais, necessárias a obtenção da equação 4.1 para a Componente 1. 


\begin{tabular}{cc}
\hline Paramêtro & Valor \\
\hline$\tau$ & 42.821 \\
$t c_{1}$ & 6.440 \\
$p a_{1}$ & $15.0 \%$ \\
$p c_{1}$ & $93.3 \%$ \\
$p m_{1}$ & $86.7 \%$ \\
\hline$f m_{1}$ & $13.0 \%$ \\
\hline
\end{tabular}

Tabela 4.5: Valores obtidos para as equações do fator de melhora para o Componente 1

$\mathrm{O}$ valor de $t c_{1}$ se refere ao total de trajetórias que tiveram uma ou mais correções/divisões realizadas pelo Componente 1 considerando o rótulo de entrada. Este valor não coincide com o total de trajetórias adicionais na saída obtidas após o tratamento do Componente 1. Isto ocorre, pois uma trajetória de origem pode ser dividida em mais de uma trajetória, como pode ser observado nas amostras $k=3$ onde foram realizadas 3 divisões, e $k=6$ com duas divisões.

O Componente 1 obteve uma corretude de $93.3 \%$ no processo de tratamento. Considerando a abrangência, o Componente 1 corrigiu um total de trajetórias 6.440 (15.0\%). Tais resultados sugerem que a coleção de dados original é procedente de um ambiente com elevada densidade e várias situações de oclusão.

$\mathrm{O}$ fator de melhora obtido para o componente $\mathrm{fm}_{1}=13.0 \%$ indica que houve ume melhora em aproximadamente 5.566 trajetórias $(13.38 \% \times 42.821)$. Dependendo do objetivo da análise, os parâmetros utilizados podem ser flexibilizados para atingir uma amplitude maior na quantidade de trajetórias corrigidas em detrimento de uma eventual redução no patamar atual de corretude.

\subsubsection{Efetividade do Componente 2}

Os detalhes do cálculo da equação 4.6 estão disponíveis no Apêndice A na Tabela A.1 que é similar a apresentada para o Componente 1 , mas os valores adotados para as seguintes variaveis diferem semanticamente conforme descrição abaixo pela própria natureza das correções:

- $t c_{2}$ : total de trajetórias análogas excluídas para a trajetória da amostra. Cada exclusão é considerada como uma correção;

- $c c_{2}$ : total de exclusões realizadas que de fato representavam o mesmo pedestre da trajetória origem da amostra.

A partir da apuração da equação 4.6 é possível realizar os cálculos do $f m_{2}$ conforme mostra a Tabela 4.6. 


\begin{tabular}{cc}
\hline Paramêtro & Valor \\
\hline$\tau$ & 42.821 \\
$t c_{2}$ & 6.950 \\
$p a_{2}$ & $16.2 \%$ \\
$p c_{2}$ & $92.5 \%$ \\
$p m_{2}$ & $85.0 \%$ \\
\hline$f m_{2}$ & $13.8 \%$ \\
\hline
\end{tabular}

Tabela 4.6: Valores obtidos para as equações do fator de melhora para o Componente 2

$\mathrm{O}$ valor de $t c_{2}$ se refere ao total de trajetórias que foram excluídas por representarem o rastreamento múltiplo de algum pedestre. O Componente 2 apresentou uma expressiva quantidade de trajetórias análogas, $6.950\left(16,2 \%\right.$ ), e uma corretude de $92.5 \%$, o que produz $f m_{2}=13.8 \%$. O elevado patamar de multirastreamento traz prejuízos imediatos a contagem de pedestres, visto que o ambiente aparenta estar com uma ocupação muito superior a real. Os resultados obtidos indicam uma redução significativa em falhas na contagem de pedestres no valor de $13.8 \%$, que é a diferença entre o percentual de trajetórias análogas excluídas corretamente $15.0 \%(6.2 \% \times 92.5 \%)$ e o percentual excluído de forma indevida, $1.2 \%(16.2 \% \times$ $7.5 \%)$.

\subsubsection{Efetividade do Componente 3}

As váriaveis para o cálculo da equação 4.6 se basearam nas seguintes definições:

- $t c_{3}$ : total de trajetórias parciais unidas, por representarem o percurso de um mesmo pedestre;

- $c c_{3}$ : total de uniões de trajetórias parciais realizadas que de fato representavam o percurso de um mesmo pedestre.

O cálculo completo da equação 4.6 está disponível no Apêndice A, na Tabela A.2. A apuração das equações para a obtenção de $f m_{3}$ estão na Tabela 4.7 .

\begin{tabular}{cc}
\hline Paramêtro & Valor \\
\hline$\tau$ & 42.821 \\
$t c_{3}$ & 552 \\
$p a_{3}$ & $1.3 \%$ \\
$p c_{3}$ & $90.0 \%$ \\
$p m_{3}$ & $80.0 \%$ \\
\hline$f m_{3}$ & $1.0 \%$ \\
\hline
\end{tabular}

Tabela 4.7: Valores obtidos para as equações do fator de melhora para o Componente 3

$\mathrm{O}$ valor de $t c_{3}$ representa total de trajetórias parciais unidas, por representarem o percurso de um mesmo pedestre. O Componente 3 apresentou uma baixa capacidade de detecção de percursos parciais que representassem a continuidade do movimento do pedestre $(1,3 \%)$ e uma corretude razoável $(90,0 \%)$ o que gera 
$f m_{3}=1.0 \%$. A expectativa era de que fosse obtida uma abrangência mais relevante, pois há uma elevada quantidade de trajetórias parciais na coleção de dados.

Uma das razões que justificam a baixa abrangência deste componente é que foram utilizados dados de um terminal de grande circulação, ou seja, alta densidade. Nestas áreas, os pedestres caminham muito próximos uns dos outros e precisam reduzir a velocidade e mudar de direção para evitar colisões. Estas mudanças no comportamento padrão contrasta as premissas utilizadas pelo algoritmo do componente e prejudica a capacidade de unir as trajetórias parciais para identificação do percurso completo. Alguns experimentos foram realizados na tentativa de obter uma maior abrangência com a flexibilização dos parâmetros adotados, mas os resultados tiveram um impacto muito negativo na corretude com várias junções de trajetórias de pedestres diferentes.

Outro motivo para a baixa abrangência está na ausência da trajetória que representa o percurso do pedestre, tanto pela sobreposição de imagens nos momentos de maior fluxo, onde alguns pedestres não têm a trajetória atribuída, como também pela iluminação e sombreamento que interferem na identificação do pedestre.

Apesar do desempenho inferior ao dos demais componentes, os resultados constatam a determinação mais completa do percurso para um número razoável de pedestres. Além disto, o desempenho pode variar bastante se a coleção de dados analisada apresentar características distintas daquelas que foram utilizadas nesta pesquisa.

\subsubsection{Efetividade Total}

A partir dos resultados de cada um dos componente, a efetividade total da ferramenta pode ser calculada. O FMT é obtido pela soma dos fatores de melhora de cada componente (equação 4.8) conforme demonstrado no cálculo:

$$
F M T=f m_{1}+f m_{2}+f m_{3}=13.0 \%+13.8 \%+1.0 \%=27.8 \%
$$

O resultado total pode ser interpretado como um balizador da quantidade total de trajetórias modificadas que se favoreceram da agregação das informações do contexto em pelo menos algum destes aspectos: 1) contagem de pedestres, 2) definição de fluxos e/ou, 3) determinação do percurso dos pedestres. A ferramenta realizou alterações em um total de 13.942 trajetórias $\left(t c_{1}+t c_{2}+t c_{3}\right)$.

\subsection{Aplicações e Limitações da Ferramenta}

Os experimentos constataram a relevância de utilizar informações do contexto para melhorar a análise de terminais urbanos. Esta ferramenta melhora a aquisição de informações de pedestres de terminais instalados e gera relatórios para possibilitar que engenheiros possam desenvolver melhorias em terminais urbanos já instalados. Além disto, os estudos de simulação podem se beneficiar com a obtenção de parâmetros reais.

Os benefícios do uso de informações de contexto para aumentar a qualidade das obtenção de dados de pedestres de vídeo têm como contrapartida a necessidade de ajustar os parâmetros da ferramenta, o que para ser feito de forma apropriada, demanda que seja feita a verificação manual. Apesar de existir esta desvantagem, a ferramenta facilita a realização desta etapa com a geração de relatórios que sintetizam de forma eficiente as informações cruciais para a realização destes ajustes.

Até onde sabemos, as pesquisas anteriores não se propuseram a tratar os dados processados de vídeo 
com a agregação de informações relevantes do contexto. Esta pesquisa explorou vários aspectos a serem melhorados com estas informações, criou uma ferramenta para melhorar a aquisição de dados agregando as características do contexto, possibilitou que esta parametrização possa ser realizada pela ferramenta para diferentes contextos, e criou um conjunto de relatórios que disponibilizam informações importantes para a avaliação de terminais reais. 


\section{Capítulo 5}

\section{Conclusões e trabalhos futuros}

\subsection{Considerações Finais}

Este trabalho produziu uma ferramenta para analisar informações de pedestres a partir de dados extraídos de vídeos em terminais urbanos. A ferramenta adotou uma abordagem multicamada que provê flexibilidade para ser utilizada e ajustada de acordo com insuficiências de informações do comportamento observado dos pedestres. A questão central de pesquisa nesta tese é se as informações do contexto podem ser utilizadas para modificar a interpretação dos dados obtidos de vídeos e realizar correções para aprimorar a análise de pedestres nestes ambientes.

Os experimentos utilizaram dados coletados de um terminal real - Grand Central Terminal de Nova York. Os resultados demonstraram que a ferramenta possui capacidade de tratar falhas de dados e melhorar a análise de cenários reais através da agregação de informações de contexto. A agregação faz uso de parâmetros que podem ser ajustados de acordo com os dados disponíveis e seu uso previsto. Esta parametrização é muito útil, pois traz flexibilidade para a análise das informações por engenheiros de transporte.

Os resultados apresentaram contribuições potencialmente importantes na análise do comportamento de pedestres, pois aumentam a precisão na contagem de pedestres, melhoram a definição de fluxos e a determinação do percurso dos pedestres em cenários reais a partir de informações de vídeos.

\subsection{Sugestões para Pesquisas Futuras}

A partir dos resultados apresentados, diversas iniciativas podem ser desenvolvidas, dentre as quais destacamos:

- Os parâmetros utilizados para calibrar as ferramentas apresentadas são ajustados manualmente na versão apresentada neste trabalho. Uma evolução da ferramenta pode incorporar mecanismos de aprendizado de máquina para otimizar os parâmetros com base em dados parcialmente rotulados ou métodos de aprendizado semi-supervisionado e aprendizado por reforço.

- Dependendo do objetivo e uso pretendido da análise a ser desenvolvida, algumas informações podem ser mais relevantes do que outras no que se refere à precisão e corretude. Por exemplo, estudos voltados para marketing podem ter maior interesse na quantidade exata de pessoas que passem por um certo ponto, enquanto que estudos voltados para a segurança pública podem ter maior interesse na velocidade do fluxo das pessoas, independentemente da quantidade de pessoas que apresentem aquela 
velocidade. Mecanismos de ajuste da ferramenta para privilegiar um componente de correção e, ao mesmo tempo, preservar a consistência entre os diferentes componentes, poderão ser desenvolvidos no futuro.

- Embora os resultados apresentados sejam genéricos e independentes dos dados coletados, será interessante, no futuro, aferir se as ferramentas propostas têm boa eficiência ao serem utilizadas em diferentes cenários e tomando como base diferentes algoritmos de rastreamento. Além disto, em coleções de dados mais complexas, com maior de duração e variação de densidade, seria possível realizar uma análise de sensibilidade à densidade, para verificar como a variação da densidade altera a acurácia dos componentes da ferramenta.

- A contribuição do componente 3, se comparada aos demais componentes, é significativamente menor. Tal resultado sugere que haja espaço para a realização de melhorias, como por exemplo, a inclusão de novos parâmetros. Um outro aspecto que não foi considerado neste componente e que poderia ser desenvolvido é a junção de trajetórias de pedestres que ficam parados por um determinado período de tempo. Esta melhoria poderia aumentar a abrangência do componente com o aumento da quantidade de trajetórias corrigidas.

- Finalmente, esta ferramenta tem por objetivo preparar dados fidedignos para que outras ferramentas possam indicar decisões otimizadas. Será interessante integrar a ferramenta apresentada no presente trabalho com algum ambiente para tomada de decisões, para que a usabilidade da ferramenta possa ser otimizada. 


\section{Apêndice A}

\section{Tabelas}

\begin{tabular}{|c|c|c|c|}
\hline$k$ & $t c_{2}$ & $c c_{2}$ & $c c_{2} / t c_{2}$ \\
\hline 1 & 4 & 3 & $75 \%$ \\
\hline 2 & 1 & 1 & $100 \%$ \\
\hline 3 & 1 & 1 & $100 \%$ \\
\hline 4 & 4 & 4 & $100 \%$ \\
\hline 5 & 1 & 1 & $100 \%$ \\
\hline 6 & 4 & 4 & $100 \%$ \\
\hline 7 & 1 & 1 & $100 \%$ \\
\hline 8 & 1 & 1 & $100 \%$ \\
\hline 9 & 1 & 1 & $100 \%$ \\
\hline 10 & 1 & 1 & $100 \%$ \\
\hline 11 & 4 & 4 & $100 \%$ \\
\hline 12 & 1 & 1 & $100 \%$ \\
\hline 13 & 1 & 1 & $100 \%$ \\
\hline 14 & 1 & 0 & $0 \%$ \\
\hline 15 & 1 & 1 & $100 \%$ \\
\hline 16 & 1 & 1 & $100 \%$ \\
\hline 17 & 1 & 1 & $100 \%$ \\
\hline 18 & 1 & 1 & $100 \%$ \\
\hline 19 & 1 & 1 & $100 \%$ \\
\hline 20 & 1 & 1 & $100 \%$ \\
\hline 21 & 1 & 1 & $100 \%$ \\
\hline 22 & 2 & 2 & $100 \%$ \\
\hline 23 & 1 & 1 & $100 \%$ \\
\hline 24 & 1 & 1 & $100 \%$ \\
\hline 25 & 1 & 1 & $100 \%$ \\
\hline 26 & 1 & 1 & $100 \%$ \\
\hline 27 & 1 & 1 & $100 \%$ \\
\hline 28 & 1 & 1 & $100 \%$ \\
\hline 29 & 1 & 1 & $100 \%$ \\
\hline 30 & 1 & 0 & $0 \%$ \\
\hline
\end{tabular}

Tabela A.1: Apuração da equação 4.6 para o Componente 2 e amostra de tamanho $\eta=30$ 


\begin{tabular}{|c|c|c|c|}
\hline$k$ & $t c_{3}$ & $c c_{3}$ & $c c_{3} / t c_{3}$ \\
\hline 1 & 1 & 1 & $100 \%$ \\
\hline 2 & 1 & 1 & $100 \%$ \\
\hline 3 & 1 & 1 & $100 \%$ \\
\hline 4 & 1 & 1 & $100 \%$ \\
\hline 5 & 1 & 1 & $100 \%$ \\
\hline 6 & 1 & 1 & $100 \%$ \\
\hline 7 & 1 & 1 & $100 \%$ \\
\hline 8 & 1 & 1 & $100 \%$ \\
\hline 9 & 1 & 1 & $100 \%$ \\
\hline 10 & 1 & 0 & $0 \%$ \\
\hline 11 & 1 & 1 & $100 \%$ \\
\hline 12 & 1 & 1 & $100 \%$ \\
\hline 13 & 1 & 1 & $100 \%$ \\
\hline 14 & 1 & 1 & $100 \%$ \\
\hline 15 & 1 & 1 & $100 \%$ \\
\hline 16 & 1 & 1 & $100 \%$ \\
\hline 17 & 1 & 1 & $100 \%$ \\
\hline 18 & 1 & 1 & $100 \%$ \\
\hline 19 & 1 & 1 & $100 \%$ \\
\hline 20 & 1 & 1 & $100 \%$ \\
\hline 21 & 1 & 1 & $100 \%$ \\
\hline 22 & 1 & 1 & $100 \%$ \\
\hline 23 & 1 & 0 & $0 \%$ \\
\hline 24 & 2 & 2 & $100 \%$ \\
\hline 25 & 1 & 0 & $0 \%$ \\
\hline 26 & 1 & 1 & $100 \%$ \\
\hline 27 & 1 & 1 & $100 \%$ \\
\hline 28 & 1 & 1 & $100 \%$ \\
\hline 29 & 1 & 0 & $0 \%$ \\
\hline 30 & 1 & 1 & $100 \%$ \\
\hline
\end{tabular}

Tabela A.2: Apuração da equação 4.6 para o Componente 3 e amostra de tamanho $\eta=30$ 


\title{
Referências Bibliográficas
}

\begin{abstract}
Ahn et al.(2017) Yoongho Ahn, Tomoya Kowada, Hiroshi Tsukaguchi e Upali Vandebona. Estimation of passenger flow for planning and management of railway stations. Transportation Research Procedia, 25:315 - 330. ISSN 2352-1465. doi: https://doi.org/10.1016/j.trpro.2017.05.408. URL http://www. sciencedirect.com/science/article/pii/S2352146517307159. World Conference on Transport Research WCTR 2016 Shanghai. 10-15 July 2016. Citado na pág. 16

Ali e Shah(2008) Saad Ali e Mubarak Shah. Floor fields for tracking in high density crowd scenes. Em Proceedings of the 10th European Conference on Computer Vision: Part II, ECCV '08, páginas 1-14, Berlin, Heidelberg. Springer-Verlag. ISBN 978-3-540-88685-3. doi: 10.1007/978-3-540-88688-4_1. URL http://dx.doi.org/10.1007/978-3-540-88688-4_1. Citado na pág. 11
\end{abstract}

Almeida et al.(2013) João Emilio Almeida, Rosaldo J. F. Rossetti e Antonio Leca Coelho. Crowd Simulation Modeling Applied to Emergency and Evacuation Simulations using Multi-Agent Systems. CoRR, abs/1303.4692. URL http://arxiv.org/abs/1303.4692. Citado na pág. 11

Austroads(1995) Austroads. Guide to traffic engineering practice. part 13-pedestrians. Austroads, 11: 13-95. Citado na pág. 16, 17

Buchmueller e Weidmann(2006) Stefan Buchmueller e Ulrich Weidmann. Parameters of pedestrians, pedestrian traffic and walking facilities. IVT Schriftenreihe, 132. Citado na pág. 17

Burstedde et al.(2001) Carsten Burstedde, K. Klauck, A. Schadschneider e J. Zittartz. Simulation of pedestrian dynamics using a two-dimensional cellular automaton. Physica A: Statistical Mechanics and its Applications, 295:507-525. Citado na pág. 11

Corbetta et al.(2018) Alessandro Corbetta, Jasper A. Meeusen, Chung-min Lee, Roberto Benzi e Federico Toschi. Physics-based modeling and data representation of pairwise interactions among pedestrians. Phys. Rev. E, 98:062310. doi: 10.1103/PhysRevE.98.062310. URL https://link.aps.org/doi/10.1103/ PhysRevE.98.062310. Citado na pág. 46

Crociani et al.(2016) L. Crociani, G. Lammel e G. Vizzari. Multi-scale simulation for crowd management: A case study in an urban scenario. Autonomous Agents and Multiagent Systems. AAMAS 2016. Lecture Notes in Computer Science, vol 10002. Springer, Cham. Citado na pág. 3

Croft e Panchuk(2017) James L. Croft e Derek Panchuk. Watch where you're going? interferer velocity and visual behavior predicts avoidance strategy during pedestrian encounters. Journal of motor behavior, 50 4:353-363. Citado na pág. 14, 16

Daamen(2004) Winnie Daamen. Modelling passenger flows in public transport facilities. Citado na pág. 17 
Durupinar et al.(2016) Funda Durupinar, Ugur Gudukbay, Aytek Aman e Norman I. Badler. Psychological parameters for crowd simulation: From audiences to mobs. IEEE Transactions on Visualization and Computer Graphics, 22(9):2145-2159. Citado na pág. 2

Fiorini e Shiller(1998) P Fiorini e Z Shiller. Motion planning in dynamic environments using velocity obstacles. International Journal of Robotics Research, 17(Copyright 1998, IEE):760-772. ISSN 02783649. doi: Doi10.1177/027836499801700706. URL http://dblp.uni-trier.de/db/journals/ijrr/ijrr17. html\{\#\}FioriniS98. Citado na pág. 11

Fruin(1987) J. J. Fruin. Pedestrian Planning and Design. Mobile. AL: Elevator World, Inc. Citado na pág. 19, 20,21

Fryar et al.(2016) Cheryl D Fryar, Qiuping Gu, Cynthia L Ogden e Katherine M Flegal. Anthropometric reference data for children and adults; united states, 2011-2014. Citado na pág. 47

Gorrini et al.(2016) Andrea Gorrini, Giuseppe Vizzari e Stefania Bandini. Towards Modelling PedestrianVehicle Interactions: Empirical Study on Urban Unsignalized Intersection. CoRR, abs/1610.07892. URL http://arxiv.org/abs/1610.07892. Citado na pág. 3, 10

Grant e Flynn(2017) Jason M. Grant e Patrick J. Flynn. Crowd scene understanding from video: A survey. ACM Trans. Multimedia Comput. Commun. Appl., 13(2):19:1-19:23. ISSN 1551-6857. doi: 10.1145/ 3052930. URL http://doi.acm.org.ez67.periodicos.capes.gov.br/10.1145/3052930. Citado na pág. 15

Gu e Deng(2013) Qin Gu e Zhigang Deng. Generating freestyle group formations in agent-based crowd simulations. IEEE Computer Graphics and Applications, 33(1):20-31. ISSN 02721716. doi: 10.1109/ MCG.2011.87. Citado na pág. 11

Guy et al.(2011) Stephen J. Guy, Sujeong Kim, Ming C. Lin e Dinesh Manocha. Simulating heterogeneous crowd behaviors using personality trait theory. Em Proceedings of the 2011 ACM SIGGRAPH/Eurographics Symposium on Computer Animation, SCA '11, páginas 43-52, New York, NY, USA. ACM. ISBN 978-1-4503-0923-3. doi: 10.1145/2019406.2019413. URL http://doi.acm.org/10.1145/2019406. 2019413. Citado na pág. 2

Haghani e Sarvi(2017) Milad Haghani e Majid Sarvi. Crowd behaviour and motion: Empirical methods. Transportation Research Part B: Methodological, 107. doi: 10.1016/j.trb.2017.06.017. Citado na pág. 2, 4, 12,14

Hänseler et al.(2015) Flurin Hänseler, Michel Bierlaire, Nicholas Molyneaux, Riccardo Scarinci e Michaël Thémans. Modeling pedestrian flows in train stations: The example of lausanne railway station. Em Swiss Transportation Research Conference, number CONF. Citado na pág. 16

Helbing e Molnar(1998) Dirk Helbing e Peter Molnar. Social Force Model for Pedestrian Dynamics. Physical Review E. ISSN 1063651X. doi: 10.1103/PhysRevE.51.4282. URL http://arxiv.org/abs/cond-mat/ 9805244\{\%\}0Ahttp://dx.doi.org/10.1103/PhysRevE.51.4282. Citado na pág. 11

Heuvel e Hoogenraad(2014) J.P.A. Heuvel e J.H. Hoogenraad. Monitoring the performance of the pedestrian transfer function of train stations using automatic fare collection data. Transportation Research Procedia, 2:642 - 650. ISSN 2352-1465. doi: https://doi.org/10.1016/j.trpro.2014.09.107. URL 
http://www.sciencedirect.com/science/article/pii/S2352146514001434. The Conference on Pedestrian and Evacuation Dynamics 2014 (PED 2014), 22-24 October 2014, Delft, The Netherlands. Citado na pág. 15

Ijaz et al.(2015) Kiran Ijaz, Shaleeza Sohail e Sonia Hashish. A Survey of Latest Approaches for Crowd Simulation and Modeling using Hybrid Techniques. 17th UKSIM-AMSS International Conference on Modelling and Simulation, páginas 111-116. doi: 10.1109/UKSim.2015.46. Citado na pág. 12

in OpenCV(2019) Image Processing in OpenCV. Geometric transformations of images, 032019. URL https://docs.opencv.org/3.0-beta/doc/py_tutorials/py_imgproc/py_geometric_transformations/py_ geometric_transformations.html. Citado na pág. 24

Jodoin et al.(2013) Pierre-Marc Jodoin, Yannick Benezeth e Yi Wang. Meta-tracking for video scene understanding. Em IEEE International Conference on Advanced Video and Signal Based Surveillance, 2013, páginas 1-6. Citado na pág. 44

Junior et al.(2010) J C S Jacques Junior, S R Musse e C R Jung. Crowd Analysis Using Computer Vision Techniques. IEEE Signal Processing Magazine, 27(September):66-77. ISSN 10535888. doi: 10.1109/ MSP.2010.937394. URL http://ieeexplore.ieee.org/xpls/abs\{_\}all.jsp?arnumber=5562657. Citado na pág. 1, 9

Kim et al.(2012) Sujeong Kim, Stephen J. Guy, Dinesh Manocha e Ming C. Lin. Interactive simulation of dynamic crowd behaviors using general adaptation syndrome theory. Em Proceedings of the ACM SIGGRAPH Symposium on Interactive 3D Graphics and Games, I3D '12, páginas 55-62, New York, NY, USA. ACM. ISBN 978-1-4503-1194-6. doi: 10.1145/2159616.2159626. URL http://doi.acm.org/ 10.1145/2159616.2159626. Citado na pág. 2

Kim et al.(2015) Sujeong Kim, Stephen J Guy, Wenxi Liu, David Wilkie, Rynson WH Lau, Ming C Lin e Dinesh Manocha. Brvo: Predicting pedestrian trajectories using velocity-space reasoning. The International Journal of Robotics Research, 34(2):201-217. Citado na pág. 33

Kone(2005) Corporation Kone. Planning guide for people flow in transit stations. https://www.kone.nl/ Images/7172_People_Flow_Planning_Guide_for_Transit_centers_tcm30-25526.pdf, Maio 2005. Último acesso em 27/11/2019. Citado na pág. 5, 14, 17, 18, 20, 21

Kullu et al.(2017) Kurtulus Kullu, Ugur Güdükbay e Dinesh Manocha. ACMICS: an agent communication model for interacting crowd simulation. Autonomous Agents and Multi-Agent Systems, 31(6):1403-1423. ISSN 1573-7454. doi: 10.1007/s10458-017-9366-8. URL https://doi.org/10.1007/s10458-017-9366-8. Citado na pág. 11

Lam et al.(1999) William H. K. Lam, Chung-Yu Cheung e C. F. Lam. A study of crowding effects at the Hong Kong light rail transit stations. Transportation Research Part A: Policy and Practice, 33(5): 401-415. URL https://ideas.repec.org/a/eee/transa/v33y1999i5p401-415.html. Citado na pág. 15

Maheshwari e Heda(2016) Saurabh Maheshwari e Surbhi Heda. A review on crowd behavior analysis methods for video surveillance. páginas 1-5. doi: 10.1145/2905055.2905258. Citado na pág. 1, 14, 15

Mikhail et al.(2001) E. M. Mikhail, J. S. Bethel e J. C. McGlone. Introduction to modern photogrammetry, volume 31. Citado na pág. 24 
Moussaid et al.(2011) M. Moussaid, D. Helbing e G. Theraulaz. How simple rules determine pedestrian behavior and crowd disasters. Proceedings of the National Academy of Sciences, 108(17):68846888. ISSN 0027-8424. doi: 10.1073/pnas.1016507108. URL http://www.pnas.org/cgi/doi/10.1073/ pnas.1016507108. Citado na pág. 3

Moussaïd et al.(2016a) Mehdi Moussaïd, Mubbasir Kapadia, Tyler Thrash, Robert W Sumner, Markus Gross, Dirk Helbing e Christoph Hölscher. Crowd behaviour during high-stress evacuations in an immersive virtual environment. Journal of the Royal Society Interface, 13(122):20160414. ISSN 1742-5689. doi: 10.1098/rsif.2016.0414. URL http://www.ncbi.nlm.nih.gov/pmc/articles/PMC5046946/. Citado na pág. 9

Moussaïd et al.(2016b) Mehdi Moussaïd, Mubbasir Kapadia, Tyler Thrash, Robert W. Sumner, Markus Gross, Dirk Helbing e Christoph Hölscher. Crowd behaviour during high-stress evacuations in an immersive virtual environment. Journal of The Royal Society Interface, 13(122):20160414. ISSN 17425689. doi: 10.1098/rsif.2016.0414. URL http://rsif.royalsocietypublishing.org/lookup/doi/10.1098/rsif. 2016.0414. Citado na pág. 3

Murray et al.(1970) M P Murray, R.C. Kory e S.B. Sepic. Walking patterns of normal women. Archives of Physical Medicine and Rehabilation, 51:637-650. Citado na pág. 46

NPTEL(2007) NPTEL. National programme on technology enhanced learning - transportation engineering i (web), lecture 31: Fundamental parameters of traffic flow, 2007. URL: https://nptel.ac.in/courses/ 105101087/downloads/Lec-30.pdf. Last visited on 2019/02/19. Citado na pág. 19

Parsons e Wooldridge(2002) Simon Parsons e Michael Wooldridge. Game Theory and Decision Theory in Multi-Agent Systems. Autonomous Agents and Multi-Agent Systems, 5(3):243-254. ISSN 1573-7454. doi: 10.1023/A:1015575522401. URL https://doi.org/10.1023/A:1015575522401. Citado na pág. 10

Roberto et al.(2017) Leandro Roberto, Sidney Andrade Lima, Sidnei João Siqueira Sant'Anna e Elcio Hideiti Shiguemori. Correção de distorção projetiva em imagens obtidas com câmera a bordo de vant. Em XVIII Simpósio Brasileiro de Sensoriamento Remoto. Citado na pág. 24

Ronchi(2017) Enrico Ronchi, editor. New approaches to evacuation modelling. Number 3209 in LUTVDG/TVBB. Lund University, Department of Fire Safety Engineering. Citado na pág. 13

Selltiz et al.(1965) C. Selltiz, L. S. Wrightsman e S. W. Cook. Métodos de pesquisa das relações sociais. São Paulo: Herder. Citado na pág. 4

Teknomo e Takeyama(2016) Kardi Teknomo e Yasushi Takeyama. Determination of pedestrian flow performance based on video tracking and microscopic simulations. Citado na pág. 20

Teknomo et al.(2016) Kardi Teknomo, Yasushi Takeyama e Hajime Inamura. Determination of pedestrian flow performance based on video tracking and microscopic simulations. CoRR, abs/1609.02243. Citado na pág. $2,14,15$

Tomasi e Kanade(1991) Carlo Tomasi e Takeo Kanade. Detection and tracking of point features. Relatório técnico, International Journal of Computer Vision. Citado na pág. 44 
Van Berg et al.(2008) Jur Den Van Berg, Ming Lin e Dinesh Manocha. Reciprocal velocity obstacles for real-time multi-agent navigation. Proceedings - IEEE International Conference on Robotics and Automation, páginas 1928-1935. ISSN 10504729. doi: 10.1109/ROBOT.2008.4543489. Citado na pág. 11

Wang et al.(2009) Xiaogang Wang, Xiaoxu Ma e W. Eric L. Grimson. Unsupervised activity perception in crowded and complicated scenes using hierarchical bayesian models. IEEE Trans. Pattern Anal. Mach. Intell., 31(3):539-555. Citado na pág. 43

Weidmann(1993) Ulrich Weidmann. Transporttechnik der fußgänger: transporttechnische eigenschaften des fußgängerverkehrs, literaturauswertung. IVT Schriftenreihe, 90. Citado na pág. 18, 47

Zhan et al.(2008) Beibei Zhan, Dorothy N. Monekosso, Paolo Remagnino, Sergio A. Velastin e Li-Qun Xu. Crowd analysis: a survey. Machine Vision and Applications, 19(5):345-357. ISSN 1432-1769. doi: 10.1007/s00138-008-0132-4. URL https://doi.org/10.1007/s00138-008-0132-4. Citado na pág. 1, 9

Zhong et al.(2015) Jinghui Zhong, Wentong Cai, Linbo Luo e Haiyan Yin. Learning Behavior Patterns from Video : A Data-driven Framework for Agent-based Crowd Modeling. Aamas - International Conference on Autonomous Agents and Multiagent Systems, páginas 801-809. ISSN 15582914. Citado na pág. 3, 14, 38, 48

Zhou et al.(2012) Bolei Zhou, Xiaogang Wang e Xiaoou Tang. Understanding collective crowd behaviors: Learning a mixture model of dynamic pedestrian-agents. Em 2012 IEEE Conference on Computer Vision and Pattern Recognition, Providence, RI, USA, June 16-21, 2012, páginas 2871-2878. IEEE Computer Society. doi: 10.1109/CVPR.2012.6248013. URL https://doi.org/10.1109/CVPR.2012.6248013. Citado na pág. $43,44,48$

Zhou et al.(2014) Bolei Zhou, Xiaoou Tang e Xiaogang Wang. Learning Collective Crowd Behaviors with Dynamic Pedestrian-Agents. International Journal of Computer Vision, 111(1):50-68. ISSN 15731405. doi: 10.1007/s11263-014-0735-3. Citado na pág. 3

Zhou et al.(2010) Suiping Zhou, Dan Chen, Wentong Cai, Linbo Luo, Malcolm Yoke Hean Low, Feng Tian, Victor Su-Han Tay, Darren Wee Sze Ong e Benjamin D. Hamilton. Crowd modeling and simulation technologies. ACM Transactions on Modeling and Computer Simulation, 20(4):1-35. ISSN 10493301. doi: 10.1145/1842722.1842725. URL http://eprints.bournemouth.ac.uk/13285/1/licence.txt\{\%\}5Cnhttp: //portal.acm.org/citation.cfm?doid=1842722.1842725. Citado na pág. 10, 11

Zipf(1949) G.K. Zipf. Human Behaviour and the Principle of Least Effort. Addison-Wesley. Citado na pág. 28,30

Zitouni et al.(2016) M. Sami Zitouni, H. Bhaskar, J. Dias e M.E. Al-Mualla. Advances and trends in visual crowd analysis: A systematic survey and evaluation of crowd modelling techniques. Neurocomputing, 186(Supplement C):139 - 159. ISSN 0925-2312. doi: https://doi.org/10.1016/j.neucom.2015.12.070. URL http://www.sciencedirect.com/science/article/pii/S092523121502041X. Citado na pág. 15, 44 